1990

Roberto Costa

\title{
CONTRIBUIÇÃO AO ESTUDO DA
}

ESTIMULAÇÃO VENTRICULAR E DA ATRIOVENTRICULAR UNIVERSAL EM PORTADORES DA MIOCARDIOPATIA CHAGÁSICA:

Avaliação Clínica e Hemodinâmica em Repouso e Exercício

Tese de Doutorado apresentada à

Faculdade de Medicina da Universidade de São Paulo Área de Clínica Cirúrgica

Orientador: Prof. Dr. Kenji Nakiri 
FICHA CATALOGRÁFICA

Preparada pela Biblioteca da

Faculdade de Medicina da Universidade de São Paulo

Costa, Roberto

Contribuição ao estudo da estimulação ventricular e da atrioventricular universal em portadores da miocardiopatia chagásica: avaliação clínica e hemodinâmica em repouso e exercício / Roberto

Costa. --São Paulo, 1990.

Tese (doutorado)--Faculdade de Medicina da Universidade

de São Paulo. Departamento de Cirurgia.

Área de concentração: Clínica Cirúrgica.

Orientador: Kenji Nakiri.

Descritores: 1.MARCAPASSO ARTIFICIAL 2.BLOQUEIO CARDÍACO/terapia 3.MIOCARDIOPATIA CHAGÁSICA/patologia 4.CATETERISMO CARDÍACO/métodos 5.TESTE DE ESFORÇO/métodos

USP/FM-B-43/90 
A meus pais, Ísola e Dalton, a minha esposa, Inês,

a minhas filhas, Sílvia e Marina. 


\section{AGRADECIMENTOS}

A elaboração desse trabalho só foi possível graças ao esforço de um grupo de pessoas, médicos ou não, que de maneira desinteressada e movidas por espírito de colaboração, orientaram e apoiaram seu desenvolvimento. Por ser difícil enumerá-las, a elas agradeço de maneira geral.

Não gostaria de deixar de mencionar alguns agradecimentos em particular.

Aos Professores Adib Jatene e Fúlvio Pileggi, pelo estímulo constante e apoio às minhas iniciativas.

Ao Prof. Geraldo Verginelli, pela amizade e confiança em mim depositada, principalmente no início de minha atividade como especialista em marcapassos.

Ao Prof. Noedir Stolf, amigo desde meus tempos de estudante, principal responsável pelo meu aprendizado como cirurgião.

Aos colegas da Divisão de Cirurgia (Prof. Delmont Bittencourt) , da Área Clínica (Prof. Giovanni Bellotti), do Serviço de Hemodinâmica ( Prof. Siguemituzo Arie), da Divisão de Métodos Gráficos (Prof. Paulo Moffa) e em particular do Grupo de Arritmias (Prof. Eduardo Sosa), pelo apoio, amizade e convívio.

Ao Prof. Kenji Nakiri, pela orientação precisa desse trabalho e de meu curso de pós-graduação.

Ao Prof. Pedro Carlos Piantino Lemos, um agradecimento especial, pelas suas sugestões e revisão cuidadosa desse trabalho.

Aos Drs. Lauro Kawabe e Paulo Manuel Pêgo-Fernandes, pela ajuda desinteressada nas atividades de rotina, durante o desenvolvimento desse trabalho. 
Aos colegas Augusto Scalabrini Neto, Luiz Felipe Pinho Moreira, Martino Martinelli Filho, Miguel Rati e Silvana D'Orio Nishioka, pela colaboração e participação direta no estudo dos pacientes. Sem eles esse trabalho não teria sido possível.

À Sra. Valéria de Vilena Lombardi e às acadêmicas Andréa Costa Pinto e Glaura Souza Alvarenga, pela colaboração na elaboração das referências bibliográficas.

Às Sras. Ivete Kittler, Tereza Hitomi Inada e Mitsuko Oshiro Mori, ao Sr. João Antonio Amaro Carneiro e ao Dr. Ricardo Beyruti, pela inestimável e paciente participação na composição gráfica.

Finalmente, meu agradecimento à Sra. Etelvina de Paula Leão e ao Sr. Carlos Fernando de Paula Leão, pela revisão ortográfica e à Dra. Maria Inês de Paula Leão, pela cuidadosa revisão crítica desse trabalho. 
SUMÁRIO

AGRADECIMENTOS

SUMÁRIO

ABREVIATURAS UTILIZADAS ...................................................................iii

UNIDADES UTILIZADAS

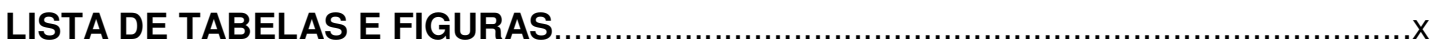

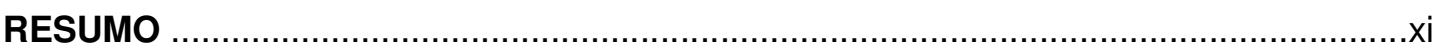

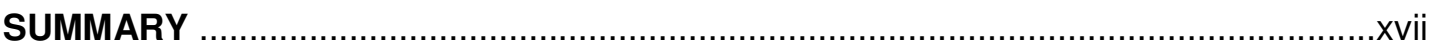

I - INTRODUÇÃO

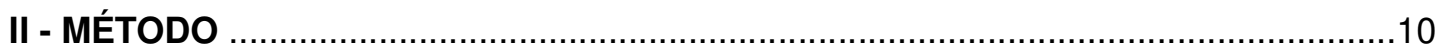

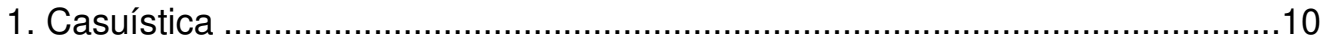

2. Característica do marcapasso utilizado ....................................................12

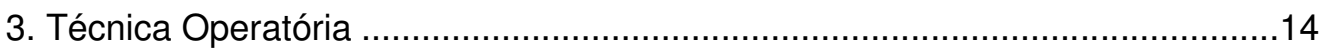

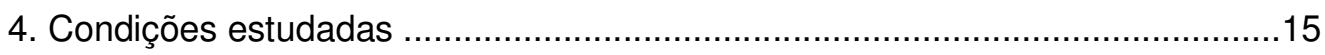

5. Modos de estimulação utilizados .............................................................16

6. Padronização do esforço ...............................................................................16

7. Estudo hemodinâmico ……………….......................................................17

7.1. Classificação quanto à função dos ventrículos direito e esquerdo .....18

8. Estudo do consumo periférico de oxigênio ......................................................20

9. Padronização da avaliação da evolução clínica................................................20

10. Critérios para a separação dos pacientes em grupos.......................................21

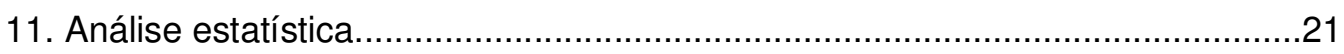

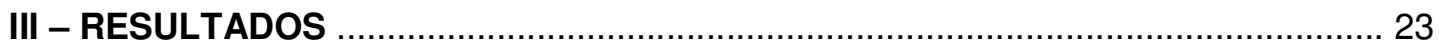

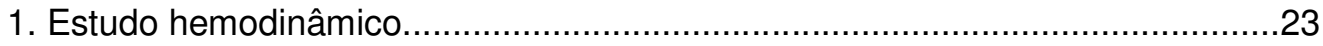

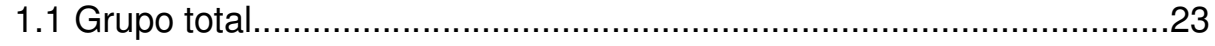

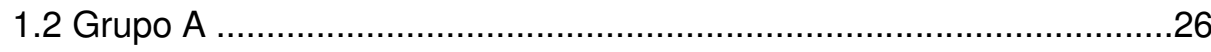

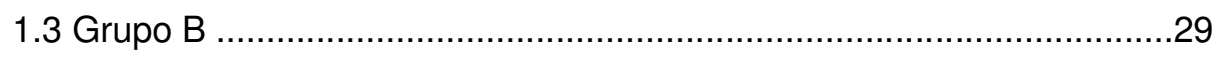

1.4 Comparação estatística dos grupos A e B ..........................................32

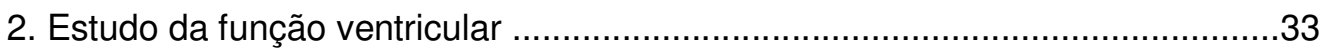

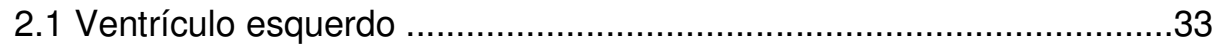

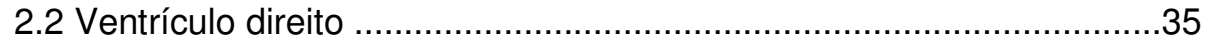

3. Estudo do consumo periférico de oxigênio......................................................

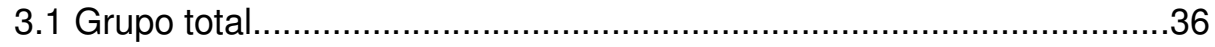


3.2 Grupo A .38

3.3 Grupo B .40

3.4 Comparação estatística do comportamento dos grupos A e B .......... 43

4. Evolução clínica dos pacientes..............................................................43

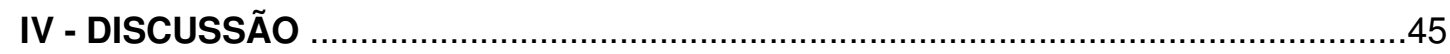

1. Considerações gerais sobre a metodologia..................................................45

1.1 Estudo hemodinâmico e exercício ................................................45

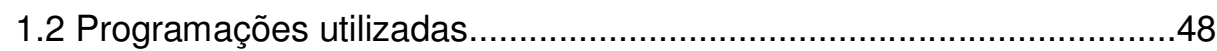

2. Análise da resposta hemodinâmica ao exercício............................................49

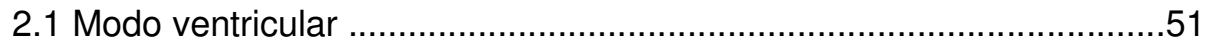

2.2 Modo atrioventricular universal.................................................52

3. Análise da resposta hemodinâmica à mudança do modo de estimulação .......54

3.1 Comportamento durante o repouso...............................................54

3.2 Comportamento durante o exercício...............................................55

4. Estudo comparativo entre os grupos A e B …...........................................57

4.1 Comportamento da freqüência cardíaca.........................................57

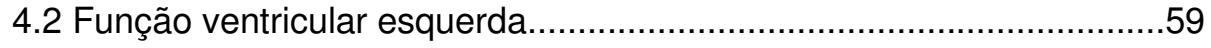

4.3 Resistência vascular periférica..................................................65

4.4 Função ventricular direita.........................................................69

4.5 Resistência arteriolar pulmonar ..................................................71

5. Estudo do consumo periférico de oxigênio...................................................73

6. Análise da evolução clínica dos pacientes.....................................................77

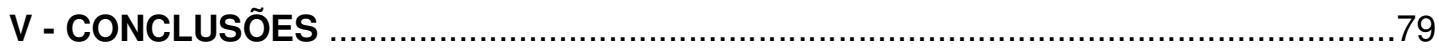

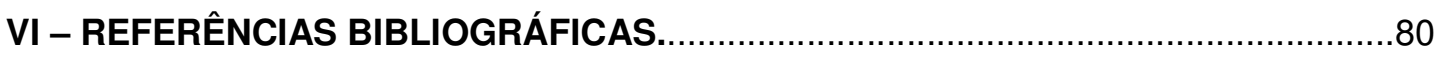

VII - APÊNDICE 


\section{ABREVIATURAS UTILIZADAS}

\section{$(+): \quad$ presente}

$(-)$ : $\quad$ ausente

$\Delta \% \mathrm{R} / \mathrm{E}: \quad$ variação percentual ocorrida com a mudança da condição repouso para exercício em um dado modo de estimulação.

$\triangle \%$ VVI/DDD: variação percentual ocorrida com a mudança do modo ventricular inibido para o modo atrioventricular universal em uma dada condição.

$\triangle \mathrm{D} \%$ : $\quad$ fração de encurtamento do ventrículo esquerdo à ecocardiografia

A-V: atrioventricular

B: raça branca

BAV 2:1: $\quad$ bloqueio atrioventricular do segundo grau do tipo 2 para 1

BAVT: bloqueio atrioventricular do terceiro grau

$\mathrm{CaO}_{2}$ :

$\mathrm{CvO}_{2}$ :

DC:

DDD: concentração arterial de oxigênio concentração venosa de oxigênio débito cardíaco

DDD-E: $\quad$ modo atrioventricular universal durante esforço

DDD-R: modo atrioventricular universal ao repouso

$\mathrm{E}:$

$\mathrm{EO}_{2}:$

$\mathrm{F}:$

FC:

IC:

ICC:

IS:

ITS:

$\mathrm{IVO}_{2}$ :

$\mathrm{M}$ :

MODO:

$\mathrm{N}:$

NYHA:

$\mathrm{p}:$

PA:

PAD:

PAP:

PAS:

PCP:

$\mathrm{R}$ :

RAP:

RVS:

$\mathrm{SaO}_{2}$ :

$\mathrm{SvO}_{2}$ :

VVI:

VVI-E:

VVI-R: exercício

extração de oxigênio

sexo feminino

freqüência cardíaca

índice cardíaco

insuficiência cardíaca congestiva

índice sistólico

índice do trabalho sistólico do ventrículo esquerdo

índice de consumo de oxigênio

sexo masculino

modo de estimulação

raça negra

New York Heart Association

nível de significância estatística

pressão média da aorta

pressão média do átrio direito

pressão média da artéria pulmonar

pressão arterial sistêmica

pressão média do capilar pulmonar

repouso

resistência arteriolar pulmonar

resistência vascular sistêmica

saturação arterial de oxigênio

saturação venosa de oxigênio

modo ventricular inibido pela onda $R$

modo ventricular durante esforço

modo ventricular ao repouso 


\section{UNIDADES UTILIZADAS}

$\begin{array}{ll}\text { bpm: } & \text { batimento por minuto } \\ \mathrm{cm}^{5}: & \text { centímetro quinta potência } \\ \mathrm{dyn}: & \text { dina } \\ \mathrm{gm}: & \text { grâmetro } \\ \mathrm{l}: & \text { litro } \\ \mathrm{m}^{2}: & \text { metro quadrado } \\ \mathrm{min}: & \text { minuto } \\ \mathrm{ml}: & \text { mililitro } \\ \mathrm{mmHg}: & \text { milímetro de mercúrio } \\ \mathrm{ms}: & \text { milésimo de segundo } \\ \mathrm{mV}: & \text { milivolt } \\ \mathrm{ppm}: & \text { pulso por minuto } \\ \mathrm{s}: & \text { segundo } \\ \mathrm{V}: & \text { volt } \\ \mathrm{vol} \%: & \text { volumes por cento } \\ \mathrm{W}: & \text { watt }\end{array}$




\section{ÍNDICE DE TABELAS E FIGURAS}

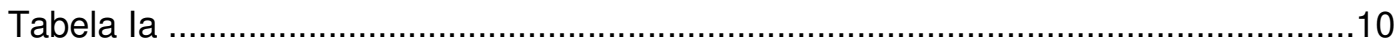

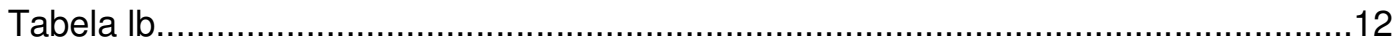

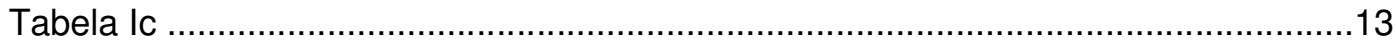

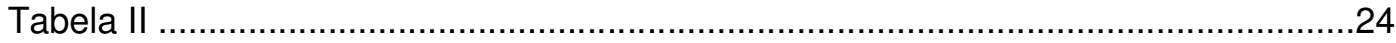

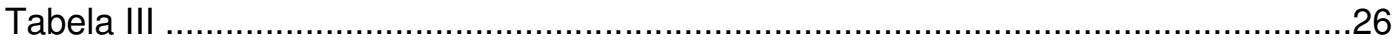

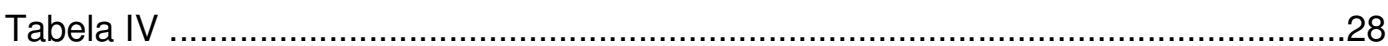

Tabela V

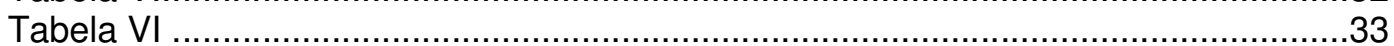

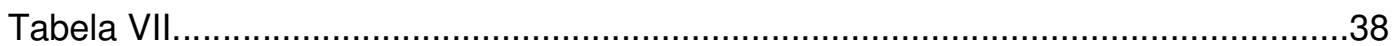

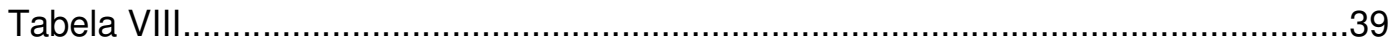

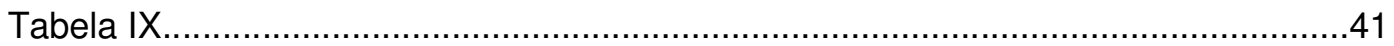

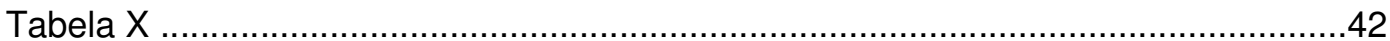

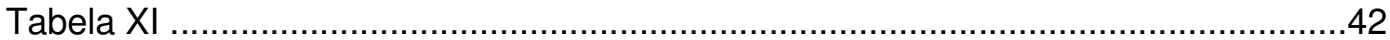

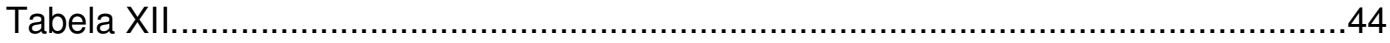

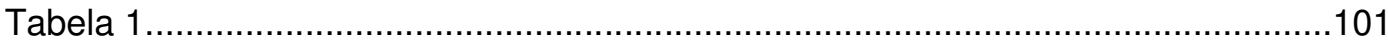

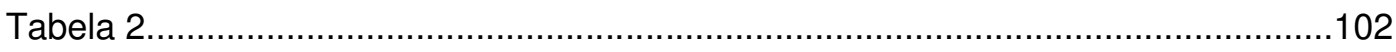

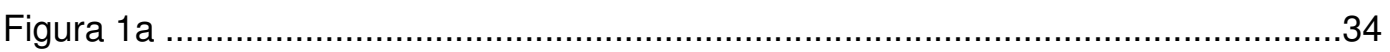

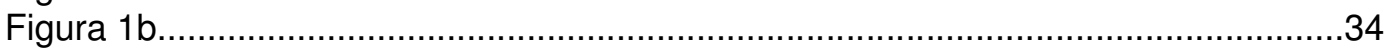

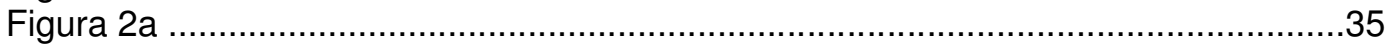

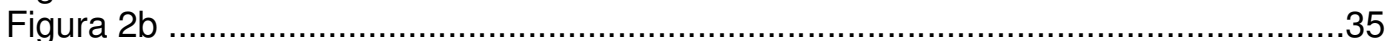

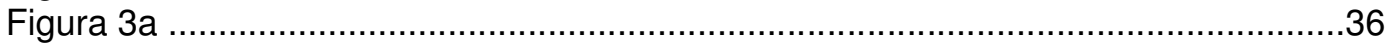

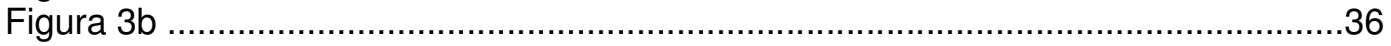

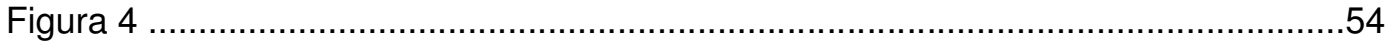

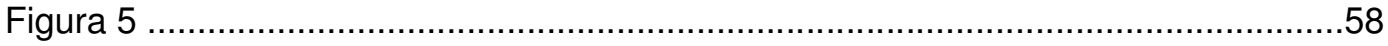

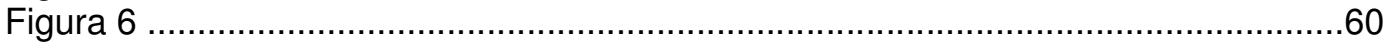

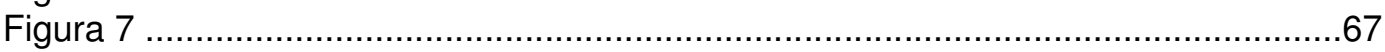

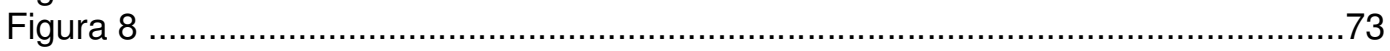




\section{RESUMO}

Roberto Costa: Contribuição ao Estudo da Estimulação Ventricular e da Atrioventricular Universal em Portadores da Miocardiopatia Chagásica: Avaliação Clínica e Hemodinâmica em Repouso e Exercício

Foram estudados dez pacientes portadores de cardiopatia chagásica, com bloqueio avançado da condução atrioventricular, submetidos a implante de marcapasso atrioventricular universal.

Os pacientes foram selecionados a partir do estudo clínico, que identificou os portadores de insuficiência cardíaca congestiva de grau leve (classes funcionais I e II); radiológico, com índice cardiotorácico médio de 0,51 \pm 0,05; e ecocardiográfico, com diâmetro diastólico do ventrículo esquerdo médio de 58,2 $\pm 5,1 \mathrm{~mm}$ e fração de encurtamento do ventrículo esquerdo de 0,29 $\pm 0,08$. Pelos critérios ecocardiográficos, cinco pacientes foram considerados morfologicamente normais, três pacientes classificados como portadores de miocardiopatia leve, e dois, de miocardiopatia moderada.

O estudo consistiu na avaliação hemodinâmica e metabólica realizada na posição supina, em quatro condições distintas:
Modo ventricular em repouso
(WI-R)
Modo atrioventricular em repouso
(DDD-R)
Modo ventricular sob esforço
(WI-E)
Modo atrioventricular sob esforço
(DDD-E) 
A programação do marcapasso para o modo ventricular (WI) constou de freqüência fixa em 70 bpm, enquanto que, para o modo atrioventricular universal (DDD), a freqüência mínima foi de 70 bpm, a máxima, 175 bpm e o intervalo atrioventricular, 150 ms.

O esforço foi realizado através de cicloergômetro acoplado à mesa hemodinâmica com carga constante de $50 \mathrm{~W} / \mathrm{s}$, durante seis minutos.

Foram estudados: a freqüência cardíaca (FC); as pressões médias em átrio direito (PAD), em artéria pulmonar (PAP), em capilar pulmonar (PCP) e na aorta (PA); o índice cardíaco (IC); o índice sistólico (IS); o índice do trabalho sistólico (ITS); a resistência vascular sistêmica (RVS); a resistência arteriolar pulmonar (RAP); a diferença arteriovenosa de oxigênio $\left(\operatorname{Dav} 0_{2}\right)$; a extração de oxigênio $\left(\mathrm{EO}_{2}\right)$ e o índice de consumo de oxigênio $\left(\mathrm{IVO}_{2}\right)$.

Os resultados obtidos nas condições WI-R, DDD-R, VVI-E e DDD-E foram, respectivamente: freqüência cardíaca de $72,1 \pm 1,4 ; 79,7 \pm 8,8 ; 71,9 \pm 1,2$ e 101,2 $\pm 18,0$ bpm; pressão média em átrio direito de 4,8 $\pm 2,2 ; 2,6 \pm 1,7 ; 8,3 \pm 2,7$ e 6,5 $\pm 3,1 \mathrm{mmHg}$; pressão média em artéria pulmonar de $17,6 \pm 6,2 ; 14,7 \pm 4,1 ; 26,6 \pm 4,5$ e $26,7 \pm 5,8$ mmHg; pressão média em capilar pulmonar de 9,0 \pm 3,6; 6,4 $\pm 2,8 ; 15,9 \pm 4,7$ e 14,8 \pm 5,7 mmHg; pressão média na aorta de 99,5 \pm 7,8; 100,5 \pm 7,1; 105,4 \pm 10,5 e 112,7 \pm 10,9 mmHg; índice cardíaco de 2,5 \pm 1,0; $2,8 \pm 1,2 ; 3,9 \pm 1,4$ e 4,7 \pm 2,2 l/min. $\mathrm{m}^{2}$; índice sistólico de $34,4 \pm 15,1 ; 35,7 \pm 16,1 ; 54,3 \pm 19,9$ e 48,0 $\pm 22,8 \mathrm{ml} / \mathrm{m}^{2}$; índice de trabalho sistólico de 41,9 $\pm 16,9 ; 45,2 \pm 18,1 ; 65,8 \pm 24,5$ e $64,0 \pm 30,7 \mathrm{gm} / \mathrm{m}^{2}$; resistência vascular sistêmica de 2347,5 \pm 933,4; 2137,6 \pm 810,2; 1526,2 \pm 699,7 e 1511,6 \pm 783,8 dyn.s/cm ${ }^{5}$; resistência arteriolar pulmonar de $223,7 \pm 145,4 ; 179,2 \pm 79,1 ; 169,9 \pm 124,6$ e $162,1 \pm$ 76,7 dyn.s/cm ${ }^{5}$; diferença arteriovenosa de oxigênio de 5,0 \pm 1,3; 4,7 $\pm 2,4 ; 9,2 \pm 3,6$ e 8,6 \pm 3,1 vol. \%; extração de oxigênio de 0,25 $\pm 0,06 ; 0,23 \pm 0,10 ; 0,45 \pm 0,15$ e 0,43 \pm 0,14; 
índice de consumo de oxigênio de $103,2 \pm 19,9 ; 110,0 \pm 52,7 ; 302,5 \pm 126,1$ e $326,0 \pm$ $115,8 \mathrm{ml} / \mathrm{min} \cdot \mathrm{m}^{2}$.

A análise da resposta hemodinâmica demonstrou que a realização do esforço provocou, com o modo ventricular (VVI), aumento do índice cardíaco de 57,7\% ( $p<0,001)$, propiciado por aumento do índice sistólico de $57,8 \% \quad(p<0,001)$ e diminuição da resistência vascular sistêmica de 35,0\% ( $p<0,001)$; com o modo atrioventricular universal (DDD), aumento do índice cardíaco de 66,8\% (p<0,01), devido ao aumento da freqüência cardíaca de 27,0\% $(p<0,001)$, aumento do índice sistólico de $34,2 \%(p<0,01)$ e queda da resistência vascular sistêmica de 29,3\% $(p<0,001)$.

A mudança do modo de estimulação ventricular (VVI) para atrioventricular universal (DDD) causou, durante o repouso, aumento do índice cardíaco de 14,1\% (NS), resultante da elevação da freqüência cardíaca de 10,5\% $(p<0.05)$, do aumento do índice sistólico de 3,8\% (NS) e da diminuição da resistência vascular sistêmica de 8,9\% (NS); e durante o exercício, aumento do índice cardíaco de 20,6\% $(p<0.05)$ propiciado por aumento da freqüência cardíaca de 40,8\% (p<0.001), diminuição do índice sistólico de $11,7 \%$ (NS) e diminuição da resistência vascular sistêmica de 1,0\% (NS).

O comportamento individual do índice cardíaco ao exercício, com a mudança do modo de estimulação WI para DDD, justificou a separação dos resultados em dois grupos distintos de pacientes: no grupo $\mathrm{A}$, ficaram os pacientes que apresentaram queda ou elevação discreta do índice cardíaco (-1,4\% em média); e no grupo B, os pacientes que atingiram aumentos expressivos do índice cardíaco ( $+33,8 \%$ em média). A análise estatística demonstrou desempenho hemodinâmico significativamente diferente entre esses dois grupos com relação aos parâmetros índice cardíaco, índice sistólico, índice de trabalho sistólico, resistência vascular sistêmica e resistência arteriolar pulmonar, em todas as condições estudadas. 
No grupo A, os resultados obtidos nas condições VVI-R, DDD-R, VVI-E e DDD-E, foram, respectivamente: freqüência cardíaca de 73,2 \pm 0,7; 82,2 $\pm 9,7 ; 72,6 \pm 1,0$ e 105,2 \pm 20,6 bpm; pressão média em átrio direito de 4,6 $\pm 2,4 ; 2,4 \pm 1,4 ; 8,0 \pm 2,8$ e 7,2 $\pm 2,5 \mathrm{mmHg}$; pressão média em artéria pulmonar de 18,8 \pm 7,6; 16,0 $\pm 4,3 ; 28,6 \pm 3,3$ e 27,8 \pm 6,5 mmHg; pressão média em capilar pulmonar de 8,6 $\pm 3,9 ; 7,0 \pm 2,5 ; 17,0 \pm 6,0$ e 16,6 \pm 5,6 mmHg; pressão média na aorta de 101,0 $\pm 10,1 ; 103,8 \pm 6,9 ; 108,0 \pm 11,5 \mathrm{e}$ $114,2 \pm 13,0 \mathrm{mmHg}$; índice cardíaco de 1,8 \pm 0,4; $2,0 \pm 0,6 ; 2,8 \pm 0,8$ e 2,8 \pm 0,8 l/min. $\mathrm{m}^{2}$; índice sistólico de 24,8 $\pm 5,4 ; 24,8 \pm 6,0 ; 39,2 \pm 11,1$ e 27,6 $\pm 7,9 \mathrm{ml} / \mathrm{m}^{2}$; índice de trabalho sistólico de $31,4 \pm 8,4 ; 33,1 \pm 9,9 ; 48,8 \pm 16,6$ e $37,1 \pm 12,8 \mathrm{gm} / \mathrm{m}^{2}$; resistência vascular sistêmica de $2953,2 \pm 754,0 ; 2773,6 \pm 498,8 ; 2014,1 \pm 632,6$ e $2163,3 \pm 572,8$ dyn.s/cm ; resistência arteriolar pulmonar de 315,5 $\pm 148,5 ; 240,4 \pm 63,6 ; 236,7 \pm 147,3$ e $222,3 \pm 59,9$ dyn.s/cm 5 ; conteúdo arterial de oxigênio de 19,9 $\pm 2,6 ; 19,8 \pm 2,7 ; 20,0 \pm 2,4$ e 20,0 \pm 2,7 vol.\%; conteúdo venoso de oxigênio de 14,5 $\pm 2,3 ; 15,2 \pm 2,1 ; 9,1 \pm 1,5$ e 9,3 \pm 1,3 vol.\%; diferença arteriovenosa de oxigênio de $5,4 \pm 1,5 ; 4,6 \pm 1,1 ; 10,9 \pm 2,0$ e 10,7 $\pm 2,3$ vol. \%; extração de oxigênio de $0,27 \pm 0,06 ; 0,23 \pm 0,04 ; 0,54 \pm 0,06$ e 0,53 $\pm 0,06$ e índice de consumo de oxigênio de $93,4 \pm 16,0 ; 88,9 \pm 17,2 ; 298,6 \pm 72,0$ e $292,8 \pm 90,1$ $\mathrm{ml} / \mathrm{min} \cdot \mathrm{m}^{2}$.

No grupo $B$, os resultados obtidos nas condições VVI-R, DDD-R, VVI-E e DDD-E, foram, respectivamente: freqüência cardíaca de 71,0 $\pm 1,4 ; 77,2 \pm 6,6 ; 71,2 \pm 0,9$ e 97,2 $\pm 12,7$ bpm; pressão média em átrio direito de 5,0 $\pm 1,8 ; 2,8 \pm 1,9 ; 8,6 \pm 2,9$ e 5,8 \pm 3,7 mmHg; pressão média em artéria pulmonar de 16,4 $\pm 3,6 ; 13,4 \pm 3,2 ; 24,6 \pm 5,2$ e $25,6 \pm 5,0 \mathrm{mmHg}$; pressão média em capilar pulmonar de 9,4 $\pm 3,0 ; 5,8 \pm 2,8 ; 14,8 \pm 4,5 \mathrm{e}$ $13,0 \pm 5,4 \mathrm{mmHg}$; pressão média na aorta de 98,0 \pm 4,6; 97,2 $\pm 5,2 ; 102,8 \pm 11,8$ e 111,2 $\pm 11,5 \mathrm{mmHg} ;$ índice cardíaco de 3,1 $\pm 1,1 ; 3,6 \pm 1,3 ; 4,9 \pm 1,2$ e 6,6 $\pm 1,81 / \mathrm{min}^{2} \mathrm{~m}^{2}$; índice sistólico de 44,0 $\pm 15,9 ; 46,7 \pm 16,1 ; 69,4 \pm 17,1$ e $68,3 \pm 17,7 \mathrm{ml} / \mathrm{m}^{2}$; índice de trabalho sistólico de $52,4 \pm 17,8 ; 57,2 \pm 17,2 ; 82,7 \pm 19,7$ e $90,9 \pm 21,6 \mathrm{gm} / \mathrm{m}^{2}$; resistência vascular 
sistêmica de $1741,7 \pm 641,8 ; 1501,5 \pm 617,6 ; 1038,2 \pm 453,4$ e $860,0 \pm 467,9$ dyn.s $/ \mathrm{cm}^{5}$; resistência arteriolar pulmonar de 131,9 \pm 57,2; 118,0 $\pm 38,0 ; 103,0 \pm 22,6$ e 101,9 $\pm 43,5$ dyn.s/cm ; conteúdo arterial de oxigênio de 20,2 $\pm 4,3 ; 20,1 \pm 4,3 ; 20,2 \pm 4,2$ e 20,1 $\pm 4,2$ vol.\%; conteúdo venoso de oxigênio de $15,7 \pm 3,6 ; 15,3 \pm 4,0 ; 13,1 \pm 1,6$ e 14,3 \pm 4,5 vol. \%; diferença arteriovenosa de oxigênio de $4,5 \pm 0,9 ; 4,8 \pm 3,3 ; 7,1 \pm 4,1$ e 5,8 \pm 1,3 vol.\%; extração de oxigênio de $0,23 \pm 0,04 \pm 0,23 \pm 0,15 ; 0,33 \pm 0,14$ e 0,31 $\pm 0,11$ e índice de consumo de oxigênio de $115,5 \pm 17,4 ; 136,3 \pm 68,0 ; 307,5 \pm 171,1$ e $367,5 \pm 130,2$ $\mathrm{ml} / \mathrm{min} \cdot \mathrm{m}^{2}$.

Durante o seguimento clínico, ocorreram três óbitos dentre os pacientes do grupo A. Não houve óbitos no grupo B.

Tendo em vista os resultados obtidos, conclui-se que:

1. Foram identificados dois grupos de pacientes (A e B), que se diferenciaram pelo comportamento do índice cardíaco e da resistência vascular sistêmica, nas condições do presente trabalho.

No grupo A, a mudança do modo de estimulação WI para DDD, durante o exercício, não propiciou aumento do índice cardíaco, a despeito da elevação da freqüência cardíaca, observando-se elevação da resistência vascular sistêmica e diminuição do índice sistólico.

No grupo B, a melhora do desempenho hemodinâmico com a mudança do modo de estimulação WI para DDD, durante exercício, caracterizada pelo aumento do índice cardíaco, deveu-se ao aumento da freqüência cardíaca, manutenção do índice sistólico e diminuição da resistência vascular periférica.

2. Níveis anormalmente elevados de resistência vascular sistêmica, em pacientes chagásicos com bloqueios avançados da condução atrioventricular, têm valor na predição de que a estimulação atrioventricular universal não trará melhora do 
desempenho hemodinâmico, durante o esforço, quando comparada à estimulação ventricular. 


\section{SUMMARY}

Roberto Costa: Clinical and Haemodynamic Evaluation of Ventricular versus Atrioventricular Pacing in Patients with Chagas' Cardiomyopathy at Rest and during Exercise.

Ten patients with chronic Chagas' cardiomyopathy, high degree atrioventricular block and implanted atrioventricular universal pacemaker, were studied.

The population was selected based on Class I or II (NYHA) functional status, cardiothoracic index of $0.51 \pm 0.05$ (mean \pm STD) on X-Ray, and diastolic left ventricular diameter of $58.2 \pm 5.1 \mathrm{~mm}$ and shortening fraction of $0.29 \pm 0.08$ on M-mode echocardiogram. According to echocardiografic classification, five patients were normal, three had mild, and two, moderate left ventricular dysfunction.

The study consisted of haemodynamic (during standard right and left cardiac catheterization) and metabolic (arterial and venous blood gases) evaluation in supine position of four distinct conditions: ventricular inhibited pacing at rest (WI-R); universal atrioventricular pacing at rest (DDD-R); ventricular inhibited pacing during exercise (VVIE); universal atrioventricular pacing during exercise (DDD-E).

When in ventricular mode (VVI), the pulse generator was programmed to fixed 70ppm, while, in the atrioventricular universal mode (DDD), the minimum rate was 70 ppm, the upper rate was 175 ppm and the atrioventricular delay was $150 \mathrm{~ms}$.

The exercise consisted of standard stress test with 50 Watt/sec during six minutes.

This protocol allowed us to analyze the following data: heart rate $(\mathrm{HR}, \mathrm{bpm})$; right atrial pressure (RAP, $\mathrm{mmHg}$ ), mean pulmonary artery pressure (PAP, mmHg); 
pulmonary wedge pressure (PWP, $\mathrm{mmHg}$ ); mean aortic pressure (AP, $\mathrm{mmHg}$ ); cardiac index $\left(\mathrm{Cl}, \mathrm{I} / \mathrm{min} \cdot \mathrm{m}^{2}\right)$; stroke index $\left(\mathrm{SI}, \mathrm{ml} / \mathrm{m}^{2}\right)$; stroke work index (SW, gm $\left./ \mathrm{m}^{2}\right)$; systemic vascular resistance (SVR, dyn.s/cm ${ }^{5}$ ); pulmonary arteriolar resistance(PAR, dyn.s/cm ${ }^{5}$ ); arteriovenous oxygen difference $\left(\mathrm{DavO}_{2}\right.$, vol.\%); oxygen extraction $\left(\mathrm{EO}_{2}\right)$ and oxygen uptake $\left(\mathrm{IVO}_{2}, \mathrm{ml} / \mathrm{min} \cdot \mathrm{m}^{2}\right)$.

Obtained results in conditions WI-R, DDD-R, WI-E and DDD-E, respectively, were: heart rate $72.1 \pm 1.4,79.7 \pm 8.8,71.9 \pm 1.2$ and $101.2 \pm 18.0 \mathrm{bpm}$; right atrial pressure $4.8 \pm 2.2,2.6 \pm 1.7,8.3 \pm 2.7$ and $6.5 \pm 3.1 \mathrm{mmHg}$; mean pulmonary artery pressure $17.6 \pm 6.2,14.7 \pm 4.1,26.6 \pm 4.5$ and $26.7 \pm 5.8 \mathrm{mmHg}$; pulmonary wedge pressure $9.0 \pm 3.6,6.4 \pm 2.8,15.9 \pm 4.7$ and $14.8 \pm 5.7 \mathrm{mmHg}$; mean aortic pressure $99.5 \pm 7.8,100.5 \pm 7.1,105.4 \pm 10.5$ and $112.7 \pm 10.9 \mathrm{mmHg}$; cardiac index $2.5 \pm 1.0$, $2.8 \pm 1.2,3.9 \pm 1.4$ and $4,7 \pm 2.2 \mathrm{l} / \mathrm{min}^{2} \mathrm{~m}^{2} ;$ stroke index $34.4 \pm 15.1,35.7 \pm 16.1,54.3 \pm$ 19.9 and $48.0 \pm 22.8 \mathrm{ml} / \mathrm{m}^{2}$; stroke work index $41.9 \pm 16.9,45.2 \pm 18.1,65.8 \pm 24.5$ and $64.0 \pm 30.7 \mathrm{gm} / \mathrm{m}^{2}$; systemic vascular resistance $2347.5 \pm 933.4,2137.6 \pm 810.2$ $1526.2 \pm 699.7$ and $1511.6 \pm 783.8$ dyn.s $/ \mathrm{cm}^{5}$; pulmonary arteriolar resistance $223.7 \pm$ $145.4,179.2 \pm 79.1,169.9 \pm 124,6$ and $162.1 \pm 76.7$ dyn.s $/ \mathrm{cm}^{5}$; arteriovenous oxygen difference $5,0 \pm 1.3,4.7 \pm 2.4,9.2 \pm 3.6$ and $8.6 \pm 3.1 \mathrm{vol} . \%$; oxygen extraction $0.25 \pm$ $0.06,0,23 \pm 0.10,0.45 \pm 0.15$ and $0.43 \pm 0.14$; oxygen uptake $103.2 \pm 19.9,110.0 \pm 52.7$, $302.5 \pm 126.1$ and $326.0 \pm 115.8 \mathrm{ml} / \mathrm{min} \cdot \mathrm{m}^{2}$.

The analysis of the haemodynamic behavior shows that, during WI pacing, the exercise increased cardiac index of $57.7 \%(p<0.001$ vs WI at rest), due to an $57.8 \%$ $(p<0.001)$ increase of stroke index, and 35.0\% $(p<0.001)$ decrease of systemic vascular resistance .During DDD pacing, cardiac index increased $66.8 \%(p<0.01)$ due to an $27.0 \%$ $(p<0.001)$ increase of heart rate, $34.2 \%(p<0.01)$ increase of stroke index, and $29.3 \%$ $(p<0.001)$ decrease of systemic vascular resistance. 
The change of pacing mode from VVI to DDD resulted in: $14.1 \%$ (NS) increase of cardiac index due to $10.5 \%(p<0.05)$ increase of heart rate, $3.8 \%$ (NS) increase of stroke index, and $8.9 \%$ (NS) decrease of systemic vascular resistance, at rest; and $20.6 \%(p<0.05)$ increase of cardiac index due to $40.8 \%(p<0.001)$ increase of heart rate, $11.7 \%$ (NS) decrease of stroke index, and 1.0\% (NS) decrease of systemic vascular resistance, during exercise.

The behavior of cardiac index when the pacing mode was changed from $\mathrm{WI}$ to DDD, during exercise, justified the separation of the patients in two groups: in group A, patients presenting with a fall or mild increase in cardiac index; and, in group B, patients presenting with an expressive increase in cardiac index.

The results obtained in group A, for conditions WI-R, DDD-R, WI-E and DDDE were, respectively: heart rate $73.2 \pm 0.7,82.2 \pm 9.7,72.6 \pm 1.0$ and $105.2 \pm 20.6 \mathrm{bpm}$; right atrial pressure $4.6 \pm 2.4,2.4 \pm 1.4,8.0 \pm 2.8$ and $7.2 \pm 2.5 \mathrm{mmHg}$; mean pulmonary artery pressure $18.8 \pm 7.6,16.0 \pm 4.3,28.6 \pm 3.3$ and $27.8 \pm 6.5 \mathrm{mmHg}$; pulmonary wedge pressure $8.6 \pm 3.9,7.0 \pm 2.5 ; 17.0 \pm 6.0$ and $16.6 \pm 5.6 \mathrm{mmHg}$, mean aortic pressure $101.0 \pm 10.1,103.8 \pm 6.9,108.0 \pm 11.5$ and $114.2 \pm 13.0 \mathrm{mmHg}$; cardiac index $1.8 \pm 0.4,2.0 \pm 0.6,2.8 \pm 0.8$ and $2.8 \pm 0.8 \mathrm{l} / \mathrm{min} . \mathrm{m}^{2}$; stroke index $24.8 \pm 5.4,24.8$ $\pm 6.0,39.2 \pm 11.1$ and $27.6 \pm 7.9 \mathrm{ml} / \mathrm{m}^{2}$; stroke work index $31.4 \pm 8.4,33.1 \pm 9.9,48.8 \pm$ 16.6 and $37.1 \pm 12.8 \mathrm{gm} / \mathrm{m}^{2}$; systemic vascular resistance $2953.2 \pm 754.0,2773.6 \pm$ 498.8, $2014.1 \pm 632.6$ and $2163.3 \pm 572.8$ dyn.s $/ \mathrm{cm}^{5}$; pulmonary arteriolar resistance $315.5 \pm 148.5,240.4 \pm 63.6,236.7 \pm 147.3$ and $222.3 \pm 59.9$ dyn.s $/ \mathrm{cm}^{5}$; arteriovenous oxygen difference $5.4 \pm 1.5,4.6 \pm 1.1,10.9 \pm 2.0$ and $10.7 \pm 2.3$ vol.\%; oxygen extraction $0.27 \pm 0.06,0.23 \pm 0.04,0.54 \pm 0.06$ and $0.53 \pm 0.06$ and oxygen uptake 93.4 $\pm 16.0,88.9 \pm 17.2,298.6 \pm 72.0$ and $292.8 \pm 90.1 \mathrm{ml} / \mathrm{min} . \mathrm{m}^{2}$. 
The results obtained in group $B$, for conditions VVI-R, DDD-R, WI-E and DDDE were, respectively: heart rate $71.0 \pm 1.4,77.2 \pm 6.6,71.2 \pm 0.9$ and $97.2 \pm 12.7 \mathrm{bpm}$; right atrial pressure $5.0 \pm 1.8,2.8 \pm 1.9,86 \pm 2.9$ and $5.8 \pm 3.7 \mathrm{mmHg}$; mean pulmonary artery pressure $16.4 \pm 3.6,13.4 \pm 3.2,24.6 \pm 5.2$ and $25.6 \pm 5.0 \mathrm{mmHg}$; pulmonary wedge pressure $9.4 \pm 3.0,5.8 \pm 2.8,14.8 \pm 4.5$ and $13.0 \pm 5.4 \mathrm{mmHg}$; mean aortic pressure $98.0 \pm 4.6,97.2 \pm 5.2,102.8 \pm 11.8$ and $111.2 \pm 11.5 \mathrm{mmHg}$; cardiac index $3.1 \pm 1.1,3.6 \pm 1.3,4.9 \pm 1.2$ and $6.6 \pm .81 / \mathrm{min} . \mathrm{m}^{2}$; stroke index $44.0 \pm 15.9,46.7$ $\pm 16.1,69.4 \pm 17.1$ and $68.3 \pm 17.7 \mathrm{ml} / \mathrm{m}^{2}$; stroke work index $52.4 \pm 17.8,57.2 \pm 17.2$, $82.7 \pm 19.7$ and $90.9 \pm 21.6 \mathrm{gm} / \mathrm{m}^{2}$; systemic vascular resistance $1741.7 \pm 641.8$, $1501.5 \pm 617.6,1038.2 \pm 453.4$ and $860.0 \pm 467.9$ dyn.s $/ \mathrm{cm}^{5}$, pulmonary arteriolar resistance $131.9 \pm 57.2,118.0 \pm 38.0,103.0 \pm 22.6$ and $101.9 \pm 43.5$ dyn.s $/ \mathrm{cm}^{5}$; arteriovenous oxygen difference $4.5 \pm 0.9,4.8 \pm 3.3,7.1 \pm 4.1$ and $5.8 \pm 1.3$ vol.\%; oxygen extraction $0.23 \pm 0.04,0.23 \pm 0.15,0.33 \pm 0.14$ and $0.31 \pm 0.11$ and oxygen uptake $115.5 \pm 17.4,136.3 \pm 68.0,307.5 \pm 171.1$ and $367.5 \pm 130.2 \mathrm{ml} / \mathrm{min} . \mathrm{m}^{2}$.

During a follow-up period of $64.2 \pm 13.4$ months, three patients in group A died and no deaths were recorded in group $B$.

We concluded that:

1. The behavior of cardiac index and systemic vascular resistance identified two groups of patients:

In group $A$, the change in pacing mode from WI to DDD did not improve the haemodynamic response to exercise, because the high systemic vascular resistance prevents stroke index from increase in response to the heart rate.

In group $B$, on the other hand, changing the stimulation mode improved significantly the hemodynamic response to exercise, as far as the low values for systemic vascular resistance allow a better adaptation of stroke index. 
2. In Chagas' cardiomyopathy and high degree atrioventricular block, abnormally high values for systemic vascular resistance are useful in selecting patients who will or not benefit from WI or DDD stimulation. 


\section{I - INTRODUÇÃO}

A estimulação elétrica artificial do coração firmou-se, nas três últimas décadas, como o método mais efetivo para o tratamento dos bloqueios atrioventriculares avançados. Dentre seus objetivos estão o de aumentar a sobrevida, tratar os sintomas decorrentes da bradicardia e melhorar a qualidade de vida dos pacientes. O primeiro destes objetivos foi plenamente atingido pelas primeiras gerações de marcapassos, os ventriculares; no entanto, apesar de desfrutarem de uma maior sobrevida, muitos pacientes exibiam sintomas remanescentes ou baixa capacidade física. O grande desenvolvimento tecnológico ocorrido nos anos 80 fez com que novos tipos de estimuladores cardíacos fossem desenvolvidos. Um novo impulso em direção à estimulação fisiológica foi imprimido pela possibilidade de captar e estimular a câmara atrial, conferindo a esta nova geração de aparelhos a capacidade de variar a freqüência cardíaca em função da demanda metabólica.

Embora para a grande maioria dos distúrbios da condução atrioventricular existam hoje critérios objetivos no sentido de se indicar qual sistema de estimulação deva ser utilizado, quanto ao caso particular do bloqueio atrioventricular avançado, com função sinusal preservada, ainda existem grandes controvérsias. Da mesma forma que alguns autores têm demonstrado o melhor desempenho hemodinâmico oferecido pelos marcapassos mais modernos, e portanto mais fisiológicos, outros defendem a utilização dos marcapassos ventriculares, mais baratos e de simples manuseio e implantação, referindo resultados hemodinâmicos muito semelhantes com ambos os tipos de marcapasso. Essa controvérsia é ainda mais aguda no bloqueio atrioventricular secundário à cardiopatia chagásica, onde a literatura tem demonstrado opiniões divergentes com relação a qual modo de estimulação deva ser indicado: o ventricular ou o atrioventricular universal. 
A história da estimulação cardíaca artificial começou em 1819, quando ALDINI, pela primeira vez, descreveu a possibilidade de se estimular o coração através da corrente galvânica, com o objetivo de tratar episódios sincopais. Coube, no entanto, a HYMAN, em 1932, descrever o primeiro marcapasso com a capacidade de estimular artificialmente o coração de animais de experimentação. Este autor sugeriu ainda que aquele tipo de aparelho poderia vir a ser, no futuro, implantado em seres humanos. Nos anos 50, com o advento da cirurgia cardíaca, e, portanto, com a necessidade concreta de se recuperarem corações em fibrilação ou em assistolia ventricular, a estimulação elétrica artificial ganhou novo impulso. Já em 1951, CALLAGHAN \& BIGELOW descreveram a estimulação elétrica artificial em cães, com um par de eletrodos inseridos em uma agulha que puncionava o coração, com o sistema de condução intacto. No ano seguinte, ZOLL descreveu a primeira utilização em seres humanos, com sucesso, de um marcapasso para tratamento dos episódios da síndrome de Stokes-Adams, aplicando um par de eletrodos à parede costal e estimulando indiretamente o músculo cardíaco com o emprego de alta energia. A estimulação direta do miocárdio em seres humanos foi relatada pela primeira vez por THEVENET et al., 1958, após o implante transtorácico do eletrodo na superfície epimiocárdica. Neste mesmo ano, FURMAN \& ROBINSON descreveram a possibilidade de se utilizar a via transvenosa para a colocação dos eletrodos na cavidade do ventrículo direito.

A aplicação de um marcapasso ventricular completamente implantável foi realizada pela primeira vez por SENNING, em 1958. Este sistema, desenvolvido por ELMQUIST, tinha como fonte de energia duas baterias recarregáveis de níquel-cádmio. (ELMQUIST \& SENNING, 1959). Em 1960, CHARDACK et al. iniciaram a utilização de baterias de mercúrio-zinco que, por quase duas décadas, foram a principal opção de fonte de energia para os marcapassos implantáveis. 
A preocupação com o desempenho hemodinâmico proporcionado pela estimulação unicamente ventricular remonta ao advento dos marcapassos implantáveis. NATHAN et al., 1962, utilizaram pela primeira vez um marcapasso que estimulava os ventrículos, após captar as ondas de atividade elétrica atrial, através de um eletrodo suturado na parede do átrio esquerdo. Quando empregado em pacientes portadores de bloqueios avançados da condução atrioventricular, este tipo de marcapasso possibilitava dois grandes benefícios: o restabelecimento da relação seqüencial entre as contrações atrial e ventricular, e a variação da freqüência cardíaca, de acordo com as necessidades metabólicas do paciente. No entanto, a dificuldade em se implantar o eletrodo atrial e, principalmente, o grande consumo de energia de tais geradores, fez com que sua utilização não passasse da experimentação clínica, até o final dos anos 70 .

Grandes avanços no desenvolvimento dos marcapassos marcaram o início dos anos 80: a utilização das baterias de sais de lítio, de grande durabilidade, possibilitou o fechamento hermético dos marcapassos, aumentando a sua segurança; o rápido progresso da microeletrônica e da informática permitiu a contração de tamanho, a multiprogramabilidade e a telemetria bidirecional dos geradores de pulso; e o desenvolvimento de novas ligas metálicas condutoras e resinas isolantes levou à fabricação de cabos-eletrodos mais flexíveis, resistentes, histocompatíveis e de fácil implantação na cavidade atrial direita. (PARSONNET et al., 1983; BERNSTEIN et al., 1984; HAUSER et al., 1986; BERNSTEIN, 1987). Iniciou-se, definitivamente, a utilização clínica da estimulação "fisiológica", e, com ela, as grandes controvérsias com relação ao seu real benefício.

As principais vantagens dos marcapassos ventriculares são a simplicidade de implante e de acompanhamento, e o menor custo. Os argumentos de defesa de sua indicação são o aumento de sobrevida de seus portadores e os baixos índices de sintomas remanescentes, nos pacientes com bloqueios atrioventriculares avançados. Os 
resultados comparativos do tratamento de tais pacientes, com e sem marcapasso (FORICHON, 1975; HETZEL et al., 1978; GAUCH et al., 1982; SANT'ANNA et al., 1982; GRECO et al., 1984; ESPINOSA et al., 1985; ZANINI et al., 1989), demonstraram claramente a eficiência da estimulação ventricular, em pacientes chagásicos ou não. A mortalidade, da ordem de $70 \%$ ao final de 5 anos, e de $80 \%$ após 10 anos de seguimento sem o implante de marcapasso, decresceu, em média, para 40 e 50\% respectivamente, quando os pacientes eram submetidos à estimulação cardíaca artificial ventricular permanente. A persistência de sintomas, nestes últimos, também é pequena e, geralmente, relacionada à ocorrência de disfunção ventricular associada. (BENCHIMOL et al., 1965; CHAMBERLAIN et al, 1970; GAUCH et al., 1982; MARTINELLI et al., 1983.)

As maiores desvantagens dos marcapassos ventriculares estão diretamente ligadas ao desaparecimento da relação normal entre as contrações atrial e ventricular, e à incapacidade destes geradores de alterar a freqüência cardíaca. A persistência ou o desenvolvimento de sintomas e sinais de insuficiência cardíaca congestiva direita e esquerda, assim como de palpitações, tonturas e síncopes têm sido freqüentemente relatados, principalmente em portadores de disfunções sinusais (PATEL et al., 1977; ALICANDRI et al., 1978; JOHNSON et al., 1978: EL GAMAL \& VAN GELDER, 1981; LEWIS et al., 1981; COSTA et al., 1985b), quadro este que foi caracterizado como "síndrome do marcapasso". As conseqüências do desaparecimento da relação normal entre as contrações atrial e ventricular foram exaustivamente estudadas. A utilização, em estudos pareados, das estimulações atrial, atrioventricular seqüencial e ventricular isolada, permitiu o estabelecimento das repercussões hemodinâmicas ocasionadas pela dissociação atrioventricular e pela despolarização ventricular ocorrendo fixamente antes da atrial. (SKINNER et al., 1963; SAMET et al., 1966; SCULLY et al., 1973; COSTA et al., 1984a; MARTINELLI et al., 1985). Foram também avaliadas: a importância da contribuição atrial ao enchimento ventricular; a existência ou não de refluxo sangüíneo 
pelas valvas atrioventriculares; o desenvolvimento de batimentos cardíacos recíprocos inefetivos; as arritmias atriais por reentrada do estímulo elétrico do marcapasso; e o consumo de oxigênio pelo miocárdio, em cada uma daquelas condições. (OGAWA et al., 1978; NAITO et al. 1983; COSTA et al., 1984; MOREIRA et al., 1985; DREIFUS et al., 1986). Ficou demonstrado que a diminuição do débito cardíaco e o aumento do de consumo de oxigênio miocárdico são muito importantes quando existe a condução retrógrada ventrículo-atrial; porém, durante a dissociação atrioventricular completa, estes distúrbios são pouco expressivos. Quanto à incapacidade de alterar a freqüência cardíaca, a literatura tem sido unânime em afirmar que, em média, a capacidade física dos pacientes não chagásicos é menor durante a estimulação ventricular em freqüência fixa, quando comparada aos resultados obtidos com a estimulação ventricular com freqüência variável. (HUMEN et al., 1985; SMEDGARD et al., 1987; ALT et al., 1988; FETTER et al., 1988; LAU \& CAMM, 1988; LAU et al., 1988; ZEGELMAN et al., 1988; HEDMAN \& NORDLANDER, 1989; LAU et al., 1989.)

A estimulação atrioventricular universal tem como principais vantagens a manutenção do sincronismo atrioventricular e a capacidade de elevar a freqüência ventricular quando o nó sinusal é normal. A superioridade da estimulação atrioventricular sobre a estimulação ventricular foi definitivamente comprovada para os pacientes com as seguintes indicações: disfunção do nó sinusal (CURTIS et al., 1981; STONE et al., 1982; MAHMUD et al., 1983; NISHIMURA et al., 1983; RAZA et al., 1984; COSTA et al., 1985b; MITSUOKA et al., 1988; REDIKER et al., 1988); forma cardioinibitória da hipersensibilidade do seio carotídeo (COSTA et al., 1984b; MADIGAN et al., 1984); bloqueios atrioventriculares associados à estenose subaórtica hipertrófica (SHEMIN et al., 1979) e bloqueios atrioventriculares associados à insuficiência coronária crônica (KENNY et al., 1986; SHEFER et al., 1987). A baixa incidência de complicações 
relacionadas ao implante do eletrodo atrial foi demonstrada em crianças e adultos. (COSTA et al., 1986; GILLETTE et al., 1987.)

KRUSE \& RYDÉN, 1981; KRUSE et al., 1982; PEHRSSON, 1983; PERRINS et al., 1983; KRISTENSSON et al., 1985a; KRISTENSSON et al., 1985b, em estudos clínicos pareados, relataram a melhora da capacidade física dos pacientes, de 13 a $22 \%$, com a mudança da estimulação ventricular para atrioventricular. KARLÖF, 1974; KAPPENBERGER et al., 1982; KRUSE et al., 1982; PEHRSSON \& ASTRÖM, 1983 e NORDLANDER et al., 1987, referiram a melhora do débito cardíaco dos pacientes, de 15,5 a 41,7\%, em média, durante o exercício, com a mudança do modo de estimulação. NORDLANDER et al., em 1987, estudando o metabolismo do oxigênio, demonstraram que a diferença arteriovenosa periférica de oxigênio é maior com o modo ventricular, quando comparado ao modo atrioventricular, para o mesmo tipo de esforço, evidenciando melhor adaptação a este segundo modo de estimulação. Nesse mesmo estudo, relataram ainda que, para o mesmo tipo de esforço, o consumo de oxigênio miocárdico é semelhante em ambos os modos de estimulação, a despeito das diferenças de freqüência cardíaca.

As principais desvantagens da estimulação atrioventricular universal são: presença de dois eletrodos intravasculares; maior tempo cirúrgico; menor duração da bateria do gerador de pulsos, devido ao maior consumo de energia e custo (cerca de $40 \%$ maior que os sistemas ventriculares). (DODINOT \& KUBLER, 1982; KRISTENSSON et al., 1984). Outras desvantagens são: maior dificuldade para o complexo diagnóstico eletrocardiográfico das complicações, maior tempo dispendido para as avaliações e reprogramações do gerador e arritmias cardíacas mediadas por este tipo de aparelho. (FURMAN \& FISHER, 1982; FURMAN, 1985; ZIMMERN et al., 1986: MARTINELLI et al., 1987.) 
As controvérsias quanto à indicação de estimulação ventricular ou atrioventricular ocorrem exatamente diante dos pacientes portadores de bloqueios atrioventriculares avançados. Tais pacientes apresentam baixa incidência de condução retrógrada ventrículo-atrial e, conseqüentemente, é reduzido o percentual dos que exibem sintomas e sinais que caracterizam a "síndrome do marcapasso" (MOREIRA et al., 1984; WESTVEER et al., 1984). Em documento oficial, a "North American Society of Pacing and Electrophysiology - NASPE" (PARSONNET et al., 1984) classifica as indicações de marcapassos atrioventriculares, e inclui, dentre as situações onde existe concordância geral de que um marcapasso atrioventricular está indicado, todos os pacientes portadores de bloqueios atrioventriculares com função sinusal normal, principalmente os portadores de baixa complacência ventricular e de insuficiência cardíaca congestiva. A despeito desse parecer oficial da "NASPE", muitos autores têm discordado da superioridade hemodinâmica dos marcapassos atrioventriculares sobre os ventriculares, em portadores de bloqueio atrioventricular crônico associado à disfunção do ventrículo esquerdo. (REITER \& HINDMAN, 1982; MOREIRA et al., 1989). Mesmo a melhora da capacidade física com a mudança do modo ventricular para atrioventricular em portadores de graus leve e moderado de disfunção ventricular tem sido negada. (YEE et al., 1984; MARTINELLI et al., 1986; ARDITO et al., 1987). KARLÖF, 1974 e PEHRSSON \& ASTRÖM, 1983, chamam a atenção para a grande variabilidade dos resultados individuais, quando alguns pacientes atingem percentuais elevados de melhora do índice cardíaco, enquanto que outros pacientes elevam pouco ou até diminuem o índice cardíaco com a mudança de modo de estimulação ventricular para atrioventricular.

Nos pacientes portadores de cardiopatia chagásica com disfunção ventricular esquerda de grau severo, associada ao bloqueio avançado da condução atrioventricular, existe uma forte tendência ao uso da estimulação ventricular, porque esta impede a elevação indesejada da freqüência cardíaca. KORMANN et al., 1975, relataram a 
melhora da insuficiência cardíaca congestiva de pacientes com cardiomegalia acentuada, com a diminuição da freqüência de estimulação em longo prazo. A deterioração hemodinâmica ocorrida com a elevação da freqüência de 50 para 100 batimentos por minuto, acarretando o choque cardiogênico e síncopes, foi documentada por MOREIRA et al., 1989, em um paciente com miocardiopatia chagásica de grau severo.

Não existe concordância com relação a qual modo de estimulação deva ser indicado aos pacientes portadores de cardiopatia chagásica com disfunção ventricular esquerda, de graus leve e moderado, com bloqueio atrioventricular avançado. COSTA et al, 1985a, estudando oito pacientes portadores de miocardiopatia com disfunção, leve a moderada, do ventrículo esquerdo, encontraram aumento do débito cardíaco de 16,9\%, em média, com a mudança do modo ventricular para atrioventricular, durante o exercício. Este aumento pode ser considerado dos menos expressivos, quando comparado aos resultados relatados para pacientes não chagásicos. MARTINELLI et al., 1986, através da ecocardiografia e da ergoespirometria, concluíram que não havia diferença significativa entre os dois modos de estimulação, com relação à capacidade física. ARDITO et al., 1986, avaliaram a evolução clínica e a capacidade de trabalho pelo estudo ergométrico, não encontrando, também, diferença entre as estimulações ventricular e atrioventricular universal.

Tendo em vista que ainda não foi demonstrada a superioridade dos resultados clínicos e hemodinâmicos dos marcapassos atrioventriculares sobre os ventriculares, em pacientes chagásicos portadores de bloqueios avançados da condução atrioventricular, e que os marcapassos atrioventriculares têm maior custo e são mais complexos para o implante e acompanhamento dos pacientes, está justificada a continuidade das pesquisas nesse campo. 
INTRODUÇÃO

O objetivo do presente estudo é comparar os resultados hemodinâmicos da estimulação atrioventricular universal com os da estimulação ventricular, em pacientes portadores de bloqueios avançados da condução atrioventricular, associados à miocardiopatia dilatada de etiologia chagásica, de graus leve e moderado, durante o repouso e o exercício. 


\section{II - MÉTODO}

\section{Casuística}

A casuística desta tese consta da observação de dez pacientes do Instituto do Coração do Hospital das Clínicas da Faculdade de Medicina da Universidade de São Paulo, portadores de cardiopatia chagásica com bloqueio avançado da condução atrioventricular.

A idade dos pacientes variou de 18 a 50 anos, com média de 37 anos. Sete pacientes eram do sexo masculino e três do sexo feminino, sendo nove da raça branca e um da raça negra. (Tabela la).

TABELA la - DADOS GERAIS DA CASUÍSTICA

\begin{tabular}{|c|c|c|c|c|c|}
\hline CASO & INICIAIS & IDADE & SEXO & RAÇA & $\begin{array}{c}\text { ICC } \\
\text { (NYHA) }\end{array}$ \\
\hline 1 & AGF & 34 & $M$ & B & II \\
\hline 2 & ATS & 34 & $M$ & B & II \\
\hline 3 & JLR & 39 & $M$ & B & II \\
\hline 4 & JAS & 18 & $\mathrm{M}$ & B & II \\
\hline 5 & MDM & 50 & $M$ & B & II \\
\hline 6 & MMC & 38 & $\mathrm{~F}$ & B & I \\
\hline 7 & ASE & 49 & $\mathrm{~F}$ & $\mathrm{~N}$ & II \\
\hline 8 & ATO & 34 & $M$ & B & II \\
\hline 9 & FFT & 44 & $\mathrm{~F}$ & B & I \\
\hline 10 & LB & 30 & $\mathrm{M}$ & $\mathrm{B}$ & II \\
\hline
\end{tabular}

ICC: Insuficiência Cardíaca Congestiva; NYHA: New York Heart

Association; M: masculino; F: feminino; B: branca; N: negra.

O critério de seleção utilizado visou a identificar pacientes portadores de bradiarritmia com sintomas de baixo fluxo cerebral ou que apresentassem alto risco de morte súbita, porém, que tivessem pequena limitação física como conseqüência de insuficiência cardíaca congestiva. 
Os sintomas relatados pelos pacientes foram: dispnéia aos grandes esforços, em oito; palpitações, em cinco; tonturas, em seis e síncopes, em um paciente. Dois pacientes eram assintomáticos. (Tabela Ib).

O exame físico geral demonstrou pressão arterial sistólica variando de 110 a 200 mmHg e diastólica variando de 60 a 100 mmHg. A mínima freqüência cardíaca encontrada foi de $32 \mathrm{bpm}$ e a máxima, de $47 \mathrm{bpm}$. A presença de edema de membros inferiores ao exame físico, ou a referência deste tipo de achado foi verificada em cinco pacientes. (Tabela Ib.)

Medicamentos tinham sido utilizados por seis pacientes. Três deles tinham tomado digitálicos, três haviam recebido diuréticos e apenas um paciente fora medicado com antiarrítmico. (Tabela lb.)

O estudo eletrocardiográfico, utilizando as derivações clássicas, demonstrou que todos os pacientes estavam em ritmo sinusal para os átrios.Todos os pacientes apresentavam bloqueio atrioventricular, sendo que em oito deles o bloqueio era total, com ritmo idioventricular, e em dois o bloqueio era do segundo grau do tipo 2:1. A duração do complexo QRS era aumentada em todos os pacientes, e variou de 0,14 a 0,16 segundos. Quatro pacientes apresentavam extra-sístoles ventriculares, sendo unifocais em um deles e polifocais em três. (Tabela Ic.)

O estudo radiológico do tórax realizado na projeção póstero-anterior visou a calcular o índice cardiotorácico, que variou de 0,46 a 0,61 com valor médio de 0,51 e desvio padrão de 0,05. (Tabela Ic.) Ao estudo ecocardiográfico, o diâmetro diastólico do ventrículo esquerdo variou de 51 a $66 \mathrm{~mm}$, com valor médio de 58,2 e desvio padrão de 5,1 mm. A fração de encurtamento do ventrículo esquerdo variou de 0,17 a 0,46 com valor médio de 0,29 e desvio padrão de 0,08. Como resultado final, cinco pacientes foram 
considerados morfologicamente normais, três pacientes classificados como portadores de miocardiopatia leve, e dois de miocardiopatia moderada. (Tabela Ic.)

\section{TABELA Ib - DADOS DE HISTÓRIA E EXAME FÍSICO}

\begin{tabular}{ccccccccccc}
\hline \hline \multirow{2}{*}{ CASO } & \multicolumn{3}{c}{ SINTOMAS } & \multicolumn{3}{c}{ EXAME FÍSICO } & \multicolumn{3}{c}{ MEDICAMENTOS EM USO } \\
\cline { 2 - 10 } & DISPNÉIA & PALPIT & SINC/TONT & PAS & FC & EDEMAS & DIGIT & DIUR & ANTIAR \\
\hline \hline 1 & + & - & + & $150 / 70$ & 32 & - & + & - & - \\
2 & + & - & + & $120 / 80$ & 47 & - & - & - & - \\
3 & + & - & + & $110 / 60$ & 32 & + & - & - & + \\
4 & + & + & - & $110 / 65$ & 35 & - & - & - & - \\
5 & + & + & + & $120 / 80$ & 40 & - & - & + & - \\
6 & - & - & - & $150 / 80$ & 40 & + & - & + & - \\
7 & + & - & - & $140 / 80$ & 42 & + & + & + & - \\
8 & + & + & - & $160 / 90$ & 42 & + & + & - & - \\
9 & - & + & + & $110 / 70$ & 41 & - & - & - & - \\
10 & + & + & + & $200 / 100$ & 33 & + & - & - & - \\
\hline \hline
\end{tabular}

DISPNÉIA: Referência de dispnéia; PALPIT: Referência de palpitações; SINC/TONT:Referência de episódios sincopais ou tonturas; PAS: Pressão arterial sistêmica; FC:Freqüência de pulso; EDEMAS: Presença ou referência de edemas; DIGIT: Referência de uso de digitálicos; DIUR: Referência de uso de diuréticos; ANTIAR: Referência de uso de anti-arrítmicos; (+): presente; (-): ausente.

\section{Características do marcapasso utilizado}

Em todos os pacientes foram utilizados sistemas de estimulação cardíaca artificial implantável do tipo atrioventricular universal multiprogramável.

Estes marcapassos são dotados de dois cabos-eletrodos, um para os átrios e outro para os ventrículos e um gerador de pulsos.

O gerador de pulsos tem como fonte de energia uma bateria de sal de lítio, e seu circuito eletrônico permite a mudança da programação da freqüência de estimulação e do modo de estimulação, dentre outros parâmetros programáveis. Essas alterações da programação são realizadas de maneira não invasiva, através do uso de um programador externo, que transmite sinais de radiofreqüência para o gerador de pulsos, modificando suas características. 
TABELA IC - EXAMES COMPLEMENTARES

\begin{tabular}{|c|c|c|c|c|c|c|c|}
\hline \multirow[t]{2}{*}{ CASO } & \multicolumn{3}{|c|}{ ECG } & \multirow{2}{*}{$\begin{array}{c}\mathrm{RX} \\
\mathrm{ICT} \\
\end{array}$} & \multicolumn{3}{|c|}{ ECO } \\
\hline & RITMO & COND A-V & ESV & & D Diast & D Sist & $\Delta \mathrm{D} \%$ \\
\hline 1 & SINUSAL & BAVT & - & 0,46 & 53 & 35 & 0,34 \\
\hline 2 & SINUSAL & BAV 2:1 & UNIF & 0,50 & 51 & 32 & 0,37 \\
\hline 3 & SINUSAL & BAVT & POLIF & 0,46 & 61 & 47 & 0,23 \\
\hline 4 & SINUSAL & BAVT & - & 0,55 & 66 & 55 & 0,17 \\
\hline 5 & SINUSAL & BAVT & - & 0,48 & 63 & 49 & 0,22 \\
\hline 6 & SINUSAL & BAVT & POLIF & 0,61 & 65 & 48 & 0,26 \\
\hline 7 & SINUSAL & BAVT & - & 0,53 & 59 & 43 & 0,27 \\
\hline 8 & SINUSAL & BAVT & - & 0,51 & 53 & 37 & 0,30 \\
\hline 9 & SINUSAL & BAV 2:1 & POLIF & 0,50 & 54 & 38 & 0,30 \\
\hline 10 & SINUSAL & BAVT & - & 0,46 & 57 & 31 & 0,46 \\
\hline
\end{tabular}

ECG: Estudo Eletrocardiográfico; RITMO: Ritmo Cardíaco (para os átrios); COND A-V: Condução Atrioventricular; ESV: Extrassístoles ventriculares; Rx: Estudo Radiológico do Tórax; ICT: Índice Cardiotorácico; ECO: Estudo Ecocardiográfico do Coração; D Diast: Diâmetro Diastólico do Ventrículo Esquerdo; D Sist: Diâmetro Sistólico do Ventrículo Esquerdo; $\Delta \mathrm{D} \%$ : Fração de Encurtamento do Ventrículo Esquerdo; (-): Ausente; BAVT: Bloqueio atrioventricular do terceiro grau; BAV 2:1: Bloqueio atrioventricular do segundo grau do tipo 2:1; UNIF: Extrassístoles ventriculares unifocais; POLIF: Extrassístoles ventriculares polimórficas ou polifocais.

Foram utilizados nesse estudo dois modos de programação: o ventricular de demanda e o atrioventricular universal. A partir de 1984 foi estabelecido um código para padronização dos modos de estimulação cardíaca artificial (BERNSTEIN et al., 1984), que tem sido utilizado internacionalmente. Este código considera três letras, sendo que a primeira letra define as câmaras cardíacas que são estimuladas pelo marcapasso, a segunda letra define as câmaras cardíacas cujos potenciais elétricos são captados pelo marcapasso e a terceira letra define qual tipo de mecanismo de estimulação ou inibição do marcapasso é desencadeado após a captação de um potencial elétrico espontâneo (não estimulado artificialmente). Para as duas primeiras posições (letras) utilizam-se: A para identificar átrios; V para identificar ventrículos; e D para identificar os modos de estimulação que estimulam ou captam ambas as câmaras cardíacas. Na terceira posição utilizam-se: I para inibição; T para deflagração; e D para identificar modos de estimulação 
que executam essas duas operações. Com o objetivo de facilitar a interpretação das figuras e tabelas, principalmente, utilizaremos o código acima descrito.

A estimulação ventricular de demanda (modo WI) constitui-se em uma forma de programação do marcapasso implantado, que permite estimular apenas a as câmaras ventriculares, em freqüência de pulso fixa, porém também programável. Quando o paciente apresenta ritmo cardíaco espontâneo com freqüência cardíaca resultante maior que a freqüência programada no marcapasso, este se inibe.

A estimulação atrioventricular universal (modo DDD) permite a estimulação e captação tanto dos átrios quanto dos ventrículos, e executa funções tanto de inibição (átrios e ventrículos) quanto de deflagração (apenas para os ventrículos). Realiza a estimulação seqüencial de átrios e ventrículos, caso a freqüência sinusal do paciente esteja abaixo da freqüência mínima programada no marcapasso; caso contrário, estimula apenas os ventrículos, logo após captar uma despolarização atrial espontânea.

\section{Técnica Operatória}

Todos os pacientes foram submetidos a implante de marcapasso atrioventricular universal pela via endocavitária, sob anestesia local.

A incisão realizada foi transversa, na fossa infraclavicular, iniciando-se no sulco deltopeitoral e prolongando-se por cerca de sete centímetros em direção ao esterno, sendo paralela à clavícula e à distância de dois centímetros desta.

O eletrodo ventricular utilizado, sempre de fixação passiva por "farpas", foi introduzido por dissecção da veia cefálica em todos os pacientes, sendo seu pólo distal implantado na parede diafragmática do ventrículo direito, com o auxílio da radioscopia.

O eletrodo atrial foi de fixação passiva em apenas um paciente, tendo todos os demais recebido eletrodos de fixação ativa do tipo "saca-rolha". A via de acesso, em 
todos os pacientes, foi a punção da veia subclávia, tendo sido o pólo distal implantado na aurícula direita também em todos os pacientes, sob o controle radioscópico.

O controle do adequado funcionamento dos eletrodos implantados foi realizado: pela leitura direta da impedância do sistema cabo-eletrodo-miocárdio; pela observação do limiar de excitabilidade, variando-se a amplitude do pulso de estimulação com duração do pulso fixada em $0,5 \mathrm{~ms}$; e pela medida do potencial elétrico da onda eletrocardiográfica captada pelos eletrodos implantados.

A impedância dos cabos-eletrodos atriais variou de 425 a 768 Ohms e a dos ventriculares, de 450 a 916 Ohms. O limiar de excitabilidade atrial variou de 0,4 a 1,1 V e o ventricular, de 0,2 a 1,2 V. A sensibilidade à onda "P" variou de 1,2 a 7,8 mV e ao complexo "QRS", de 7,0 a 16,8 mV.

Os geradores foram fixados sobre o músculo peitoral após realização da "bolsa do gerador" entre o tecido celular subcutâneo e o músculo peitoral maior. O fechamento da parede foi realizado com sutura contínua em chuleio simples com fio absorvível, no plano subcutâneo, e sutura contínua intradérmica inabsorvível, na pele.

\section{Condições estudadas}

O estudo hemodinâmico realizado entre o quarto e décimo quarto dias após o implante do marcapasso (6,8 dias em média) constou, para cada paciente, de quatro fases distintas, com dez minutos de intervalo entre o final da fase anterior e o início da subseqüente:
a) Modo ventricular em repouso
$(\mathrm{VVI}-\mathrm{R})$
b) Modo atrioventricular em repouso (DDD-R)
c) Modo ventricular sob esforço
(VVI-E)
d) Modo atrioventricular sob esforço (DDD-E) 


\section{Modos de estimulação utilizados}

Os pacientes foram submetidos a dois tipos de programação padronizados para avaliar sua condição hemodinâmica. A mudança da programação do marcapasso foi sempre realizada de maneira não invasiva por telemetria do gerador.

\section{a) Modo ventricular (VVI)}

Este modo de programação permitiu a estimulação artificial dos ventrículos em freqüência única e constante, padronizada em torno de 70 pulsos por minuto. Uma vez que estavam todos em bloqueio atrioventricular de grau avançado, os pacientes permaneceram constantemente sob estimulação artificial dos ventrículos, com dissociação completa entre os batimentos atriais e ventriculares.

\section{b) Modo atrioventricular universal (DDD)}

Este modo de programação permitiu a estimulação do coração, mantendo-se o sincronismo atrioventricular através de dois mecanismos: estimulação seqüencial de átrios e ventrículos na freqüência de 70 ppm sempre que a freqüência sinusal estava abaixo daquele valor (com o objetivo de propiciar termo de comparação com a freqüência fixa do modo ventricular); e estimulação ventricular sincronizada à onda "P", sempre que a freqüência sinusal ultrapassava $70 \mathrm{bpm}$. A freqüência ventricular máxima permitida foi programada para $175 \mathrm{bpm}$. O intervalo atrioventricular programado foi sempre $150 \mathrm{~ms}$.

\section{Padronização do esforço}

O esforço foi realizado através de cicloergômetro da Funbec, com acoplamento especial à mesa hemodinâmica.

Os pacientes foram mantidos em posição supina, pedalando em ritmo constante de aproximadamente 40 a 60 rotações por minuto. O exercício foi realizado de maneira contínua, com duração total de aproximadamente seis minutos, com carga constante de 
$50 \mathrm{~W} / \mathrm{s}$, dando-se início às medidas hemodinâmicas sempre três minutos após o início do esforço, para permitir que a condição de equilíbrio fosse atingida. (BLACKMON et al., 1967.)

\section{Estudo hemodinâmico}

O estudo hemodinâmico foi realizado com o paciente em posição supina, nas condições de repouso $(R)$ e exercício $(E)$, em modos ventricular e atrioventricular.

As medidas foram obtidas após introdução dos cateteres de Swan-Ganz (93A118-7F), pela veia basílica direita, ao nível da artéria pulmonar, e de Sones (8F), através da artéria braquial direita, posicionado na aorta ascendente. Ambos os cateteres foram conectados ao transdutor de pressão, mantido ao nível da linha médio-torácica, admitida como ponto de referência zero (GROSSMAN, 1980b). Tendo em vista as medidas, foi utilizado o sistema de computação aplicado ao diagnóstico do Serviço de Hemodinâmica do Instituto do Coração (HP-21511-A). Dessa forma, foram obtidos os seguintes parâmetros: freqüência cardíaca (FC), em batimentos por minuto (bpm); pressões médias em átrio direito (PAD), em artéria pulmonar (PAP), em capilar pulmonar (PCP) e na aorta (PA), expressas em mmHg.

O débito cardíaco (DC) foi determinado pelo método da diluição do corante (GROSSMAN, 1980a), através de injeção única de $1 \mathrm{ml}$ de "indocyanine green", na concentração de $5 \mathrm{mg} / \mathrm{ml}$, em artéria pulmonar. As amostras de sangue arterial foram colhidas pelo cateter posicionado na aorta, através da aspiração contínua por bomba Harvard, na velocidade de $15 \mathrm{ml} / \mathrm{min}$, passando pelo densitômetro de Gilford, capaz de medir a concentração de corante no sangue. O sistema foi previamente calibrado numa conhecida concentração do corante no sangue. O DC, em litros por minuto (I/min), foi calculado pelo sistema HP-21511-A, após a análise da curva de diluição do corante. O valor final foi obtido através da média de três medidas de DC. 
Os parâmetros hemodinâmicos derivados foram obtidos através das seguintes fórmulas (YANG et al., 1978):

a) Índice Cardíaco $(\mathrm{IC})=\mathrm{DC} / \mathrm{SC}$ em $\mathrm{l} / \mathrm{min} \cdot \mathrm{m}^{2}$, em que SC representa a superfície corpórea;

b) Índice Sistólico (IS) = IC/FC em $\mathrm{ml} / \mathrm{m}^{2}$;

c) Índice do Trabalho Sistólico (ITS) = IS x (AO-CP) x 0,0136 em gm/ $/ \mathrm{m}^{2}$ em que 0,0136 representa o fator de conversão de mmHg.ml em gm;

d) Resistência Vascular Sistêmica (RVS) $=(P A-P A D) / D C \times 80$ em dyn.s/cm em que 80 representa o fator de conversão de $\mathrm{mmHg} \cdot \mathrm{min} / \mathrm{l}$ em dyn.s $/ \mathrm{cm}^{5}$;

e) Resistência Arteriolar Pulmonar (RAP) $=($ PAP-PCP $) / D C \times 80$ em dyn.s $/ \mathrm{cm}^{5}$.

\subsection{Classificação quanto à função dos ventrículos direito e esquerdo}

A classificação hemodinâmica foi realizada através da distribuição dos pacientes em subgrupos, procurando discriminá-los a partir do desempenho ventricular (LITTLE, 1981).

A função ventricular esquerda foi analisada através da relação entre a pressão capilar pulmonar com o índice cardíaco, respectivamente em abscissa e ordenada. Da mesma maneira, a função ventricular direita foi analisada pela relação da pressão do átrio direito com o índice cardíaco, respectivamente em abscissa e ordenada. Foram analisadas no mesmo gráfico as condições repouso e exercício, para cada um dos modos de estimulação estudados (ventricular ou atrioventricular universal).

Com base nas faixas de valores considerados normais (BARRATT - BOYES \& WOOD, 1958; SWAN \& GANZ, 1983), adotou-se o limite inferior para o índice cardíaco e os limites superiores para a pressão capilar pulmonar e pressão do átrio direito, de tal forma que foram admitidos como discriminatórios os valores: índice cardíaco menor ou 
igual a 2,8 I/min. $\mathrm{m}^{2}$, pressão capilar pulmonar maior ou igual a $15 \mathrm{mmHg}$ e pressão do átrio direito maior ou igual a $8 \mathrm{mmHg}$.

A partir desses dados, foram constituídos quatro subgrupos para a função ventricular esquerda: subgrupos I, II, III e IV. Os subgrupos I e II representam a normalidade do índice cardíaco e os subgrupos I e III a normalidade da pressão capilar pulmonar. Os valores anormais do índice cardíaco estão representados nos subgrupos III e IV e os da pressão capilar pulmonar em II e IV. (figuras 1a e 1b.)

O mesmo critério de classificação foi adotado para a função ventricular direita, isto é, foram constituídos quatro subgrupos: subgrupos I, II, III e IV. Os subgrupos I e II representam a normalidade do índice cardíaco e os subgrupos I e III a normalidade da pressão do átrio direito. Os valores anormais do índice cardíaco estão representados nos subgrupos III e IV e os da pressão do átrio direito, em II e IV. (figuras 3a e 3b.)

Um segundo critério foi ainda adotado para a avaliação da função ventricular esquerda, utilizando as variações da pressão de enchimento do ventrículo esquerdo e do índice sistólico ocorridas com o exercício (ROSS et al., 1966). Estudando pacientes com diagnósticos previamente firmados, esses autores puderam classificar o comportamento do índice sistólico e da pressão de enchimento do ventrículo esquerdo de pacientes classificados em três subgrupos: pacientes com função ventricular normal, pacientes com anormalidade da dinâmica do ventrículo esquerdo e pacientes com depressão da função do ventrículo esquerdo. Segundo esses autores, os pacientes portadores de função ventricular normal, quando submetidos ao exercício, apresentaram variação negativa da pressão de enchimento do ventrículo esquerdo, independentemente do comportamento do índice sistólico. Os pacientes portadores de anormalidade da dinâmica ventricular apresentaram variação positiva da pressão de enchimento associada à elevação do índice sistólico na mesma condição ao esforço Os pacientes portadores de depressão da 
função ventricular apresentaram aumento da pressão de enchimento do ventrículo esquerdo, associado à diminuição do índice sistólico, com a realização do exercício. (figuras $2 a$ e 2b.)

\section{Estudo do consumo periférico de oxigênio}

A partir dos cateteres da aorta e da artéria pulmonar, foi possível obter duas amostras de sangue arterial e duas de sangue venoso, de um mililitro cada, para cada uma das condições estudadas. Uma das amostras foi utilizada para a determinação da saturação de oxigênio através do Oxímetro de Reflexão (Reflection Oximeter II -405800 Micro Sample Model/American Optical Corporation). A segunda amostra foi empregada para a determinação da pressão parcial de oxigênio no sangue arterial $\left(\mathrm{paO}_{2}\right)$ e venoso $\left(\mathrm{pvO}_{2}\right)$, através do equipamento analisador de gases (Instrumentation Laboratory pH/Blood Gas Analyser -mod. 313). Com esses dados, foram calculados para cada uma das condições estudadas:

a) a diferença arteriovenosa de oxigênio $\left(\mathrm{DavO}_{2}\right)=\mathrm{CaO}_{2}-\mathrm{Cv} \mathrm{O}_{2}$ em vol. $\% \mathrm{O}_{2}$, onde $\mathrm{CaO}_{2}$ representa o conteúdo arterial e $\mathrm{CvO}_{2}$ o conteúdo venoso do oxigênio;

b) a extração de oxigênio $\left(\mathrm{EO}_{2}\right)=\left(\mathrm{CaO}_{2}-\mathrm{CvO}_{2}\right) / \mathrm{CaO}_{2}$;

c) o índice de consumo de oxigênio $\left(\mathrm{IVO}_{2}\right)=\mathrm{IC} \times \operatorname{DavO}_{2} \times 10 \mathrm{em} \mathrm{ml} / \mathrm{min} \cdot \mathrm{m}^{2}$.

\section{Padronização da avaliação da evolução clínica}

O seguimento clínico de todos os pacientes foi realizado por médicos da clínica de marcapasso do Instituto do Coração, sem que estes soubessem da existência do protocolo de investigação. Desta maneira, os pacientes foram mantidos com a programação do modo de estimulação do marcapasso e medicamentos que o médico julgou necessários. 
Os pacientes foram analisados segundo sua classe funcional (New York Heart Association), incidência de intercorrências, modo de estimulação do marcapasso em que foram mantidos, uso de medicamentos, duração do gerador de pulsos, tempo de sobrevida e causa de óbito. Os medicamentos foram agrupados em quatro categorias: digitálicos, diuréticos, antiarrítmicos e vasodilatadores periféricos.

\section{Critérios para a separação dos pacientes em grupos}

Da mesma forma relatada por KARLÖF, 1974 e PEHRSSON \& ASTRÖM, 1983, o comportamento hemodinâmico individual dos pacientes do presente estudo foi heterogêneo. Alguns pacientes, durante o esforço, apresentaram aumento importante do débito cardíaco com a mudança do modo de estimulação ventricular para atrioventricular universal. Outros pacientes apresentaram queda ou aumento pouco expressivo do débito cardíaco. Estes autores consideraram expressivos os aumentos do débito cardíaco maiores que $20 \%$, com a mudança do modo de estimulação ventricular para atrioventricular universal.

Com o objetivo de elucidar o mecanismo pelo qual esta heterogeneidade de comportamento ocorria, os pacientes foram subdivididos em dois grupos distintos:

Grupo A: Pacientes que apresentaram queda ou melhora discreta do índice cardíaco com a mudança do modo ventricular (VVI) para atrioventricular universal (DDD) durante o esforço.

Grupo B: Pacientes que apresentaram melhora expressiva do índice cardíaco, com a mudança do modo ventricular para atrioventricular universal durante o esforço.

\section{Análise estatística}

Foram calculados os valores médios, desvios padrão e as variações percentuais ocorridas pelas mudanças de condições (esforço e modo de estimulação). Os efeitos da 
mudança do modo de estimulação foram analisados, fixando-se a condição repouso ou exercício. Os efeitos produzidos pela realização do esforço foram avaliados, fixando-se o modo de estimulação ventricular (VVI) ou atrioventricular universal (DDD).

Os valores acima relacionados foram calculados para os grupos $A$ e $B$, assim como para a totalidade dos pacientes.

Para a avaliação do comportamento dos grupos $A$ e B com relação às variáveis hemodinâmicas e metabólicas, foi adotado o nível de significância de 5\%, e foram utilizadas as seguintes análises estatísticas (BATSON, 1956):

a) Teste de t pareado, de Student, comparando-se, dentro do mesmo grupo, os resultados obtidos com as mudanças de condição de estudo: modo ventricular para atrioventricular universal (separadamente para as condições repouso e esforço) e repouso para exercício (separadamente para os modos ventricular e atrioventricular universal).

b) Teste de t não pareado, de Student, para a comparação do comportamento de cada uma das variáveis hemodinâmicas e do consumo de oxigênio entre os grupos $\mathrm{A}$ e B, em cada uma das condições estudadas. 


\section{III - RESULTADOS}

\section{Estudo hemodinâmico}

\subsection{Grupo Total}

No grupo total dos pacientes, os valores médios e os desvios padrão obtidos nas condições VVI repouso, DDD repouso, VVI exercício, e DDD exercício foram, respectivamente: freqüência cardíaca de 72,1 com desvio padrão de 1,4; 79,7 com desvio padrão de 8,8; 71,9 com desvio padrão de 1,2 e 101,2 com desvio padrão de 18,0 bpm; pressão média em átrio direito de 4,8 com desvio padrão de 2,2; 2,6 com desvio padrão de 1,7; 8,3 com desvio padrão de 2,7 e 6,5 com desvio padrão de 3,1 mmHg; pressão média em artéria pulmonar de 17,6 com desvio padrão de 6,2; 14,7 com desvio padrão de 4,1; 26,6 com desvio padrão de 4,5 e 26,7 com desvio padrão de 5,8 mmHg; pressão média em capilar pulmonar de 9,0 com desvio padrão de 3,6; 6,4 com desvio padrão de 2,8; 15,9 com desvio padrão de 4,7 e 14,8 com desvio padrão de 5,7 mmHg; pressão média na aorta de 99,5 com desvio padrão de 7,8; 100,5 com desvio padrão de 7,$1 ; 105,4$ com desvio padrão de 10,5 e 112,7 com desvio padrão de 10,9 mmHg; índice cardíaco de 2,5 com desvio padrão de 1,0; 2,8 com desvio padrão de 1,2; 3,9 com desvio padrão de 1,4 e 4,7 com desvio padrão de 2,21/min.m²; índice sistólico de 34,4 com desvio padrão de 15,$1 ; 5,7$ com desvio padrão de 16,$1 ; 54,3$ com desvio padrão de 19,9 e 48,0 com desvio padrão de 22,8 ml/ $\mathrm{m}^{2}$; índice do trabalho sistólico de 41,9 com desvio padrão de 16,9; 45,2 com desvio padrão de 18,$1 ; 65,8$ com desvio padrão de 24,5 e 64,0 com desvio padrão de $30,7 \mathrm{gm} / \mathrm{m}^{2}$; resistência vascular sistêmica de 2347,5 com desvio padrão de 933,4; 2137,6 com desvio padrão de 810,2; 1526,2 com desvio padrão de 699,7 e 1511,6 com desvio padrão de 783,8 dyn.s/cm ${ }^{5}$ e resistência arteriolar pulmonar de 223,7 com desvio padrão de 145,4; 179,2 com 
desvio padrão de 79,1; 169,9 com desvio padrão de 124,6 e 162,1 com desvio padrão de 76,7 dyn.s/cm ${ }^{5}$. (tabela II.)

\section{TABELA II - VALORES DESCRITIVOS DAS VARIÁVEIS HEMODINÂMICAS DO GRUPO TOTAL}

\begin{tabular}{|c|c|c|c|c|c|}
\hline \multirow{2}{*}{ Variável } & \multirow{2}{*}{ Condição } & \multicolumn{2}{|c|}{ MODO } & \multirow{2}{*}{$p$} & \multirow{2}{*}{$\begin{array}{c}\Delta l \% \\
\text { WI/DDD }\end{array}$} \\
\hline & & WI & DDD & & \\
\hline $\begin{array}{c}\mathrm{FC} \\
(\mathrm{bpm})\end{array}$ & $\begin{array}{l}\mathrm{R} \\
\mathrm{E}\end{array}$ & $\begin{array}{l}72,1 \pm 1,4 \\
71,9 \pm 1,2\end{array}$ & $\begin{array}{c}79,7 \pm 8,8 \\
101,2 \pm 18,0\end{array}$ & $\begin{array}{l}<<0,05 \\
<0,001\end{array}$ & $\begin{array}{l}+10,5 \% \\
+40,8 \%\end{array}$ \\
\hline $\begin{array}{c}\text { PAD } \\
(\mathrm{mmHa})\end{array}$ & $\begin{array}{l}\mathrm{R} \\
\mathrm{E}\end{array}$ & $\begin{array}{l}4,8 \pm 2,2 \\
83+27\end{array}$ & $\begin{array}{l}2,6 \pm 1,7 \\
65+3,1\end{array}$ & $<0,01$ & $-45,8 \%$ \\
\hline $\begin{array}{c}\text { PAP } \\
(\mathrm{mmHg})\end{array}$ & $\begin{array}{l}\mathrm{R} \\
\mathrm{E}\end{array}$ & $\begin{array}{l}17,6 \pm 6,2 \\
26,6 \pm 4,5\end{array}$ & $\begin{array}{l}14,7 \pm 4,1 \\
26,7 \pm 5,8\end{array}$ & $\begin{array}{c}<0,02 \\
N S\end{array}$ & $\begin{array}{r}-16,5 \% \\
+0,4 \%\end{array}$ \\
\hline $\begin{array}{c}\mathrm{PCP} \\
(\mathrm{mmHg})\end{array}$ & $\begin{array}{l}\mathrm{R} \\
\mathrm{E}\end{array}$ & $\begin{array}{c}9,0 \pm 3,6 \\
15,9 \pm 4,7\end{array}$ & $\begin{array}{c}6,4 \pm 2,8 \\
14,8 \pm 5,7\end{array}$ & $\begin{array}{c}<0,02 \\
\text { NS }\end{array}$ & $\begin{array}{c}-28,9 \% \\
-6,9 \%\end{array}$ \\
\hline $\begin{array}{c}\mathrm{PA} \\
(\mathrm{mmHg})\end{array}$ & $\begin{array}{l}\mathrm{R} \\
\mathrm{E}\end{array}$ & $\begin{array}{c}99,5 \pm 7,8 \\
105,4 \pm 10,5\end{array}$ & $\begin{array}{l}100,5 \pm 7,1 \\
112,7 \pm 10,9\end{array}$ & $\begin{array}{c}\mathrm{NS} \\
<0,02 \\
\end{array}$ & $\begin{array}{l}+1,0 \% \\
+6,9 \% \\
\end{array}$ \\
\hline $\begin{array}{c}\mathrm{IC} \\
\left(\mathrm{I} / \mathrm{min} \cdot \mathrm{m}^{2}\right)\end{array}$ & $\begin{array}{l}\mathrm{R} \\
\mathrm{E}\end{array}$ & $\begin{array}{l}2,5 \pm 1,0 \\
3,9 \pm 1,4\end{array}$ & $\begin{array}{l}2,8 \pm 1,2 \\
4,7 \pm 2,2\end{array}$ & $\begin{array}{c}\mathrm{NS} \\
<0,05\end{array}$ & $\begin{array}{l}+14,1 \% \\
+20,6 \%\end{array}$ \\
\hline $\begin{array}{c}\text { IS } \\
\left(\mathrm{ml} / \mathrm{m}^{2}\right)\end{array}$ & $\begin{array}{l}\mathrm{R} \\
\mathrm{E}\end{array}$ & $\begin{array}{l}34,4 \pm 15,1 \\
54,3 \pm 19,9\end{array}$ & $\begin{array}{l}35,7 \pm 16,1 \\
48,0 \pm 22,8\end{array}$ & $\begin{array}{l}\text { NS } \\
\text { NS }\end{array}$ & $\begin{array}{l}+3,8 \% \\
-11,7 \%\end{array}$ \\
\hline $\begin{array}{c}\text { ITS } \\
\left(\mathrm{gm} / \mathrm{m}^{2}\right)\end{array}$ & $\begin{array}{l}\mathrm{R} \\
\mathrm{E}\end{array}$ & $\begin{array}{l}41,9 \pm 16,9 \\
65,8 \pm 24,5 \\
\end{array}$ & $\begin{array}{l}45,2 \pm 18,1 \\
64,0 \pm 30,7\end{array}$ & $\begin{array}{l}\text { NS } \\
\text { NS }\end{array}$ & $\begin{array}{l}+7,7 \% \\
-2,7 \% \\
\end{array}$ \\
\hline $\begin{array}{c}\text { RVS } \\
\left(\text { dyn.s } / \mathrm{cm}^{5}\right) \\
\end{array}$ & $\begin{array}{l}\mathrm{R} \\
\mathrm{E}\end{array}$ & $\begin{array}{l}2347,5 \pm 933,4 \\
1526,2 \pm 699,7 \\
\end{array}$ & $\begin{array}{c}2137,6 \pm 810,2 \\
1511,6 \pm 783,8\end{array}$ & $\begin{array}{l}\text { NS } \\
\text { NS } \\
\end{array}$ & $\begin{array}{l}-8,9 \% \\
-1,0 \% \\
\end{array}$ \\
\hline $\begin{array}{c}\text { RAP } \\
\left(\text { dyn.s } / \mathrm{cm}^{5}\right)\end{array}$ & $\begin{array}{l}\mathrm{R} \\
\mathrm{E}\end{array}$ & $\begin{array}{l}223,7 \pm 145,4 \\
169,9 \pm 124,6\end{array}$ & $\begin{array}{l}179,2 \pm 79,1 \\
162,1 \pm 76,7\end{array}$ & $\begin{array}{l}\text { NS } \\
\text { NS }\end{array}$ & $\begin{array}{c}-19,9 \% \\
-4,6 \%\end{array}$ \\
\hline
\end{tabular}

FC: freqüência cardíaca; PAD: pressão média do átrio direito; PAP: pressão média da artéria pulmonar; PCP: pressão média do capilar pulmonar; PA: pressão média da aorta; IC: índice cardíaco; IS: índice sistólico; ITS: índice do trabalho sistólico; RVS: resistência vascular sistêmica; RAP: resistência arteriolar pulmonar; R: repouso; E: exercício; WI: modo ventricular inibido; DDD: modo atrioventricular universal; $\mathrm{p}$ : significância estatística; $\Delta \%$ WI/DDD: variação percentual ocorrida com a mudança de modo de estimulação WI para DDD.

A variação percentual das médias dos parâmetros entre as condições repouso e exercício foi, respectivamente, para os modos WI e DDD: freqüência cardíaca de $-0,3 \%$ e +27,0\%; pressão média em átrio direito de $+72,9 \%$ e $+150,0 \%$; pressão média em artéria pulmonar de $+51,1 \%$ e $+81,6 \%$; pressão média em capilar pulmonar de $+76,7 \%$ e $+131,2 \%$; pressão média na aorta de $+5,9 \%$ e $+12,1 \%$; índice cardíaco de $+57,7 \%$ e $+66,8 \%$; índice sistólico de $+57,8 \%$ e $+34,2 \%$; índice do trabalho sistólico de $+56,8 \%$ e $+41,7 \%$; resistência vascular sistêmica de $-35,0 \%$ e $-29,3 \%$ e resistência arteriolar pulmonar de $-24,1 \%$ e $-9,5 \%$. (tabela III.) 
A comparação estatística entre as condições WI repouso e VVI exercício evidenciou diferença significativa entre os valores dos parâmetros pressão média em átrio direito, pressão média em artéria pulmonar, pressão média em capilar pulmonar, índice cardíaco, índice sistólico, índice do trabalho sistólico, resistência vascular sistêmica e resistência arteriolar pulmonar, mas não entre os dos demais parâmetros. (tabela III.)

A comparação estatística entre as condições DDD repouso e DDD exercício evidenciou diferença significativa entre os valores dos parâmetros freqüência cardíaca, pressão média em átrio direito, pressão média em artéria pulmonar, pressão média em capilar pulmonar, pressão média na aorta, índice cardíaco, índice sistólico, índice do trabalho sistólico, resistência vascular sistêmica, mas não com relação à resistência arteriolar pulmonar. (tabela III.)

A variação percentual das médias dos parâmetros com a mudança do modo WI para DDD foi, respectivamente, para as condições repouso e exercício: freqüência cardíaca de $+10,5 \%$ e $+40,8 \%$; pressão média em átrio direito de $-45,8 \%$ e $-21,7 \%$; pressão média em artéria pulmonar de $-16,5 \%$ e $+0,4 \%$; pressão média em capilar pulmonar de $-28,9 \%$ e $-6,9 \%$; pressão média na aorta de $+1,0 \%$ e $+6,9 \%$; índice cardíaco de $+14,1 \%$ e $+20,6 \%$; índice sistólico de $+3,8 \%$ e $-11,7 \%$; índice do trabalho sistólico de $+7,7 \%$ e $-2,7 \%$; resistência vascular sistêmica de $-8,9 \%$ e $-1,0 \%$ e resistência arteriolar pulmonar de $-19,9 \%$ e $-4,6$. (tabela II.)

A comparação estatística entre as condições WI repouso e DDD repouso evidenciou diferença significativa entre os valores da freqüência cardíaca, pressão média em átrio direito, pressão média em artéria pulmonar, pressão média em capilar pulmonar, mas não entre os dos demais parâmetros. (tabela II.) 
A comparação estatística entre as condições WI exercício e DDD exercício evidenciou diferença significativa entre os valores da freqüência cardíaca, pressão média em átrio direito, pressão média na aorta e índice cardíaco, mas não entre os dos demais parâmetros. (tabela II.)

\section{TABELA III - VARIAÇÃO PERCENTUAL OCORRIDA COM A REALIZAÇÃO DO EXERCÍCIO}

\begin{tabular}{|c|c|c|c|c|c|c|c|}
\hline \multirow{2}{*}{ Variável } & \multirow{2}{*}{ Modo } & \multicolumn{2}{|c|}{ "GRUPO TOTAL } & \multicolumn{2}{|c|}{ GRUPO A } & \multicolumn{2}{|c|}{ GRUPO B } \\
\hline & & $\Delta \% \mathrm{R} / \mathrm{E}$ & $p$ & $\Delta \% \mathrm{R} / \mathrm{E}$ & $p$ & $\Delta \% \mathrm{R} / \mathrm{E}$ & $p$ \\
\hline $\begin{array}{c}\text { FC } \\
\text { (bpm) }\end{array}$ & $\begin{array}{l}\text { VVI } \\
\text { DDD }\end{array}$ & $\begin{array}{c}-0,3 \% \\
+27,0 \%\end{array}$ & $\begin{array}{c}\text { NS } \\
<0,001\end{array}$ & $\begin{array}{c}-0,8 \% \\
+28,0 \%\end{array}$ & $\begin{array}{c}\text { NS } \\
<0,05\end{array}$ & $\begin{array}{r}+0,3 \% \\
+25,9 \%\end{array}$ & $\begin{array}{c}\mathrm{NS} \\
<0,02\end{array}$ \\
\hline $\begin{array}{c}\text { PAD } \\
(\mathrm{mmHg})\end{array}$ & $\begin{array}{l}\text { VVI } \\
\text { DDD }\end{array}$ & $\begin{array}{r}+72,9 \% \\
+150,0 \%\end{array}$ & $\begin{array}{l}<0,01 \\
<0,01\end{array}$ & $\begin{array}{r}+73,9 \% \\
+200,0 \%\end{array}$ & $\begin{array}{c}\mathrm{NS} \\
<0,05\end{array}$ & $\begin{array}{r}+72,0 \% \\
+107,1 \%\end{array}$ & $\begin{array}{l}<0,02 \\
<0,05\end{array}$ \\
\hline $\begin{array}{c}\text { PAP } \\
(\mathrm{mmHg})\end{array}$ & $\begin{array}{l}\text { VVI } \\
\text { DDD }\end{array}$ & $\begin{array}{l}+51,1 \% \\
+81,6 \%\end{array}$ & $\begin{array}{l}<0,001 \\
<0,001\end{array}$ & $\begin{array}{l}+52,1 \% \\
+73,7 \%\end{array}$ & $\begin{array}{l}<0,05 \\
<0,01\end{array}$ & $\begin{array}{l}+50,0 \% \\
+91,0 \%\end{array}$ & $\begin{array}{l}<0,01 \\
<0,01\end{array}$ \\
\hline $\begin{array}{c}\text { PCP } \\
(\mathrm{mmHg})\end{array}$ & $\begin{array}{l}\text { VVI } \\
\text { DDD }\end{array}$ & $\begin{array}{c}+76,7 \% \\
+131,2 \%\end{array}$ & $\begin{array}{l}<0,01 \\
<0,01\end{array}$ & $\begin{array}{r}+97,7 \% \\
+137,1 \%\end{array}$ & $\begin{array}{l}<0,05 \\
<0,02\end{array}$ & $\begin{array}{c}+57,4 \% \\
+124,1 \%\end{array}$ & $\begin{array}{l}<0,01 \\
<0,05\end{array}$ \\
\hline $\begin{array}{c}\mathrm{PA} \\
(\mathrm{mmHg})\end{array}$ & $\begin{array}{l}\text { VVI } \\
\text { DDD }\end{array}$ & $\begin{array}{r}+5,9 \% \\
+12,1 \%\end{array}$ & $\begin{array}{c}\mathrm{NS} \\
<0,01\end{array}$ & $\begin{array}{l}+6,9 \% \\
+10,0 \%\end{array}$ & $\begin{array}{l}\text { NS } \\
\text { NS }\end{array}$ & $\begin{array}{c}+4,9 \% \\
+14,4 \%\end{array}$ & $\begin{aligned} & N S \\
< & 0,01\end{aligned}$ \\
\hline $\begin{array}{c}\mathrm{IC} \\
\left(\mathrm{I} / \mathrm{min} \cdot \mathrm{m}^{2}\right)\end{array}$ & $\begin{array}{l}\text { VVI } \\
\text { DDD }\end{array}$ & $\begin{array}{l}+57,7 \% \\
+66,8 \% \\
\end{array}$ & $\begin{array}{l}<0,001 \\
<0,01\end{array}$ & $\begin{array}{l}+56,6 \% \\
+37,3 \% \\
\end{array}$ & $\begin{array}{l}<0,01 \\
<0,01\end{array}$ & $\begin{array}{l}+58,3 \% \\
+83,5 \% \\
\end{array}$ & $\begin{array}{l}<0,01 \\
<0,01\end{array}$ \\
\hline $\begin{array}{c}\text { IS } \\
\left(\mathrm{ml} / \mathrm{m}^{2}\right)\end{array}$ & $\begin{array}{l}\text { VVI } \\
\text { DDD }\end{array}$ & $\begin{array}{l}+57,8 \% \\
+34,2 \%\end{array}$ & $\begin{array}{l}<0,001 \\
<0,01\end{array}$ & $\begin{array}{l}+58,0 \% \\
+11,4 \%\end{array}$ & $\begin{array}{c}<0,01 \\
\text { NS }\end{array}$ & $\begin{array}{l}+57,6 \% \\
+46,3 \%\end{array}$ & $\begin{array}{l}<0,01 \\
<0,01\end{array}$ \\
\hline $\begin{array}{c}\text { ITS } \\
\left(\mathrm{gm} / \mathrm{m}^{2}\right)\end{array}$ & $\begin{array}{l}\text { VVI } \\
\text { DDD }\end{array}$ & $\begin{array}{l}+56,8 \% \\
+41,7 \%\end{array}$ & $\begin{array}{l}<0,001 \\
<0,02\end{array}$ & $\begin{array}{l}+55,3 \% \\
+11,9 \%\end{array}$ & $\begin{array}{c}<0,05 \\
\text { NS }\end{array}$ & $\begin{array}{l}+57,7 \% \\
+58,9 \%\end{array}$ & $\begin{array}{l}<0,01 \\
<0,01\end{array}$ \\
\hline $\begin{array}{c}\text { RVS } \\
\left(\text { dyn.s } / \mathrm{cm}^{5}\right)\end{array}$ & $\begin{array}{l}\text { VVI } \\
\text { DDD }\end{array}$ & $\begin{array}{l}-35,0 \% \\
-29,3 \% \\
\end{array}$ & $\begin{array}{l}<0,001 \\
<0,001\end{array}$ & $\begin{array}{l}-31,8 \% \\
-22,0 \% \\
\end{array}$ & $\begin{array}{l}<0,02 \\
<0,01\end{array}$ & $\begin{array}{l}-40,4 \% \\
-42,7 \%\end{array}$ & $\begin{array}{l}<0,05 \\
<0,02\end{array}$ \\
\hline $\begin{array}{c}\text { RAP } \\
\left(\text { dyn.s } / \mathrm{cm}^{5}\right)\end{array}$ & $\begin{array}{l}\text { VVI } \\
\text { DDD }\end{array}$ & $\begin{array}{l}-24,1 \% \\
-9,5 \%\end{array}$ & $\begin{array}{c}<0,05 \\
\text { NS }\end{array}$ & $\begin{array}{c}-25,0 \% \\
-7,5 \%\end{array}$ & $\begin{array}{l}\text { NS } \\
\text { NS }\end{array}$ & $\begin{array}{l}-21,9 \% \\
-13,6 \%\end{array}$ & $\begin{array}{l}\text { NS } \\
\text { NS }\end{array}$ \\
\hline
\end{tabular}

FC: freqüência cardíaca; PAD: pressão média do átrio direito; PAP: pressão média da artéria pulmonar; PCP: pressão média do capilar pulmonar; PA: pressão média da aorta; IC: índice cardíaco; IS: índice sistólico; ITS: índice do trabalho sistólico; RVS: resistência vascular sistêmica; RAP:resistência arteriolar pulmonar; R: repouso; E: exercício; WI: modo ventricular inibido; DDD: modo atrioventricular; $p$ : significância estatística; $\Delta \% \mathrm{R} / \mathrm{E}$ : variação percentual ocorrida com a realização do exercício

\subsection{Grupo $A$}

No grupo $A$, os valores médios e os desvios padrão obtidos nas condições VVI repouso, DDD repouso, VVI exercício, e DDD exercício foram, respectivamente: freqüência cardíaca de 73,2 com desvio padrão de 0,7; 82,2 com desvio padrão de 9,7; 72,6 com desvio padrão de 1,0 e 105,2 com desvio padrão de 20,6 bpm; pressão média em átrio direito de 4,6 com desvio padrão de 2,4; 2,4 com desvio padrão de 1,4; 8,0 com desvio padrão de 2,8 e 7,2 com desvio padrão de 2,5 mmHg; pressão média em artéria 
pulmonar de 18,8 com desvio padrão de 7,$6 ; 16,0$ com desvio padrão de 4,3; 28,6 com desvio padrão de 3,3 e 27,8 com desvio padrão de $6,5 \mathrm{mmHg}$; pressão média em capilar pulmonar de 8,6 com desvio padrão de 3,9; 7,0 com desvio padrão de 2,5; 17,0 com desvio padrão de 6,0 e 16,6 com desvio padrão de 5,6 mmHg; pressão média na aorta de 101,0 com desvio padrão de 10,1; 103,8 com desvio padrão de 6,9; 108,0 com desvio padrão de 11,5 e 114,2 com desvio padrão de 13,0 mmHg; índice cardíaco de 1,8 com desvio padrão de 0,4; 2,0 com desvio padrão de 0,6; 2,8 com desvio padrão de 0,8 e 2,8 com desvio padrão de 0,8 l/min.m²; índice sistólico de 24,8 com desvio padrão de 5,4; 24,8 com desvio padrão de 6,0; 39,2 com desvio padrão de 11,1 e 27,6 com desvio padrão de $7,9 \mathrm{ml} / \mathrm{m}^{2}$; índice do trabalho sistólico de 31,4 com desvio padrão de 8,4; 33,1 com desvio padrão de 9,9; 48,8 com desvio padrão de 16,6 e 37,1 com desvio padrão de $12,8 \mathrm{gm} / \mathrm{m}^{2}$; resistência vascular sistêmica de 2953,2 com desvio padrão de 754,0; 2773,6 com desvio padrão de 498,8; 2014,1 com desvio padrão de 632,6 e 2163,3 com desvio padrão de 572,8 dyn.s $/ \mathrm{cm}^{5}$ e resistência arteriolar pulmonar de 315,5 com desvio padrão de148,5; 240,4 com desvio padrão de 63,6; 236,7 com desvio padrão de 147,3 e 222,3 com desvio padrão de 59,9 dyn.s/cm ${ }^{5}$. (tabela IV.)

A variação percentual das médias dos parâmetros entre as condições repouso e exercício foi, respectivamente, para os modos WI e DDD: freqüência cardíaca de $-0,8 \%$ e $+28,0 \%$; pressão média em átrio direito de $+73,9 \%$ e $+200,0 \%$; pressão média em artéria pulmonar de $+52,1 \%$ e $+73,7 \%$; pressão média em capilar pulmonar de $+97,7 \%$ e $+137,1 \%$; pressão média na aorta de $+6,9 \%$ e $+10,0 \%$; índice cardíaco de $+56,6 \%$ e $+37,3 \%$; índice sistólico de $+58,0 \%$ e $+11,4 \%$; índice do trabalho sistólico de $+55,3 \%$ e $+11,9 \%$; resistência vascular sistêmica de $-31,8 \%$ e $-22,0 \%$ e resistência arteriolar pulmonar de $-25,0 \%$ e $-7,5 \%$. (tabela III.) 


\section{TABELA IV - VALORES DESCRITIVOS DAS VARIÁVEIS HEMODINÂMICAS DO GRUPO A}

\begin{tabular}{|c|c|c|c|c|c|}
\hline \multirow{2}{*}{ Variável } & \multirow{2}{*}{ Condição } & \multicolumn{2}{|c|}{ MODO } & \multirow{2}{*}{$p$} & \multirow{2}{*}{$\begin{array}{c}\Delta l \% \\
\text { WI/DDD }\end{array}$} \\
\hline & & WI & DDD & & \\
\hline $\begin{array}{c}\text { FC } \\
\text { (bpm) }\end{array}$ & $\begin{array}{l}\mathrm{R} \\
\mathrm{E}\end{array}$ & $\begin{array}{l}73,2 \pm 0,7 \\
72,6 \pm 1,0\end{array}$ & $\begin{array}{c}82,2 \pm 9,7 \\
105,2 \pm 20,6\end{array}$ & $\begin{array}{c}\mathrm{NS} \\
<0,05 \\
\end{array}$ & $\begin{array}{l}+12,3 \% \\
+44,9 \% \\
\end{array}$ \\
\hline PAD & $\mathrm{R}$ & $4,6 \pm 2,4$ & $2,4 \pm 1,4$ & NS & $-47,8 \%$ \\
\hline$(\mathrm{mmHg})$ & $\mathrm{E}$ & $8,0 \pm 2,8$ & $7,2 \pm 2,5$ & NS & $-10,0 \%$ \\
\hline PAP & $\mathrm{R}$ & $18,8 \pm 7,6$ & $16,0 \pm 4,3$ & NS & $-14,9 \%$ \\
\hline$(\mathrm{mmHg})$ & $E$ & $28,6 \pm 3,3$ & $27,8 \pm 6,5$ & NS & $-2,8 \%$ \\
\hline PCP & $\mathrm{R}$ & $8,6 \pm 3,9$ & $7,0 \pm 2,5$ & NS & $-18,6 \%$ \\
\hline$(\mathrm{mmHg})$ & $E$ & $17,0 \pm 6,0$ & $16,6 \pm 5,6$ & NS & $-2,4 \%$ \\
\hline PA & $\mathrm{R}$ & $101,0 \pm 10,1$ & $103,8 \pm 6,9$ & NS & $+2,8 \%$ \\
\hline$(\mathrm{mmHg})$ & $E$ & $108,0 \pm I I, 5$ & $114,2 \pm 13,0$ & NS & $+5,7 \%$ \\
\hline IC & $\mathrm{R}$ & $1,8 \pm 0,4$ & $2,0 \pm 0,6$ & NS & $+12,3 \%$ \\
\hline$\left(\mathrm{l} / \mathrm{min} \cdot \mathrm{m}^{2}\right)$ & $\mathrm{E}$ & $2,8 \pm 0,8$ & $2,8 \pm 0,8$ & NS & $-1,6 \%$ \\
\hline IS & $\mathrm{R}$ & $24,8 \pm 5,4$ & $24,8 \pm 6,0$ & NS & $-0,1 \%$ \\
\hline$\left(\mathrm{ml} / \mathrm{m}^{2}\right)$ & $E$ & $39,2 \pm I I, 1$ & $27,6 \pm 7,9$ & $<0,05$ & $-29,6 \%$ \\
\hline $\begin{array}{c}\text { ITS } \\
\left(\mathrm{gm} / \mathrm{m}^{2}\right)\end{array}$ & $\begin{array}{l}\mathrm{R} \\
\mathrm{E}\end{array}$ & $\begin{array}{c}31,4 \pm 8,4 \\
48,8 \pm 16,6\end{array}$ & $\begin{array}{c}33,1 \pm 9,9 \\
37,1 \pm 12,8\end{array}$ & $\begin{array}{c}\text { NS } \\
<0,01\end{array}$ & $\begin{array}{r}+5,3 \% \\
-24,1 \% \\
\end{array}$ \\
\hline RVS & $\mathrm{R}$ & $2953,2 \pm 754,0$ & $2773,6 \pm 498,8$ & NS & $-6,1 \%$ \\
\hline$\left(\right.$ dyn.s/cm $\left.{ }^{5}\right)$ & $\mathrm{E}$ & $2014,1 \pm 632,6$ & $2163,3 \pm 572,8$ & NS & $+7,4 \%$ \\
\hline RAP & $\mathrm{R}$ & $315,5 \pm 148,5$ & $240,4 \pm 63,6$ & NS & $-23,8 \%$ \\
\hline$\left(\right.$ dyn.s/cm $\left.{ }^{5}\right)$ & $\mathrm{E}$ & $236,7 \pm 147,3$ & $222,3 \pm 59,9$ & NS & $-6,1 \%$ \\
\hline
\end{tabular}

FC: freqüência cardíaca; PAD: pressão média do átrio direito; PAP: pressão média da artéria pulmonar; PCP: pressão média do capilar pulmonar; PA: pressão média da aorta; IC: índice cardíaco; IS: índice sistólico; ITS: índice do trabalho sistólico; RVS: resistência vascular sistêmica; RAP: resistência arteriolar pulmonar; R: repouso; E: exercício; WI: modo ventricular inibido; DDD: modo atrioventricular universal; $\mathrm{p}$ : significância estatística; $\Delta \% \mathrm{WI} / \mathrm{DDD}$ : variação percentual ocorrida com a mudança de modo de estimulação WI para DDD.

A comparação estatística entre as condições WI repouso e VVI exercício evidenciou diferença significativa entre os valores dos parâmetros pressão média em artéria pulmonar, pressão média em capilar pulmonar, índice cardíaco, índice sistólico, índice do trabalho sistólico e resistência vascular sistêmica, mas não entre os dos demais parâmetros. (tabela III.)

A comparação estatística entre as condições DDD repouso e DDD exercício evidenciou diferença significativa entre os valores dos parâmetros freqüência cardíaca, pressão média em átrio direito pressão média em artéria pulmonar, pressão média em capilar pulmonar, índice cardíaco, resistência vascular sistêmica, mas não entre os dos demais parâmetros. (tabela III.) 
A variação percentual das médias dos parâmetros com a mudança do modo de estimulação WI para DDD foi, respectivamente, para as condições repouso e exercício: freqüência cardíaca de $+12,3 \%$ e $+44,9 \%$; pressão média em átrio direito de $-47,8 \%$ e -10,0\%; pressão média em artéria pulmonar de -14,9\% e -2,8\%; pressão média em capilar pulmonar de $-18,6 \%$ e $-2,4 \%$; pressão média na aorta de $+2,8 \%$ e $+5,7 \%$; índice cardíaco de $+12,3 \%$ e $-1,6 \%$; índice sistólico de $-0,1 \%$ e $-29,6 \%$; índice do trabalho sistólico de $+5,3 \%$ e $-24,1 \%$; resistência vascular sistêmica de $-6,1 \%$ e $+7,4 \%$ e resistência arteriolar pulmonar de $-23,8 \%$ e $-6,1 \%$. (tabela IV.)

A comparação estatística entre as condições $W I$ repouso e DDD repouso não evidenciou diferença significativa entre os valores de nenhum dos parâmetros estudados. (tabela IV.)

A comparação estatística entre as condições WI exercício e DDD exercício evidenciou diferença significativa entre os valores da freqüência cardíaca, índice sistólico e índice do trabalho sistólico, mas não entre os dos demais parâmetros. (tabela IV.)

\subsection{Grupo B}

No grupo $B$, os valores médios e os desvios padrão obtidos nas condições WI repouso, DDD repouso, WI exercício, e DDD exercício foram, respectivamente: freqüência cardíaca de 71,0 com desvio padrão de 1,4; 77,2 com desvio padrão de 6,6; 71,2 com desvio padrão de 0,9 e 97,2 com desvio padrão de 12,7 bpm; pressão média em átrio direito de 5,0 com desvio padrão de 1,8; 2,8 com desvio padrão de 1,9; 8,6 com desvio padrão de 2,9 e 5,8 com desvio padrão de 3,7 mmHg; pressão média em artéria pulmonar de 16,4 com desvio padrão de 3,6; 13,4 com desvio padrão de 3,2; 24,6 com desvio padrão de 5,2 e 25,6 com desvio padrão de 5,0 mmHg; pressão média em capilar pulmonar de 9,4 com desvio padrão de 3,0; 5,8 com desvio padrão de 2,8; 14,8 com desvio padrão de 4,5 e 13,0 com desvio padrão de 5,4 mmHg; pressão média na 
aorta de 98,0 com desvio padrão de 4,6; 97,2 com desvio padrão de 5,2; 102,8 com desvio padrão de 11,8 e 111,2 com desvio padrão de 11,5 mmHg; índice cardíaco de 3,1 com desvio padrão de 1,1; 3,6 com desvio padrão de 1,3; 4,9 com desvio padrão de 1,2 e 6,6 com desvio padrão de 1,8 I/min. $\mathrm{m}^{2}$; índice sistólico de 44,0 com desvio padrão de 15,9; 46,7 com desvio padrão de 16,1; 69,4 com desvio padrão de 17,1 e 68,3 com desvio padrão de $17,7 \mathrm{ml} / \mathrm{m}^{2}$; índice do trabalho sistólico de 52,4 com desvio padrão de 17,8; 57,2 com desvio padrão de 17,2; 82,7 com desvio padrão de 19,7 e 90,9 com desvio padrão de $21,6 \mathrm{gm} / \mathrm{m}^{2}$; resistência vascular sistêmica de 1741,7 com desvio padrão de 641,8; 1501,5 com desvio padrão de 617,6; 1038,2 com desvio padrão de 453,4 e 860,0 com desvio padrão de 467,9 dyn.s $/ \mathrm{cm}^{5}$ e resistência arteriolar pulmonar de 131,9 com desvio padrão de 57,$2 ; 118,0$ com desvio padrão de 38,$0 ; 103,0$ com desvio padrão de 22,6 e 101,9 com desvio padrão de 43,5 dyn.s/cm5 . (tabela V.)

A variação percentual das médias dos parâmetros entre as condições repouso e exercício foi, respectivamente, para os modos VVI e DDD: freqüência cardíaca de $+0,3 \%$ e +25,9\%; pressão média em átrio direito de $+72,0 \%$ e $+107,1 \%$; pressão média em artéria pulmonar de $+50,0 \%$ e $+91,0 \%$; pressão média em capilar pulmonar de $+57,4 \%$ e $+124,1 \%$; pressão média na aorta de $+4,9 \%$ e $+14,4 \%$; índice cardíaco de $+58,3 \%$ e, $+83,5 \%$; índice sistólico de $+57,6 \%$ e $+46,3 \%$; índice do trabalho sistólico de $+57,7 \%$ e $+58,9 \%$; resistência vascular sistêmica de $-40,4 \%$ e $42,7 \%$ e resistência arteriolar pulmonar de $-21,9 \%$ e $-13,6 \%$. (tabela III.)

A comparação estatística entre as condições VVI repouso e WI exercício evidenciou diferença significativa entre os valores dos parâmetros pressão média em átrio direito, pressão média em artéria pulmonar, pressão média em capilar pulmonar, índice cardíaco, índice sistólico, índice do trabalho sistólico e resistência vascular sistêmica, mas não entre os dos demais parâmetros. (tabela III.) 
A comparação estatística entre as condições DDD repouso e DDD exercício evidenciou diferença significativa entre os valores dos parâmetros freqüência cardíaca, pressão média em átrio direito, pressão média em artéria pulmonar, pressão média em capilar pulmonar, pressão média na aorta, índice cardíaco, índice sistólico, índice do trabalho sistólico, resistência vascular sistêmica, mas não com relação à resistência arteriolar pulmonar. (tabela III.)

A variação percentual das médias dos parâmetros com a mudança do modo VVI para DDD foi, respectivamente, para as condições repouso e exercício: freqüência cardíaca de $+8,7 \%$ e $+36,5 \%$; pressão média em átrio direito de $-44,0 \%$ e $-32,6 \%$; pressão média em artéria pulmonar de $-18,3 \%$ e $+4,1 \%$; pressão média em capilar pulmonar de $-38,3 \%$ e $-12,2 \%$; pressão média na aorta de $-0,8 \%$ e $+8,2 \%$; índice cardíaco de $+15,1 \%$ e $+33,4 \%$; índice sistólico de $+6,0 \%$ e $-1,6 \%$; índice do trabalho sistólico de $+9,1 \%$ e $+9,9 \%$; resistência vascular sistêmica de $-13,8 \%$ e $-17,2 \%$ e resistência arteriolar pulmonar de $-10,5 \%$ e $-1,1 \%$. (tabela V.)

A comparação estatística entre as condições VVI repouso e DDD repouso evidenciou diferença significativa entre os valores da pressão média em átrio direito, pressão média em artéria pulmonar e pressão média em capilar pulmonar, mas não entre os dos demais parâmetros. (tabela V.)

A comparação estatística entre as condições VVI exercício e DDD exercício evidenciou diferença significativa entre os valores da freqüência cardíaca, pressão média em átrio direito, pressão média na aorta, índice cardíaco e resistência vascular sistêmica, mas não entre os demais parâmetros. (tabela V.) 
TABELA V - VALORES DESCRITIVOS DAS VARIÁVEIS HEMODINÂMICAS DO GRUPO B

\begin{tabular}{|c|c|c|c|c|c|}
\hline \multirow{2}{*}{ Variável } & \multirow{2}{*}{ Condição } & \multicolumn{2}{|c|}{ MODO } & \multirow{2}{*}{$p$} & \multirow{2}{*}{$\begin{array}{c}\Delta l \% \\
\text { WI/DDD }\end{array}$} \\
\hline & & WI & DDD & & \\
\hline $\begin{array}{c}\mathrm{FC} \\
(\mathrm{bpm})\end{array}$ & $\begin{array}{l}\mathrm{R} \\
\mathrm{E}\end{array}$ & $\begin{array}{l}71,0 \pm 1,4 \\
71,2 \pm 0,9\end{array}$ & $\begin{array}{c}77,2 \pm 6,6 \\
97,2 \pm 12,7\end{array}$ & $\begin{array}{c}\text { NS } \\
<0,02\end{array}$ & $\begin{array}{r}+8,7 \% \\
+365 \%\end{array}$ \\
\hline PAD & $\bar{R}$ & $5,0 \pm 1,8$ & $2,8 \pm 1,9$ & $<0,02$ & $-44,0 \%$ \\
\hline$(\mathrm{mmHg})$ & $\mathrm{E}$ & $8,6 \pm 2,9$ & $5,8 \pm 3,7$ & $<0,02$ & $-32,6 \%$ \\
\hline PAP & $\mathrm{R}$ & $16,4 \pm 3,6$ & $13,4 \pm 3,2$ & $<0,02$ & $-18,3 \%$ \\
\hline$(\mathrm{mmHg})$ & $\mathrm{E}$ & $24,6 \pm 5,2$ & $25,6 \pm 5,0$ & NS & $-4,1 \%$ \\
\hline $\mathrm{PCP}$ & $\mathrm{R}$ & $9,4 \pm 3,0$ & $5,8 \pm 2,8$ & $<0,01$ & $-38,3 \%$ \\
\hline$(\mathrm{mmHg})$ & E & $14,8 \pm 4,5$ & $13,0 \pm 5,4$ & NS & $-12,2 \%$ \\
\hline $\mathrm{PA}$ & $\mathrm{R}$ & $98,0 \pm 4,6$ & $97,2 \pm 5,2$ & NS & $-0,8 \%$ \\
\hline$(\mathrm{mmHg})$ & E & $102,8 \pm \| I, 8$ & $\mathrm{III}, 2 \pm \mathrm{II}, 5$ & $<0,05$ & $+8,2 \%$ \\
\hline IC & $\mathrm{R}$ & $3,1 \pm 1,1$ & $3,6 \pm 1,3$ & NS & $+15,1 \%$ \\
\hline$\left(\mathrm{l} / \mathrm{min} \cdot \mathrm{m}^{2}\right)$ & $E$ & $4,9 \pm 1,2$ & $6,6 \pm 1,8$ & $<0,001$ & $+33,4 \%$ \\
\hline IS & $\mathrm{R}$ & $44,0 \pm 15,9$ & $46,7 \pm 16,1$ & NS & $+6,0 \%$ \\
\hline$\left(\mathrm{ml} / \mathrm{m}^{2}\right)$ & E & $69,4 \pm 17,1$ & $68,3 \pm 17,7$ & NS & $-1,6 \%$ \\
\hline ITS & $\mathrm{R}$ & $52,4 \pm 17,8$ & $57,2 \pm 17,2$ & NS & $+9,1 \%$ \\
\hline$\left(\mathrm{gm} / \mathrm{m}^{2}\right)$ & E & $82,7 \pm 19,7$ & $90,9 \pm 21,6$ & NS & $\begin{array}{r}9,9 \% \\
\end{array}$ \\
\hline RVS & $\mathrm{R}$ & $1741,7 \pm 641,8$ & $1501,5 \pm 617,6$ & NS & $-13,8 \%$ \\
\hline$\left(\right.$ dyn.s $\left./ \mathrm{cm}^{5}\right)$ & $\mathrm{E}$ & $1038,2 \pm 453,4$ & $860,0 \pm 467,9$ & $<0,02$ & $-17,2 \%$ \\
\hline RAP & $\mathrm{R}$ & $131,9 \pm 57,2$ & $118,0 \pm 38,0$ & NS & $-10,5 \%$ \\
\hline (dyn.s/cm $\left.{ }^{5}\right)$ & $\mathrm{E}$ & $103,0 \pm 22,6$ & $101,9 \pm 43,5$ & NS & $-1,1 \%$ \\
\hline
\end{tabular}

FC: freqüência cardíaca; PAD: pressão média do átrio direito; PAP: pressão média da artéria pulmonar; PCP: pressão média do capilar pulmonar; PA: pressão média da aorta; IC: índice cardíaco; IS: índice sistólico; ITS: índice do trabalho sistólico; RVS: resistência vascular sistêmica; RAP: resistência arteriolar pulmonar; R: repouso; E: exercício; WI: modo ventricular inibido; DDD: modo atrioventricular universal; $\mathrm{p}$ : significância estatística; $\Delta \% \mathrm{WI} / \mathrm{DDD}$ : variação percentual ocorrida com a mudança de modo de estimulação WI para DDD.

\subsection{Comparação estatística do comportamento dos grupos A e B}

A comparação estatística entre os grupos A e B evidenciou diferença significativa entre as médias de índice cardíaco, índice sistólico, índice do trabalho sistólico, resistência vascular sistêmica e resistência arteriolar pulmonar nas quatro condições estudadas. Não foi observada diferença significativa entre as médias dos demais parâmetros, com exceção do parâmetro freqüência cardíaca na condição WI repouso. (tabela VI.) 


\section{TABELA VI - ESTUDO COMPARATIVO DAS VARIÁVEIS HEMODINÂMICAS ENTRE OS GRUPOS A E B}

\begin{tabular}{|c|c|c|c|c|c|}
\hline \multirow{2}{*}{ Variável } & \multirow{2}{*}{ Condição } & \multicolumn{2}{|c|}{ VVI } & \multicolumn{2}{|c|}{ DDD } \\
\hline & & $A-B$ & $p$ & $A-B$ & $p$ \\
\hline "FC & $\overline{\mathrm{R}}$ & $+2,2$ & $<0,01$ & $+5,0$ & NS \\
\hline (bpm) & $E$ & $+1,4$ & NS & $+8,0$ & NS \\
\hline PAD & $\mathrm{R}$ & $-0,4$ & NS & $-0,4$ & NS \\
\hline$(\mathrm{mmHg})$ & $E$ & $-0,6$ & NS & $+1,4$ & NS \\
\hline PAP & $\mathrm{R}$ & $+2,4$ & NS & $+2,6$ & NS \\
\hline$(\mathrm{mmHg})$ & $\mathrm{E}$ & $+4,0$ & NS & $+2,2$ & NS \\
\hline PCP & $\mathrm{R}$ & $-0,8$ & NS & $+1,2$ & NS \\
\hline$(\mathrm{mmHg})$ & $E$ & $+2,2$ & NS & $+3,6$ & NS \\
\hline PA & $\mathrm{R}$ & $+3,0$ & NS & $+6,6$ & NS \\
\hline$(\mathrm{mmHg})$ & $E$ & $+5,2$ & NS & $+3,0$ & NS \\
\hline IC & $\mathrm{R}$ & $-1,3$ & $<0,02$ & $-1,6$ & $<0,01$ \\
\hline$\left(\mathrm{l} / \mathrm{min} \cdot \mathrm{m}^{2}\right)$ & $E$ & $-2,1$ & $<0,001$ & $-3,8$ & $<0,001$ \\
\hline IS & $\mathrm{R}$ & $-19,2$ & $<0,01$ & $-21,9$ & $<0,01$ \\
\hline$\left(\mathrm{ml} / \mathrm{m}^{2}\right)$ & $E$ & $-30,2$ & $<0,001$ & $-40,7$ & $<0,001$ \\
\hline ITS & $\mathrm{R}$ & $-21,0$ & $<0,05$ & $-24,1$ & $<0,05$ \\
\hline$\left(\mathrm{gm} / \mathrm{m}^{2}\right)$ & $E$ & $-33,8$ & $<0,02$ & $-53,8$ & $<0,001$ \\
\hline RVS & $\mathrm{R}$ & $+12 I I, 5$ & $<0,01$ & $+1272,1$ & $<0,001$ \\
\hline$\left(\right.$ dyn.s/cm $\left.{ }^{5}\right)$ & $E$ & $+975,9$ & $<0,01$ & $+1303,2$ & $<0,001$ \\
\hline RAP & $\mathrm{R}$ & $+183,6$ & $<0,02$ & $+122,4$ & $<0,001$ \\
\hline$\left(\right.$ dyn.s/cm $\left.{ }^{5}\right)$ & $\mathrm{E}$ & $+133,7$ & $<0,05$ & $+120,4$ & $<0,001$ \\
\hline
\end{tabular}

FC: freqüência cardíaca; PAD: pressão média do átrio direito; PAP: pressão média da artéria pulmonar; PCP: pressão média do capilar pulmonar; PA: pressão média da aorta; IC: índice cardíaco; IS: índice sistólico; ITS: índice do trabalho sistólico; RVS: resistência vascular sistêmica; RAP: resistência arteriolar pulmonar; R: repouso; E: exercício; WI: modo ventricular inibido; DDD: modo atrioventricular universal; $p$ : significância estatística; $A-B$ : diferença entre os valores médios dos parâmetros dos grupos A e B.

\section{Estudo da função ventricular}

\subsection{Ventrículo esquerdo}

O desempenho do ventrículo esquerdo (VE) foi analisado pela relação índice cardíaco e pressão média em capilar pulmonar para separação em subgrupos de função ventricular (I, II, III e IV). O resultado foi uma distribuição heterogênea entre os subgrupos.

Com o modo $\mathrm{VVI}$, durante o repouso, foram verificados no subgrupo I, três pacientes do grupo B; no subgrupo III, seis pacientes, sendo quatro do grupo $\mathrm{A}$ e dois do grupo B; e no subgrupo IV, um paciente do grupo A. Com a realização do exercício, foram observados, no subgrupo I, quatro pacientes, sendo dois do grupo A e dois do grupo B; no subgrupo II, quatro pacientes, sendo um do grupo A e três do grupo B; no 
subgrupo III, um paciente do grupo A; e no subgrupo IV, um paciente do grupo B. (figura 1a.)

Com o modo DDD, durante o repouso, foram verificados no subgrupo I, três pacientes do grupo B; no subgrupo III, sete pacientes, sendo cinco do grupo A e dois do grupo B. Com a realização do exercício, foram observados, no subgrupo I, três pacientes, sendo um do grupo A e dois do grupo B; no subgrupo II, cinco pacientes, sendo dois do grupo A e três do grupo B; e no subgrupo III, dois pacientes do grupo A. (figura 1b.)

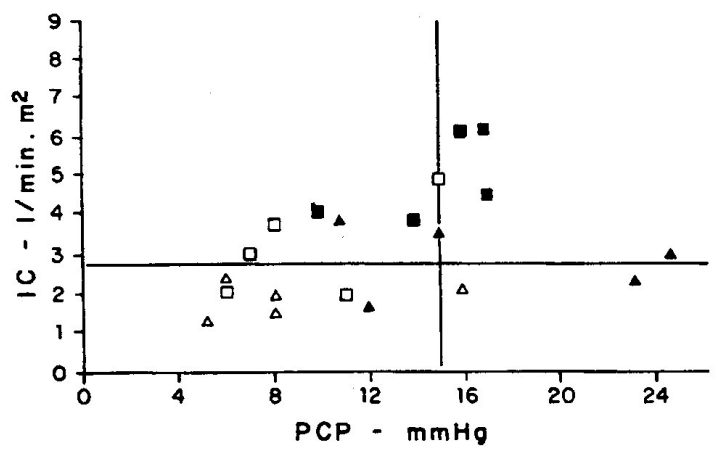

Figura 1a - Distribuição dos pacientes dos grupos Ae B de acordo com a função do ventrículo esquerdo sob o modo de estimulação WI (relação IC/PCP.)

$\Delta$ grupo A (repouso);

$\square \quad$ grupo B (repouso);

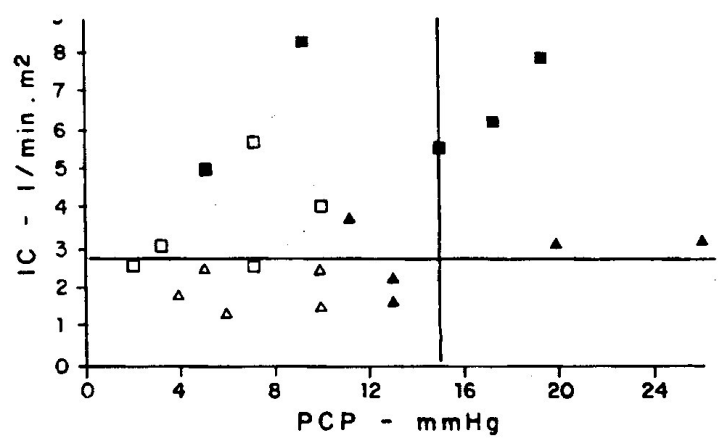

Figura $1 b$ - Distribuição dos pacientes dos grupos A e B de acordo com a função do ventrículo esquerdo sob o modo de estimulação DDD (relação IC/PCP.)

$\Delta$ grupo A (repouso);

口 grupo B (repouso);
- Grupo A (exercício);

- grupo B (exercício.)

A análise da função ventricular esquerda, utilizando-se os critérios estabelecidos por ROSS Jr. et al. (variações da pressão de enchimento do ventrículo esquerdo e do índice sistólico do ventrículo esquerdo com a mudança das condições repouso para exercício), está demonstrada nas figuras $2 a$ e $2 b$.

Com o modo WI, três pacientes, sendo dois do grupo $\mathrm{A}$ e um do grupo $\mathrm{B}$, foram classificados como portadores de função ventricular normal; cinco pacientes, sendo três do grupo $\mathrm{A}$ e dois do grupo $\mathrm{B}$, como portadores de anormalidades da dinâmica ventricular; e dois pacientes do grupo B ficaram em situação intermediária entre as faixas 
Resultados

dos normais e dos portadores de anormalidade da dinâmica ventricular. Nenhum paciente foi classificado como portador de depressão da função ventricular. (figura 2a.)

Com o modo DDD, três pacientes, sendo um do grupo $A$ e dois do grupo $B$, foram classificados como portadores de função ventricular normal; seis pacientes, sendo três do grupo A e três do grupo B, como portadores de anormalidade da dinâmica ventricular; e apenas um paciente do grupo A apresentou desempenho compatível com depressão da função ventricular. (figura 2b.)

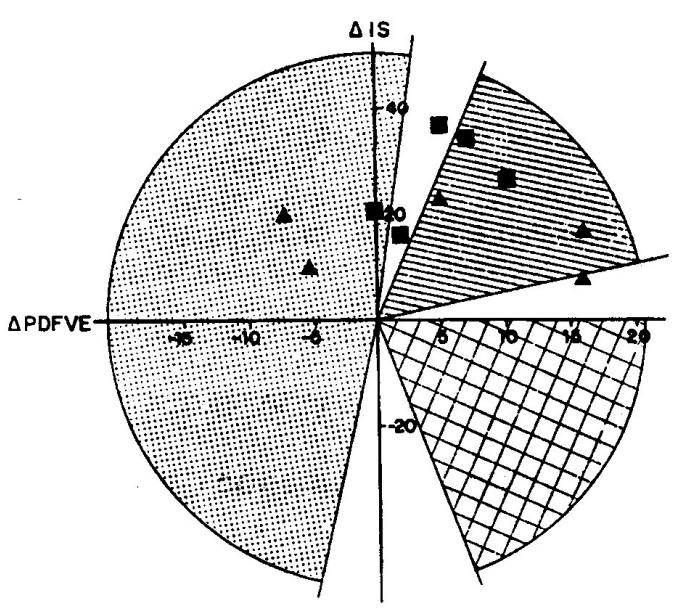

Figura 2a - Distribuição dos pacientes dos grupos Ae B de acordo com a iunção do ventrículo esquerdo sob o modo de estimulação WI segundo os critérios de Ross Jr. et al. (relação $\Delta$ IS / $\triangle$ PDfVE.)

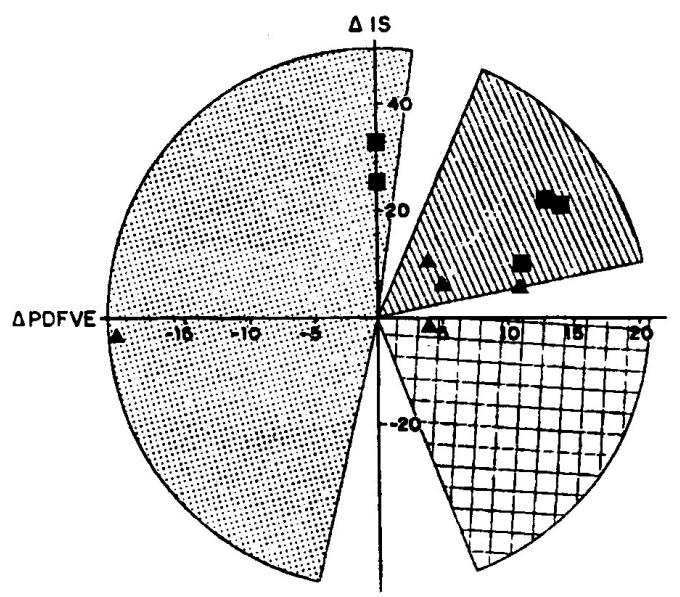

Figura 2b - Distribuição dos pacientes dos grupos $A$ e $B$ de acordo com a função do ventrículo esquerdo sob o modo de estimuiação DDD segundo os critérios de Ross Jr. et al. (relação $\Delta I S / \triangle P D F V E$.)
$\Delta$ grupo A (repouso); $\quad \Delta$ Grupo A (exercício);

口 grupo B (repouso);

ausência de disfunção ventricular
anormalidade da dinâmica ventricular
depressão da função ventricular

\subsection{Ventrículo direito}

O desempenho do ventrículo direito (VD) foi analisado pela relação índice cardíaco e pressão média em átrio direito, que evidenciou uma distribuição heterogênea entre os subgrupos. 
Com o modo VVI, durante o repouso, foram observados, no subgrupo I, três pacientes do grupo B; e, no subgrupo III, sete pacientes, sendo cinco do grupo A e dois do grupo B. Com a realização exercício foram observados, no subgrupo I, quatro pacientes, sendo dois do grupo A e dois do grupo B; no subgrupo II, quatro pacientes, sendo, um do grupo A e três do grupo B; no subgrupo III, um paciente do grupo A e no subgrupo IV, um paciente do grupo A. (figura 3a.)

Com o modo DDD, durante o repouso, foram verificados no subgrupo I, três pacientes do grupo A; e no subgrupo III, sete pacientes, sendo cinco do grupo A e dois do grupo B. Com a realização do exercício, foram observados no subgrupo I, quatro pacientes, sendo um do grupo A e três do grupo B; no subgrupo II, quatro pacientes, sendo dois do grupo A e dois do grupo B; e no subgrupo III dois pacientes do grupo A. (figura 3b.)

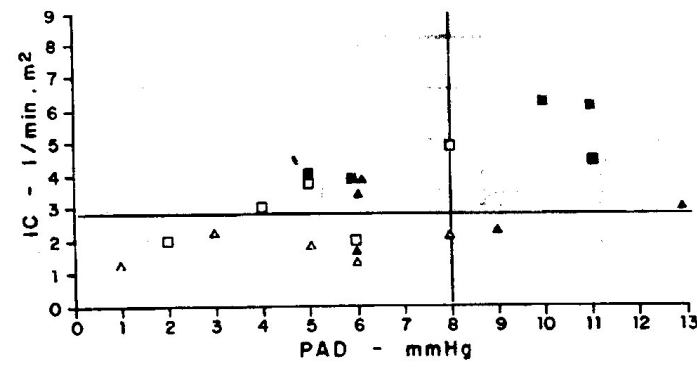

Figura 3a - Distribuição dos pacientes dos grupos $\mathrm{Ae} B$ de acordo com a função do ventrículo direito sob o modo de estimulação WI (relação IC/PAD.)

$\Delta$ grupo A (repouso);

$\square$ grupo B (repouso);
- Grupo A (exercício); grupo B (exercício.)

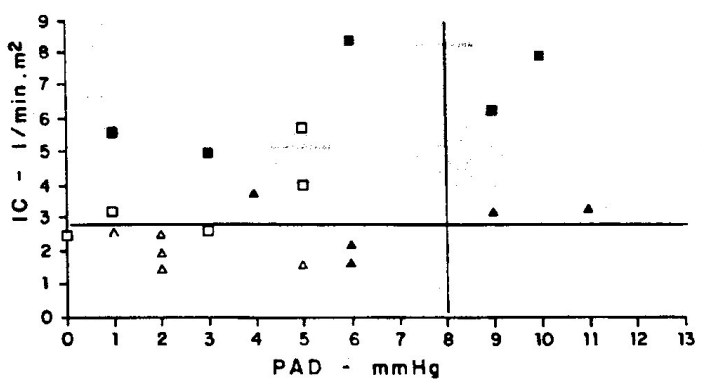

Figura 3b - Distribuição dos pacientes dos grupos A e B de acordo com a função do ventrículo direito sob o modo de estimulação DDD (relação IC/PAD.)

$\triangle$ grupo A (repouso);

grupo B (repouso);
Grupo A (exercício); grupo B (exercício.)

\section{Estudo do consumo periférico de oxigênio}

\subsection{Grupo Total}

No grupo total dos pacientes, os valores médios e os desvios padrão obtidos nas condições VVI repouso, DDD repouso, VVI exercício, e DDD exercício foram, 
respectivamente: conteúdo arterial de oxigênio de 20,0 com desvio padrão de 3,$5 ; 20,0$ com desvio padrão de 3,5; 20,0 com desvio padrão de 3,3 e 20,1 com desvio padrão de 3,4 vol. \%; conteúdo venoso de oxigênio de 15,1 com desvio padrão de 3,0; 15,3 com desvio padrão de 3,1; 10,9 com desvio padrão de 2,5 e 11,5 com desvio padrão de 4,0 vol.\%; diferença arteriovenosa de oxigênio de 5,0 com desvio padrão de 1,3; 4,7 com desvio padrão de 2,4; 9,2 com desvio padrão de 3,6 e 8,6 com desvio padrão de 3,1 vol.\%; extração de oxigênio de 0,25 com desvio padrão de 0,$06 ; 0,23$ com desvio padrão de do 0,10; 0,45 com desvio padrão de 0,15 e 0,43 com desvio padrão de 0,14 e índice de consumo de oxigênio de 103,2 com desvio padrão de 19,9; 110,0 com desvio padrão de 52,7; 302,5 com desvio padrão de 126,1 e 326,0 com desvio padrão de 115,8 $\mathrm{ml} / \mathrm{min} . \mathrm{m}^{2}$. (tabela VII.)

A variação percentual das médias dos parâmetros entre as condições repouso e exercício foi, respectivamente, para os modos WI e DDD: conteúdo arterial de oxigênio de $0,0 \%$ e +0,6\%; conteúdo venoso de oxigênio de $-27,9 \%$ e $-24,6 \%$; diferença arteriovenosa de oxigênio de $+84,2 \%$ e $+82,2 \%$; extração de oxigênio de $+78,0 \%$ e $+87,7 \%$ e índice de consumo de oxigênio de $+193,2 \%$ e $+196,5 \%$. (tabela VIII.)

A comparação estatística entre as condições WI repouso e WI exercício evidenciou diferença significativa entre os valores dos parâmetros conteúdo venoso de oxigênio, diferença arteriovenosa de oxigênio, extração de oxigênio e índice de consumo de oxigênio, mas não entre os do parâmetro conteúdo arterial de oxigênio. (tabela VIII.)

A comparação estatística entre as condições DDD repouso e DDD exercício evidenciou diferença significativa entre os valores dos parâmetros conteúdo venoso de oxigênio, diferença arteriovenosa de oxigênio, extração de oxigênio e índice de consumo de oxigênio, mas não entre os do parâmetro conteúdo arterial de oxigênio. (tabela VIII.) 
A variação percentual das médias dos parâmetros com a mudança do modo VVI para DDD foi, respectivamente, para as condições repouso e exercício: conteúdo arterial de oxigênio de $-0,5 \%$ e $+0,1 \%$; conteúdo venoso de oxigênio de $+1,3 \%$ e $+5,9 \%$; diferença arteriovenosa de oxigênio de $-5,7 \%$ e $-6,7 \%$; extração de oxigênio de $-8,1 \%$ e $-3,1 \%$ e índice de consumo de oxigênio de $+6,5 \%$ e $+7,8 \%$. (tabela VII.)

\section{TABELA VII - VALORES DESCRITIVOS DAS VARIÁVEIS DO METABOLISMO DO OXIGÊNIO NO GRUPO TOTAL}

\begin{tabular}{|c|c|c|c|c|c|}
\hline \multirow{2}{*}{ Variável } & \multirow{2}{*}{ Condição } & \multicolumn{2}{|c|}{ MODO } & \multirow{2}{*}{$p$} & \multirow{2}{*}{$\begin{array}{c}\Delta l \% \\
\text { Wl/DDD }\end{array}$} \\
\hline & & WI & DDD & & \\
\hline $\begin{array}{c}\mathrm{CaO}_{2} \\
\text { (vol.\%) }\end{array}$ & $\begin{array}{l}\mathrm{R} \\
\mathrm{E}\end{array}$ & $\begin{array}{l}20,0 \pm 3,5 \\
20,0 \pm 3,3\end{array}$ & $\begin{array}{l}20,5 \pm 3,5 \\
20,1 \pm 3,4\end{array}$ & $\begin{array}{l}\text { NS } \\
\text { NS }\end{array}$ & $\begin{array}{l}-0,5 \% \\
+0,1 \% \\
\end{array}$ \\
\hline $\begin{array}{c}\mathrm{CvO}_{2} \\
\text { (vol.\%) }\end{array}$ & $\begin{array}{l}\mathrm{R} \\
\mathrm{E}\end{array}$ & $\begin{array}{l}15,0 \pm 3,0 \\
10,9 \pm 2,5\end{array}$ & $\begin{array}{l}15,3 \pm 3,1 \\
I I, 5 \pm 4,0\end{array}$ & $\begin{array}{l}\text { NS } \\
\text { NS }\end{array}$ & $\begin{array}{l}+1,3 \% \\
+5,9 \% \\
\end{array}$ \\
\hline $\begin{array}{l}\mathrm{DavO}_{2} \\
\text { (vol.\%) }\end{array}$ & $\begin{array}{l}\mathrm{R} \\
\mathrm{E}\end{array}$ & $\begin{array}{l}5,0 \pm 1,3 \\
9,2 \pm 3,6\end{array}$ & $\begin{array}{l}4,7 \pm 2,4 \\
8,6 \pm 3,1\end{array}$ & $\begin{array}{l}\text { NS } \\
\text { NS }\end{array}$ & $\begin{array}{l}-5,7 \% \\
-6,7 \% \\
\end{array}$ \\
\hline $\mathrm{EO}_{2}$ & $\begin{array}{l}\mathrm{R} \\
\mathrm{E}\end{array}$ & $\begin{array}{l}0,25 \pm 0,06 \\
0,45 \pm 0,15\end{array}$ & $\begin{array}{l}0,23 \pm 0,10 \\
0,43 \pm 0,14\end{array}$ & $\begin{array}{l}\text { NS } \\
\text { NS }\end{array}$ & $\begin{array}{l}-8,1 \% \\
-3,1 \%\end{array}$ \\
\hline $\begin{array}{c}\mathrm{IVO}_{2} \\
\left(\mathrm{ml} / \mathrm{min}^{2} \mathrm{~m}^{2}\right)\end{array}$ & R & $\begin{array}{r}103,2 \pm 19,9 \\
302,5 \pm 126,1\end{array}$ & $\begin{array}{c}110,0 \pm 52,7 \\
326,0 \pm 115,8\end{array}$ & $\begin{array}{l}\text { NS } \\
\text { NS }\end{array}$ & $\begin{array}{r}-6,5 \% \\
+7,8 \%\end{array}$ \\
\hline
\end{tabular}

$\mathrm{CaO}_{2}$ : conteúdo arterial de oxigênio; $\mathrm{CvO}_{2}$ : conteúdo venoso de oxigênio; $\mathrm{DavO}_{2}$ : diferença arteriovenosa de oxigênio; $\mathrm{EO}_{2}$ :extração de oxigênio; $\mathrm{IVO}_{2}$ : índice de consumo de oxigênio; $\mathrm{R}$ : repouso; E: exercício; WI: modo ventricular inibido; DDD: modo atrioventricular universal; $p$ : significância estatística; $\Delta \%$ WI/DDD: variação percentual ocorrida com a mudança de modo de estimulação WI para DDD.

A comparação estatística entre as condições WI repouso e DDD repouso não evidenciou diferença significativa entre nenhum dos parâmetros, o mesmo ocorrendo com as condições VVI exercício e DDD exercício. (tabela VII.)

\subsection{Grupo $A$}

No grupo $A$, os valores médios e os desvios padrão obtidos nas condições WI repouso, DDD repouso, WI exercício, e DDD exercício foram, respectivamente: conteúdo arterial de oxigênio de 19,9 com desvio padrão de 2,6; 19,8 com desvio padrão de 2,7; 20,0 com desvio padrão de 2,4 e 20,0 com desvio padrão de 2,7 vol.\%; conteúdo venoso de oxigênio de 14,5 com desvio padrão de 2,3; 15,2 com desvio padrão de 2,1; 9,1 com desvio padrão de 1,5 e 9,3 com desvio padrão de 1,3 vol. \%; diferença 
arteriovenosa de oxigênio de 5,4 com desvio padrão de 1,5; 4,6 com desvio padrão de 1,1; 10,9 com desvio padrão de 2,0 e 10,7 com desvio padrão de 2,3 vol.\%; extração de oxigênio de 0,27 com desvio padrão de 0,06; 0,23 com desvio padrão de 0,04; 0,54 com desvio padrão de 0,06 e 0,53 com desvio padrão de 0,06 e índice de consumo de oxigênio de 93,4 com desvio padrão de 16,0; 88,9 com desvio padrão de 17,2; 298,6 com desvio padrão de 72,0 e 292,8 com desvio padrão de 90,1 ml/min.m². (tabela IX.)

\section{TABELA VIII - VARIAÇÃO PERCENTUAL OCORRIDA NAS VARIÁVEIS DO METABOLISMO DO OXIGÊNIO COM A REALIZAÇÃO DO EXERCÍCIO}

\begin{tabular}{|c|c|c|c|c|c|c|c|}
\hline \multirow{2}{*}{ Variável } & \multirow{2}{*}{ Modo } & \multicolumn{2}{|c|}{ GRUPO TOTAL } & \multicolumn{2}{|c|}{ GRUPO A } & \multicolumn{2}{|c|}{ GRUPO B } \\
\hline & & $\Delta \% \mathrm{R} / \mathrm{E}$ & $p$ & $\Delta \% \mathrm{R} / \mathrm{E}$ & $p$ & $\Delta \% \mathrm{R} / \mathrm{E}$ & $P$ \\
\hline \multirow{2}{*}{$\begin{array}{c}\mathrm{CaO}_{2} \\
\text { (vol.\%) }\end{array}$} & VVI & $0,0 \%$ & NS & $+0,3 \%$ & NS & $-0,3 \%$ & NS \\
\hline & DDD & $+6,0 \%$ & NS & $+1,1 \%$ & NS & $0,0 \%$ & NS \\
\hline \multirow{2}{*}{$\begin{array}{c}\mathrm{CvO}_{2} \\
\text { (vol.\%) }\end{array}$} & VVI & $-27,9 \%$ & $<0,01$ & $-37,5 \%$ & $<0,01$ & $-16,7 \%$ & NS \\
\hline & DDD & $-24,6 \%$ & $<0,02$ & $-38,9 \%$ & $<0,001$ & $-6,8 \%$ & NS \\
\hline \multirow{2}{*}{$\begin{array}{l}\mathrm{DavO}_{2} \\
\text { (vol.\%) }\end{array}$} & VVI & $+84,2 \%$ & $<0,01$ & $+102,7 \%$ & $<0,001$ & $+56,7 \%$ & $\mathrm{NS}$ \\
\hline & DDD & $+82,2 \%$ & $<0,05$ & $+133,1 \%$ & $<0,001$ & $+21,4 \%$ & NS \\
\hline \multirow[t]{2}{*}{$\mathrm{EO}_{2}$} & VVI & $+78,0 \%$ & $<0,01$ & $+101,2 \%$ & $<0,001$ & $+43,7 \%$ & $\mathrm{NS}$ \\
\hline & DDD & $+87,7 \%$ & $<0,02$ & $+129,9 \%$ & $<0,001$ & $+34,4 \%$ & NS \\
\hline \multirow{2}{*}{$\begin{array}{c}\mathrm{IVO}_{2} \\
\left(\mathrm{ml} / \mathrm{min}^{2} \mathrm{~m}^{2}\right)\end{array}$} & VVI & $+193,2 \%$ & $<0,01$ & $+219,7 \%$ & $<0,01$ & $+166,3 \%$ & NS \\
\hline & DDD & $+196,5 \%$ & $<0,01$ & $+229,3 \%$ & $<0,01$ & $+169,7 \%$ & NS \\
\hline
\end{tabular}

$\mathrm{CaO}_{2}$ : conteúdo arterial de oxigênio; $\mathrm{CvO}_{2}$ : conteúdo venoso de oxigênio; $\mathrm{DavO}$ : diferença arteriovenosa de oxigênio; $\mathrm{EO}_{2}$ :extração de oxigênio; $\mathrm{IVO}_{2}$ : índice de consumo de oxigênio; $\mathrm{R}$ : repouso; E: exercício; WI: modo ventricular inibido; DDD: modo atrioventricular universal; $p$ : significância estatística; $\Delta \% \mathrm{R} / \mathrm{E}$ : variação percentual ocorrida com a realização do exercício.

A variação percentual das médias dos parâmetros entre as condições repouso e exercício foi, respectivamente, para os modos WI e DDD: conteúdo arterial de oxigênio de $+0,3 \%$ e $+1,1 \%$; conteúdo venoso de oxigênio de $-37,5 \%$ e $-38,9 \%$; diferença arteriovenosa de oxigênio de $+102,7 \%$ e $+133,1 \%$; extração de oxigênio de $+101,2 \%$ e $+129,9 \%$ e índice de consumo de oxigênio de $+219,7 \%$ e $+229,3 \%$. (tabela VIII.)

A comparação estatística entre as condições WI repouso e WI exercício evidenciou diferença significativa entre os valores dos parâmetros conteúdo venoso de oxigênio, diferença arteriovenosa de oxigênio, extração de oxigênio e índice de consumo de oxigênio, mas não entre os do parâmetro conteúdo arterial de oxigênio. (tabela VIII.) 
A comparação estatística entre as condições DDD repouso e DDD exercício evidenciou diferença significativa entre os valores dos parâmetros conteúdo venoso de oxigênio, diferença arteriovenosa de oxigênio, extração de oxigênio e índice de consumo de oxigênio, mas não entre os do parâmetro conteúdo arterial de oxigênio. (tabela VIII.)

A variação percentual das médias dos parâmetros com a mudança do modo WI para DDD foi, respectivamente, para as condições repouso e exercício: conteúdo arterial de oxigênio de $-0,5 \%$ e $+0,3 \%$; conteúdo venoso de oxigênio de $+4,6 \%$ e $+2,4 \%$; diferença arteriovenosa de oxigênio de -14,2\% e -1,4\%; extração de oxigênio de $-14,3 \%$ e $-2,0 \%$ e índice de consumo de oxigênio de $-4,8 \%$ e $-1,9 \%$. (tabela IX.)

A comparação estatística entre as condições $\mathrm{V} V I$ repouso e DDD repouso não evidenciou diferença significativa entre nenhum dos parâmetros, o mesmo ocorrendo com as condições VVI exercício e DDD exercício. (tabela IX.)

\subsection{Grupo B}

No grupo $B$, os valores médios e os desvios padrão obtidos nas condições WI repouso, DDD repouso, WI exercício, e DDD exercício foram, respectivamente: conteúdo arterial de oxigênio de 20,2 com desvio padrão de 4,3; 20,1 com desvio padrão de 4,3; 20,2 com desvio padrão de 4,2 e 20,1 com desvio padrão de 4,2 vol.\%; conteúdo venoso de oxigênio de 15,7 com desvio padrão de 3,6; 15,3 com desvio padrão de 4,0; 13,1 com desvio padrão de 1,6 e 14,3 com desvio padrão de 4,5 vol.\%; diferença arteriovenosa de oxigênio de 4,5 com desvio padrão de 0,$9 ; 4,8$ com desvio padrão de 3,3; 7,1 com desvio padrão de 4,1 e 5,8 com desvio padrão de 1,3 vol.\%; extração de oxigênio de 0,23 com desvio padrão de 0,04; 0,23 com desvio padrão de 0,15; 0,33 com desvio padrão de 0,14 e 0,31 com desvio padrão de 0,11 e índice de consumo de oxigênio de 115,5 com desvio padrão de 17,4; 136,3 com desvio padrão de 68,0; 307,5 com desvio padrão de 171,1 e 367,5 com desvio padrão de 130,2 ml/min.m². (tabela X.) 
A variação percentual das médias dos parâmetros entre as condições repouso e exercício foi, respectivamente, para os modos WI e DDD: conteúdo arterial de oxigênio de $-0,3 \%$ e $0,0 \%$; conteúdo venoso de oxigênio de $-16,7 \%$ e $-6,8 \%$; diferença arteriovenosa de oxigênio de $+56,7 \%$ e $+21,4 \%$; extração de oxigênio de $+43,7 \%$ e $+34,8 \%$ e índice de consumo de oxigênio de $+166,3 \%$ e $+169,7 \%$. (tabela VIII.)

A comparação estatística entre as condições WI repouso e WI exercício não evidenciou diferença significativa entre os valores de nenhum dos parâmetros estudados, o mesmo ocorrendo entre as condições DDD repouso e DDD exercício. (tabela VIII.)

A variação percentual das médias dos parâmetros com a mudança do modo WI para DDD foi respectivamente para as condições repouso e exercício: conteúdo arterial de oxigênio de $-0,5 \%$ e $-0,2 \%$; conteúdo venoso de oxigênio de $-2,6 \%$ e $+9,0 \%$; diferença arteriovenosa de oxigênio de $+7,0 \%$ e $-17,1 \%$; extração de oxigênio de $+1,1 \%$ e $-5,4 \%$ e índice de consumo de oxigênio de $+18,0 \%$ e $+19,5 \%$. (tabela $X$. .)

\section{TABELA IX - VALORES DESCRITIVOS DAS VARIÁVEIS DO METABOLISMO DO OXIGÊNIO NO GRUPO A}

\begin{tabular}{|c|c|c|c|c|c|}
\hline \multirow{2}{*}{ Variável } & \multirow{2}{*}{ Condição } & \multicolumn{2}{|c|}{ MODO } & \multirow{2}{*}{$p$} & \multirow{2}{*}{$\begin{array}{c}\Delta l \% \\
\text { WI/DDD }\end{array}$} \\
\hline & & WI & DDD & & \\
\hline $\begin{array}{l}\mathrm{CaO}_{2} \\
\text { (vol.\%) }\end{array}$ & $\begin{array}{l}\mathrm{R} \\
\mathrm{E}\end{array}$ & $\begin{array}{l}19,9 \pm 2,6 \\
20,0 \pm 2,4\end{array}$ & $\begin{array}{l}19,8 \pm 2,7 \\
20,0 \pm 2,7\end{array}$ & $\begin{array}{l}\text { NS } \\
\text { NS }\end{array}$ & $\begin{array}{l}-0,5 \% \\
+0,3 \% \\
\end{array}$ \\
\hline $\begin{array}{c}\mathrm{CvO}_{2} \\
\text { (vol.\%) }\end{array}$ & $\begin{array}{l}\mathrm{R} \\
\mathrm{E}\end{array}$ & $\begin{array}{c}14,5 \pm 2,3 \\
9,1 \pm 1,5\end{array}$ & $\begin{array}{c}15,2 \pm 2,1 \\
9,3 \pm 1,3\end{array}$ & $\begin{array}{l}\text { NS } \\
\text { NS }\end{array}$ & $\begin{array}{l}+4,6 \% \\
+2,4 \%\end{array}$ \\
\hline $\begin{array}{l}\mathrm{DavO}_{2} \\
\text { (vol.\%) }\end{array}$ & $\begin{array}{l}\mathrm{R} \\
\mathrm{E}\end{array}$ & $\begin{array}{c}5,4 \pm 1,5 \\
10,9 \pm 2,0\end{array}$ & $\begin{array}{c}4,6 \pm 1,1 \\
10,7 \pm 2,3\end{array}$ & $\begin{array}{l}\text { NS } \\
\text { NS }\end{array}$ & $\begin{array}{c}-14,2 \% \\
-1,4 \% \\
\end{array}$ \\
\hline $\mathrm{EO}_{2}$ & $\begin{array}{l}\mathrm{R} \\
\mathrm{E}\end{array}$ & $\begin{array}{l}0,27 \pm 0,06 \\
0,54 \pm 0,06\end{array}$ & $\begin{array}{l}0,23 \pm 0,04 \\
0,53 \pm 0,06\end{array}$ & $\begin{array}{l}\text { NS } \\
\text { NS }\end{array}$ & $\begin{array}{c}-14,3 \% \\
-2,0 \% \\
\end{array}$ \\
\hline $\begin{array}{c}\mathrm{IVO}_{2} \\
\left(\mathrm{ml} / \mathrm{min} \cdot \mathrm{m}^{2}\right)\end{array}$ & $\begin{array}{l}\mathrm{R} \\
\mathrm{E}\end{array}$ & $\begin{array}{c}93,4 \pm 16,0 \\
298,6 \pm 72,0\end{array}$ & $\begin{array}{c}88,9 \pm 17,2 \\
292,8 \pm 90,1\end{array}$ & $\begin{array}{l}\text { NS } \\
\text { NS }\end{array}$ & $\begin{array}{l}-4,8 \% \\
-1,9 \% \\
\end{array}$ \\
\hline
\end{tabular}

$\mathrm{CaO}_{2}$ : conteúdo arterial de oxigênio; $\mathrm{CvO}_{2}$ : conteúdo venoso de oxigênio; $\mathrm{DavO}_{2}$ : diferença arteriovenosa de oxigênio; $\mathrm{EO}_{2}$ :extração de oxigênio; $\mathrm{IVO}_{2}$ : índice de consumo de oxigênio; R: repouso; E: exercício; WI: modo ventricular inibido; DDD: modo atrioventricular universal; $\mathrm{p}$ : significância estatística; $\Delta \%$ WI/DDD: variação percentual ocorrida com a mudança de modo de estimulação WI para DDD. 
A comparação estatística entre as condições VVI repouso e DDD repouso não evidenciou diferença significativa entre nenhum dos parâmetros, o mesmo ocorrendo com as condições VVI exercício e DDD exercício. (tabela X.)

TABELA X - VALORES DESCRITIVOS DAS VARIÁVEIS DO METABOLISMO DO OXIGÊNIO NO GRUPO B

\begin{tabular}{|c|c|c|c|c|c|}
\hline \multirow{2}{*}{ Variável } & \multirow{2}{*}{ Condição } & \multicolumn{2}{|c|}{ MODO } & \multirow{2}{*}{$p$} & \multirow{2}{*}{$\begin{array}{c}\Delta l \% \\
\text { WI/DDD }\end{array}$} \\
\hline & & WI & DDD & & \\
\hline $\begin{array}{l}\mathrm{CaO}_{2} \\
\text { (vol.\%) }\end{array}$ & $\begin{array}{l}\mathrm{R} \\
\mathrm{E}\end{array}$ & $\begin{array}{l}20,2 \pm 4,3 \\
20,2 \pm 4,2\end{array}$ & $\begin{array}{l}20,1 \pm 4,3 \\
20,1 \pm 4,2\end{array}$ & $\begin{array}{l}\mathrm{NS} \\
\mathrm{NS}\end{array}$ & $\begin{array}{l}-0,5 \% \\
-0,2 \% \\
\end{array}$ \\
\hline $\begin{array}{c}\mathrm{CvO}_{2} \\
\text { (vol.\%) }\end{array}$ & $\begin{array}{l}\mathrm{R} \\
\mathrm{E}\end{array}$ & $\begin{array}{l}15,7 \pm 3,6 \\
13,1 \pm 1,6\end{array}$ & $\begin{array}{l}15,3 \pm 4,0 \\
14,3 \pm 4,5\end{array}$ & $\begin{array}{l}\text { NS } \\
\text { NS }\end{array}$ & $\begin{array}{r}-2,6 \% \\
+9,0 \% \\
\end{array}$ \\
\hline $\begin{array}{l}\mathrm{DavO}_{2} \\
\text { (vol.\%) }\end{array}$ & $\begin{array}{l}\mathrm{R} \\
\mathrm{E}\end{array}$ & $\begin{array}{l}4,5 \pm 0,9 \\
7,1 \pm 4,1\end{array}$ & $\begin{array}{l}4,8 \pm 3,3 \\
5,8 \pm 1,3\end{array}$ & $\begin{array}{l}\text { NS } \\
\text { NS }\end{array}$ & $\begin{array}{r}+7,0 \% \\
-17,1 \% \\
\end{array}$ \\
\hline $\mathrm{EO}_{2}$ & $\begin{array}{l}\mathrm{R} \\
\mathrm{E}\end{array}$ & $\begin{array}{l}0,23 \pm 0,04 \\
0,33 \pm 0,14\end{array}$ & $\begin{array}{c}0,23 \pm 0,15 \\
0,31 \pm 0,11\end{array}$ & $\begin{array}{l}\text { NS } \\
\text { NS }\end{array}$ & $\begin{array}{l}+1,1 \% \\
-5,4 \%\end{array}$ \\
\hline $\begin{array}{c}\mathrm{IVO}_{2} \\
\left(\mathrm{ml} / \mathrm{min}^{2} \mathrm{~m}^{2}\right)\end{array}$ & $\begin{array}{l}\mathrm{R} \\
\mathrm{E}\end{array}$ & $\begin{array}{c}\text { II5,5 } \pm 17,4 \\
307,5 \pm 171,1\end{array}$ & $\begin{array}{r}136,3 \pm 68,0 \\
367,5 \pm 130,2\end{array}$ & $\begin{array}{l}\text { NS } \\
\text { NS }\end{array}$ & $\begin{array}{l}+18,0 \% \\
+19,5 \% \\
\end{array}$ \\
\hline
\end{tabular}

$\mathrm{CaO}_{2}$ : conteúdo arterial de oxigênio; $\mathrm{CvO}_{2}$ : conteúdo venoso de oxigênio; $\mathrm{DavO}_{2}$ : diferença arteriovenosa de oxigênio; $\mathrm{EO}_{2}$ :extração de oxigênio; $\mathrm{IVO}_{2}$ : índice de consumo de oxigênio; R: repouso; $\mathrm{E}$ : exercício; WI: modo ventricular inibido; DDD: modo atrioventricular universal; $\mathrm{p}$ : significância estatística; $\Delta \% \mathrm{WI} / \mathrm{DDD}$ : variação percentual ocorrida com a mudança de modo de estimulação WI para DDD.

\section{TABELA XI - ESTUDO COMPARATIVO DAS VARIÁVEIS DO METABOLISMO DO OXIGÊNIO ENTRE OS GRUPOS A E B}

\begin{tabular}{|c|c|c|c|c|c|}
\hline \multirow{2}{*}{ Variável } & \multirow{2}{*}{ Condição } & \multicolumn{2}{|c|}{ VVI } & \multicolumn{2}{|c|}{ DDD } \\
\hline & & $A-B$ & $p$ & $A-B$ & $p$ \\
\hline $\begin{array}{c}\mathrm{CaO}_{2} \\
\text { (vol.\%) }\end{array}$ & $\begin{array}{l}R \\
E\end{array}$ & $\begin{array}{l}-0,3 \\
-0,2\end{array}$ & $\begin{array}{l}\text { NS } \\
\text { NS }\end{array}$ & $\begin{array}{l}-0,3 \\
-0,1\end{array}$ & $\begin{array}{l}\text { NS } \\
\text { NS }\end{array}$ \\
\hline $\begin{array}{c}\mathrm{CvO} \\
\left(\mathrm{vol}_{2} \%\right)\end{array}$ & $\begin{array}{l}\mathrm{L} \\
\mathrm{E}\end{array}$ & $\begin{array}{l}-1,2 \\
-4,0\end{array}$ & $\begin{array}{c}\mathrm{NS} \\
<0,01\end{array}$ & $\begin{array}{l}-0,1 \\
-5,0\end{array}$ & $\begin{array}{l}\text { NS } \\
\text { NS }\end{array}$ \\
\hline $\begin{array}{l}\mathrm{DavO}_{2} \\
\text { (vol.\%) }\end{array}$ & $\begin{array}{l}\mathrm{R} \\
\mathrm{E}\end{array}$ & $\begin{array}{l}+0,9 \\
+3,8\end{array}$ & $\begin{array}{l}\text { NS } \\
\text { NS }\end{array}$ & $\begin{array}{l}-0,2 \\
+4,9\end{array}$ & $\begin{array}{c}\mathrm{NS} \\
<0,01\end{array}$ \\
\hline $\mathrm{EO}_{2}$ & $\begin{array}{l}\mathrm{R} \\
\mathrm{E}\end{array}$ & $\begin{array}{l}+0,04 \\
+0,22\end{array}$ & $\begin{array}{c}\mathrm{NS} \\
<0,02\end{array}$ & $\begin{array}{r}0,00 \\
+0,22\end{array}$ & $\begin{array}{c}\quad \mathrm{NS} \\
<0,01\end{array}$ \\
\hline $\begin{array}{c}\mathrm{IVO}_{2} \\
\left(\mathrm{ml} / \mathrm{min}^{2} \mathrm{~m}^{2}\right)\end{array}$ & $\begin{array}{l}\mathrm{R} \\
\mathrm{E}\end{array}$ & $\begin{array}{c}-22,0 \\
-8,9\end{array}$ & $\begin{array}{l}\text { NS } \\
\text { NS }\end{array}$ & $\begin{array}{l}-47,4 \\
-74,7\end{array}$ & $\begin{array}{l}\text { NS } \\
\text { NS }\end{array}$ \\
\hline
\end{tabular}

$\mathrm{CaO}_{2}$ : conteúdo arterial de oxigênio; $\mathrm{CvO}_{2}$ : conteúdo venoso de oxigênio; $\mathrm{DavO}_{2}$ : diferença arteriovenosa de oxigênio; $\mathrm{EO}_{2}$ :extração de oxigênio; $\mathrm{IVO}_{2}$ : índice de consumo de oxigênio; R: repouso; E: exercício; WI: modo ventricular inibido; DDD: modo atrioventricular universal; $\mathrm{p}$ : significância estatística; A-B: diferença entre os valores médios dos parâmetros dos grupos A e B. 


\subsection{Comparação estatística do comportamento dos grupos A e B}

A comparação estatística entre os grupos A e B evidenciou diferença significativa entre as médias de conteúdo venoso de oxigênio na condição VVI exercício, diferença arteriovenosa de oxigênio na condição DDD exercício e extração de oxigênio nas condições WI exercício e DDD exercício. Não foi observada diferença significativa entre as médias dos demais parâmetros. (tabela XI.)

\section{Evolução clínica dos pacientes}

Todos os pacientes foram seguidos em ambulatório por tempo que variou de 31,8 a 81,5 meses após o implante do marcapasso, com tempo de seguimento médio de 64,2 com desvio padrão de 13,4 meses. (tabela XII).

Três pacientes do grupo A morreram, com tempo de evolução pós-operatória de $31,8,53,3$ e 62,4 meses.

As causas dos óbitos foram: complicação pós-operatória de cirurgia para megaesôfago; insuficiência cardíaca congestiva e broncopneumonia, como complicação de pielolitotomia; e morte súbita. Uma paciente do grupo B apresentou acidente vascular cerebral isquêmico com hemiparesia direita. (tabela XII.)

$\mathrm{Na}$ época da última avaliação, sete pacientes estavam em classe funcional I, sendo três do grupo A e quatro do grupo B; um paciente do grupo A estava em classe funcional II; um paciente do grupo A em III e um paciente do grupo B em IV. Quatro pacientes não estavam utilizando medicamentos, enquanto dois pacientes estavam recebendo digitálicos, sendo um do grupo A e um do grupo B; seis pacientes recebiam diuréticos, sendo cinco do grupo A e um do grupo B; quatro pacientes do grupo A recebiam antiarrítmicos e dois pacientes recebiam vasodilatador periférico, sendo um do grupo A e um do grupo B. (tabela XII.) 
TABELA XII - EVOLUÇÃO CLÍNICA DOS PACIENTES

\begin{tabular}{|c|c|c|c|c|c|c|c|c|c|c|}
\hline \multirow[t]{2}{*}{ CASO } & \multirow{2}{*}{$\begin{array}{c}\text { TEMPO DE } \\
\text { SEGUIMENTO } \\
\text { (meses) }\end{array}$} & \multirow{2}{*}{$\begin{array}{c}\text { ICC } \\
\text { NYHA }\end{array}$} & \multirow[t]{2}{*}{ MODO } & \multicolumn{4}{|c|}{ MEDICAMENTOS EM USO } & \multirow{2}{*}{ INTERCOR. } & \multirow{2}{*}{$\begin{array}{l}\text { ÓBITO } \\
\text { CAUSA }\end{array}$} & \multirow{2}{*}{$\begin{array}{c}\text { TROCA } \\
\text { GERADOR } \\
\text { (meses) }\end{array}$} \\
\hline & & & & DIGITAL & DIUR & ANTIAR & VASOD & & & \\
\hline 1 & 81,5 & $\overline{I I}$ & DDD & - & - & - & - & - & - & $\overline{56,9}$ \\
\hline 2 & 75,2 & i & DDD & - & - & - & - & - & - & 48,8 \\
\hline 3 & 62,4 & II & DDD & + & + & & + & nefr. & $\mathrm{ICC}+\mathrm{Bcp}$ & 50,5 \\
\hline 4 & 71,1 & IV & DDD & - & + & - & + & - & - & 50,5 \\
\hline 5 & 72,5 & I & DDD & - & + & + & - & - & - & - \\
\hline 6 & 72,0 & I & DDD & - & + & + & - & - & - & - \\
\hline 7 & 31,8 & i & DDD & - & + & + & - & megaes. & indet. & - \\
\hline 8 & 53,3 & III & DDD & - & + & - & - & - & súbita & - \\
\hline 9 & 61,0 & I & DDD & - & - & - & - & $\mathrm{AVCi}$ & - & 57,2 \\
\hline 10 & 61,0 & II & DDD & - & + & - & - & - & - & - \\
\hline
\end{tabular}

ICC: Insuficiência Cardíaca Congestiva; NYHA: New York Heart Association; DIGITAL: utilização de digitálicos; DIUR: utilização de diurético; ANTIAR: utilização de antiarrítmicos; VASOD: utilização de vasodilatadores periféricos; INTERCOR: intercorrências; (+): presente; (-): ausente; NEFR: nefrolitíase operada; MEGAES: megaesôfago operado; AVCi : Acidente Vascular Cerebral Isquêmico; Bcp: Broncopneumonia; INDET: complicação pós-operatória não definida que levou ao óbito.

A programação do marcapasso foi sempre a atrioventricular universal (DDD), em todos os pacientes. Cinco pacientes foram submetidos a troca do gerador de pulsos, por exaustão da bateria, que ocorreu entre 48,8 e 57,2 meses com média de 52,8 e desvio padrão de 3,6 meses. Apenas três, dos pacientes sobreviventes, ainda não foram submetidos a troca do gerador de pulsos. Não ocorreram outras complicações relacionadas ao sistema de estimulação implantado. (tabela XII.) 


\section{V - DISCUSSÃO}

\section{Considerações gerais sobre a metodologia}

\subsection{Estudo hemodinâmico e exercício}

A avaliação da reserva cardiocirculatória de portadores de cardiopatias tem no exercício associado à monitorização hemodinâmica um método dotado de grande utilidade e precisão (FRANCIOSA et al., 1981; WEINER, 1983; BUGNI 1984; FRANCIOSA, 1984; WEBER et al., 1984a; WEBER et al., 1984b.)

Com o objetivo de estudar comparativamente modos de estimulação cardíaca artificial, o estudo hemodinâmico tem sido empregado isoladamente (SAMET et al., 1966; SAMET et al., 1968; LEINBACH et al., 1969; FANANAPAZIR et al., 1983), ou associado ao exercício (KARLÖF, 1974; KAPPENBERGER et al., 1982; KRUSE et al., 1982; PEHRSSON \& ASTRÖM, 1983).

Três aspectos relativos a esta metodologia sempre são analisados: a postura, o tipo de exercício e o intervalo entre o implante de marcapasso e o momento da realização do estudo.

CHAPMAN et al., 1960; BEVERGAR et al., 1963 e KRAMER et al., 1982, demonstraram que o índice sistólico, durante o repouso, é maior na posição supina quando comparado às posições sentada e em pé, provavelmente devido ao maior retorno venoso que ocorre na posição supina. Durante o exercício, o valor do índice sistólico nessas três posições tende à equivalência.

THADANI \& PARKER, 1978, constataram que, durante o repouso, na posição supina, os valores do índice cardíaco e da pressão média de capilar pulmonar são maiores do que na posição sentada, ocorrendo o inverso com a freqüência cardíaca, que é menor na supina. Durante o exercício, essas diferenças são mantidas, com exceção do 
índice cardíaco ao esforço máximo, que apresenta valores semelhantes em ambas as posições. Para esses autores, as alterações hemodinâmicas encontradas nas diferentes posturas mencionadas não são suficientes para invalidar conclusões quanto ao desempenho cardíaco. Sugerem, no entanto, que sejam mantidas as condições posturais iniciais durante todo o estudo.

A análise dos resultados obtidos pelos diversos autores, que utilizaram o estudo hemodinâmico, com cálculo do débito cardíaco pela técnica de diluição de corante, em posição supina, para o estudo dos modos de estimulação, demonstrou boa reprodutibilidade e constância (SAMET et al.,1966; SAMET et al., 1968; LEINBACH et al., 1969; KRUSE et al., 1982). A comparação entre os resultados obtidos na posição sentada e na posição supina, no estudo de portadores de marcapasso, também não demonstrou diferenças que justificassem a opção pela posição sentada (KARLÖF, 1974; KAPPENBERGER et al., 1982; KRUSE et al., 1982; PEHRSSON \& ASTRÖM, 1983; NORDLANDER et al., 1987).

Assim sendo, consideramos adequada a posição supina adotada no presente estudo, por ter sido freqüentemente utilizada, não ter interferido nas conclusões e ter proporcionado conforto e segurança ao paciente. Além disto, a facilidade técnica para o manuseio dos cateteres durante o estudo contribuiu para esta opção.

O tipo de exercício a ser utilizado também tem sido objeto de discussão. PEHRSSON e ASTRÖM, em 1983, estudaram seus pacientes sob três condições diferentes: posição supina com as pernas elevadas; sob exercício em carga constante e moderada; e sob esforço máximo. Naquele estudo, a variação percentual do débito cardíaco entre a primeira e a terceira condições citadas foi de $75,9 \%$, e entre a segunda e a terceira foi de $22,9 \%$. KRUSE et al., em 1982, realizaram o teste de esforço isolado previamente ao estudo hemodinâmico, e calcularam a carga máxima atingida por seus 
pacientes. Durante o estudo hemodinâmico, empregaram duas condições distintas: $30 \%$ e $60 \%$ da carga máxima atingida. A diferença do débito cardíaco entre estas condições foi de 27,9\%. KARLÖF, 1974, demonstrou que, acima de determinada freqüência cardíaca, o aumento da freqüência cardíaca é contrabalançado pela queda do índice sistólico, o que faz com que o índice cardíaco pouco se altere. Esse fato fez com que esse autor, assim como KAPPENBERGER et al., em 1982, optassem pelo estudo em condição de carga moderada e esforço constante. Concordando com o uso de cargas intermediárias no estudo de portadores de marca passo, YEE et al., em 1984, apontaram causas extracardíacas, como o condicionamento físico, como fatores co-responsáveis pela limitação do desempenho cardiovascular.

Tendo em vista os dados acima expostos, e uma vez que nosso objetivo foi o de avaliar os pacientes em condições que mais se parecessem com suas atividades habituais, optamos pelas condições repouso e exercício moderado padronizado, em carga constante, conforme foi descrito em Método.

O período em que a avaliação deve ser realizada foi estudado em 1982, por KRUSE et al., que observaram os pacientes por ocasião do implante e três meses após. Permaneceu nesse período um grupo de pacientes em uso do modo ventricular inibido, e um outro grupo em modo atrioventricular. Demonstraram não haver diferenças significativas entre os resultados do estudo, tanto em relação ao tempo, quanto ao modo utilizado no período de adaptação. KAPPENBERGER et al., 1982, também não encontraram diferenças entre o estudo hemodinâmico realizado agudamente ou 10 semanas após o implante do marcapasso.

Com base nos dados da literatura consideramos confiáveis os resultados obtidos no período pós-operatório imediato. 


\subsection{Programações utilizadas}

Dois aspectos relevantes da programação a ser utilizada no marcapasso são normalmente discutidos: a freqüência de estimulação e o intervalo atrioventricular.

SAMET et al., 1966, estudando 33 pacientes portadores de enfisema pulmonar, verificaram que a variação da freqüência de estimulação em modo ventricular na faixa de 60 a 89 bpm ou, na faixa de 90 a 109 bpm, fazia com que, em média, o débito cardíaco se alterasse em apenas 7\%. No mesmo estudo, pacientes portadores de cardiopatia reumática, naquelas mesmas faixas de freqüência cardíaca, exibiram variação de $4 \%$. SAMET et al., 1968, estudando portadores de corações normais, demonstraram que a mudança de faixa de freqüência de estimulação ventricular de 60 a 89 para 90 a 109 bpm provocava uma modificação média do débito cardíaco de 5\%. LEINBACH et al., 1969, estudando dez pacientes portadores de bradiarritmias com indicação de implante de marcapasso, demonstraram que a elevação da freqüência cardíaca acima da freqüência sinusal por estimulação ventricular, com acréscimo de 10 ou 40 bpm, provocava uma diferença no débito cardíaco de apenas 6,5\%.

KARLÖF, 1974, demonstrou que, com o modo de estimulação VVI, tanto em repouso quanto durante exercício, a variação da freqüência cardíaca de 70 a 160 bpm provocava pequena modificação no débito cardíaco. Concluiu que a melhor freqüência de estimulação para o modo VVI é 70 bpm.

KRUSE \& RYDÉN, 1981; PEHRSSON \& ASTRÖM, 1983; PERRINS et al., 1983; KRISTENSSON et al., em 1985a, estudando pacientes portadores de bloqueios da condução atrioventricular e marcapasso atrioventricular síncrono com a onda $\mathrm{P}$, em condições de esforço cuja intensidade variou de moderada a máxima, obtiveram freqüências sinusais que variaram de 126 a 152 bpm. 
A variação do intervalo atrioventricular foi estudada por LEINBACH et al., 1969, em portadores de marcapasso. Os pontos de máximo índice cardíaco verificados ocorreram entre 100 e $200 \mathrm{~ms}$ de atraso atrioventricular. Em 50\% dos pacientes o atraso atrioventricular ótimo foi $150 \mathrm{~ms}$, em $25 \%$ foi $100 \mathrm{~ms}$ e em $25 \%$ foi $200 \mathrm{~ms}$. OGAWA et al., 1978, variaram o intervalo atrioventricular de forma decremental nos valores de 100, 50, 0, -100 e -200 ms, e demonstraram os efeitos hemodinâmicos das diferentes formas de sincronização atrioventricular.

Os dados acima apresentados justificaram a nossa opção pela programação de 70 bpm para o modo ventricular (VVI), e, para o modo atrioventricular (DDD), de freqüência mínima de 70 e máxima de 175 bpm, com intervalo A-V de 150 ms. Nenhum de nossos pacientes atingiu o limite máximo de freqüência programado.

\section{Análise da resposta hemodinâmica ao exercício}

A resposta cardiocirculatória ao exercício, em condições normais, é complexa, exigindo a integração de fatores hemodinâmicos, metabólicos e neuro-humorais (PARMLEY, 1985; BRAUNWALD, 1988).

O objetivo final do organismo, do ponto de vista hemodinâmico, é a manutenção da homeostase, com a adequação do índice cardíaco às necessidades metabólicas do momento. Esse ajuste do índice cardíaco é dependente da participação principal de dois parâmetros hemodinâmicos: a freqüência cardíaca e o índice sistólico. (WANG et al., 1960; VATNER \& PAGANI, 1977; LITTLE, 1981.)

O mecanismo de atuação imediata e predominante no aumento do índice cardíaco é a freqüência cardíaca, que é regulada pelo sistema nervoso autônomo com a inibição do parassimpático e a estimulação do simpático. (VATNER \& PAGANI, 1977; MANGER, 1982.) 
O índice sistólico, em condições de variação fisiológica da freqüência cardíaca, tem participação menor no aumento do índice cardíaco (RUSHMER, 1959; HORWITZ et al., 1972), sendo que, na posição supina, esse aumento geralmente não ultrapassa 25 a 30\%. O aumento do índice sistólico é determinado pela adequação de três fatores: a précarga, a pós-carga e o estado contrátil do miocárdio (VATNER \& PAGANI, 1977; LITTLE, 1981; ORRINGER, 1983). No presente estudo, é importante notar que pode ser analisada uma condição pouco freqüente, em que um mesmo paciente é submetido a esforço idêntico em duas condições distintas: com a variação fisiológica da freqüência cardíaca (modo DDD), como encontramos na maioria dos trabalhos da literatura, e com a freqüência ventricular fixa (modo VVI), quando as modificações do índice cardíaco passam a depender exclusivamente das alterações do índice sistólico.

KARLÖF, 1974, demonstrou o comportamento do índice sistólico em pacientes portadores de bloqueio atrioventricular do terceiro grau de etiologia não chagásica, com marcapasso ventricular. Durante o repouso, com a elevação da freqüência cardíaca, a partir do ritmo idioventricular até que fosse atingido um limiar, geralmente próximo a 70 bpm, o índice sistólico permaneceu praticamente inalterado de tal forma que, nessas faixas de freqüência cardíaca, a elevação da freqüência cardíaca se traduziu em elevação do índice cardíaco. Acima desse limiar, aumentos da freqüência cardíaca passaram a provocar queda inversamente proporcional do índice sistólico, de tal forma que o índice cardíaco tendeu a manter-se o mesmo. Durante o exercício, ocorreu a elevação daquele limiar para níveis de freqüência cardíaca em torno de 110 bpm. Dessa forma, elevações da freqüência cardíaca até níveis de 110 bpm, em modo VVI ao exercício, provocaram aumento do índice cardíaco, pelo aumento do inotropismo e manutenção de índice cardíaco elevado. Com a fixação da freqüência cardíaca, KARLÖF demonstrou que a realização do exercício provocou a elevação do índice sistólico a níveis tão altos quanto os alcançados durante o ritmo idioventricular. Por conseguinte, 
podemos esperar elevação do índice cardíaco em modo WI com a realização do exercício, a despeito da freqüência cardíaca fixa.

Quanto à pós-carga, durante o exercício, normalmente ocorre uma redução da resistência vascular sistêmica, representando um mecanismo favorável na adaptação ao esforço, não somente de indivíduos normais, como de hipertensos e cardiopatas (CLEMENT \& SHEPHERD, 1977; RAMIRES, 1984.)

\subsection{Modo ventricular}

Quando os pacientes se encontravam sob o modo de estimulação VVI, a realização do exercício provocou aumento médio do índice cardíaco de 57,7\% ( $p<0,001)$. Considerando-se que a contribuição da freqüência cardíaca na elevação do índice cardíaco é nula neste modo de estimulação, nota-se uma participação muito expressiva do índice sistólico, com aumento de 57,8\% ( $p<0,001)$. Essa participação é muito superior àquela encontrada em indivíduos portadores de insuficiência cardíaca leve com resposta cronotrópica adequada. Já a pós-carga teve um desempenho dentro do esperado para indivíduos da mesma classe funcional (insuficiência cardíaca leve), com diminuição da resistência vascular sistêmica de 35,0\% ( $p<0,001)$. (tabela III.)

KARLÖF, 1974; KAPPENBERGER et al., 1982; KRUSE et al., 1982; e PEHRSSON \& ASTRÖM, 1983, referem, com a realização do exercício, em modo WI, com freqüências próximas a 70 bpm, aumentos do débito cardíaco de 57,7\%; 47,0\%; 55,0\%; 96,7\%; 35,6\% e 60,0\%, usando, respectivamente: exercício moderado com carga fixa; $200 \mathrm{kgm} / 5 \mathrm{~min} ; 30 \%$ da carga máxima; $60 \%$ da carga máxima; exercício moderado com carga fixa durante seis minutos; e carga máxima.

Nota-se que o aumento do índice cardíaco de 57,7\% encontrado em nossos pacientes é totalmente compatível com os níveis obtidos nas condições de carga intermediária relatados na literatura. Nota-se ainda que estas condições são as que 
propiciam os melhores desempenhos hemodinâmicos, atingindo seu ponto máximo, nos trabalhos encontrados na literatura, com a realização de $60 \%$ da carga máxima, resultando em débito cardíaco maior do que os relatados com carga máxima.

KARLÖF, 1974; KAPPENBERGER et al., 1982; e PEHRSSON \& ASTRÖM, 1983, referem, com a realização do exercício, em modo WI, e freqüências próximas a 70 bpm, aumentos do índice sistólico de 44,4\%; 46,8\%; 38,1\% e 58,7\%, usando, respectivamente: exercício moderado com carga fixa; $200 \mathrm{kgm} / 5 \mathrm{~min}$; exercício moderado com carga fixa durante seis minutos; e carga máxima.

Somente PEHRSSON \& ASTRÖM, 1983, estudaram o comportamento da resistência vascular sistêmica e em apenas uma das condições estudadas (carga máxima). Nesta condição foi registrada queda da resistência vascular sistêmica de $55,2 \%$, com a realização do exercício em modo WI.

\subsection{Modo atrioventricular universal}

Durante esse modo de estimulação, a realização do exercício proporcionou aumento do índice cardíaco de $66,8 \%(p<0,01)$. A contribuição da freqüência cardíaca nesse caso foi de $27,0 \%(p<0,001)$, a do índice sistólico, de $34,2 \%(p<0,01)$, sendo a queda da resistência vascular sistêmica de 29,3 \% ( $p<0,001)$. (tabela III.)

KARLÖF, 1974; KAPPENBERGER et al., 1982; KRUSE et al., 1982; e PEHRSSON \& ASTRÖM, 1983, referem, com a realização do exercício, em modo atrioventricular, aumentos do débito cardíaco de: 71,9\%; 57,0\%; 62,7\%; 108,0\%; 50,9\% e 85,5\%, usando, respectivamente: exercício moderado; com carga fixa; $200 \mathrm{kgm} / 5 \mathrm{~min}$; $30 \%$ da carga máxima; $60 \%$ da carga máxima; exercício moderado com carga fixa durante seis minutos; e carga máxima. Nestas ocasiões, a contribuição da freqüência cardíaca foi respectivamente $51,8 \% ; 52,7 \% ; 40,0 \% ; 71,4 \% ; 50,0 \%$ e $75,7 \%$. 
Da mesma forma que para o modo WI, nota-se que o aumento do índice cardíaco de $66,8 \%$ encontrado em nossos pacientes é totalmente compatível com os níveis obtidos nas condições de carga intermediária, relatados na literatura. Por outro lado, a elevação média da freqüência cardíaca que obtivemos, da ordem de 27,0\%, está muito abaixo da encontrada na literatura, para cargas semelhantes. Dois fatores poderiam explicar esta diferença: a faixa etária mais jovem de nossos pacientes, estando todos eles em plena atividade profissional, e o desequilíbrio autonômico próprio da cardiopatia chagásica. MARIN-NETO et al.,1986, estudando pacientes portadores da miocardiopatia chagásica, relatam alterações da resposta parassimpática que implicam em elevação do índice cardíaco ao exercício, provocado principalmente pela queda da resistência vascular sistêmica, a despeito de elevação da freqüência cardíaca.

KARLÖF, 1974; KAPPENBERGER et al., 1982, KRUSE et al., 1982; e PEHRSSON \& ASTRÖM, 1983, referem, com a realização do exercício em modo atrioventricular, aumentos do índice sistólico de 35,0\%; 0,9\%; 5,3\% e 2,7\% usando: respectivamente: exercício moderado com carga fixa; $200 \mathrm{kgm} / 5 \mathrm{~min}$; exercício moderado com carga fixa durante 6 minutos; e carga máxima.

Apenas os resultados de KARLÖF, 1974, são compatíveis com os nossos, em termos de índice sistólico (respectivamente $35,0 \%$ e $34,2 \%$ ). O fato de se referirem a mais baixa faixa etária citada na literatura (52 anos em média) é o principal fator de aproximação entre os dados apresentados por KARLÖF e a presente experiência.

Apenas PEHRSSON \& ASTRÖM, 1983, estudaram o comportamento da resistência vascular sistêmica e em somente uma das condições estudadas (carga máxima), quando foi registrada queda da resistência vascular sistêmica de 60,3\%, com a realização do exercício em modo DDD. 


\section{Análise da resposta hemodinâmica à mudança do modo de estimulação}

\subsection{Comportamento durante o repouso}

A avaliação hemodinâmica durante o repouso demonstrou que, com a mudança do modo WI para o modo DDD, ocorreu um aumento médio do índice cardíaco de $14,1 \%$ (NS). A análise do comportamento individual, entretanto, como é possível verificar na figura 4, mostra que este comportamento não é homogêneo, o que se traduziu como falta de significância no estudo estatístico. (tabela II)

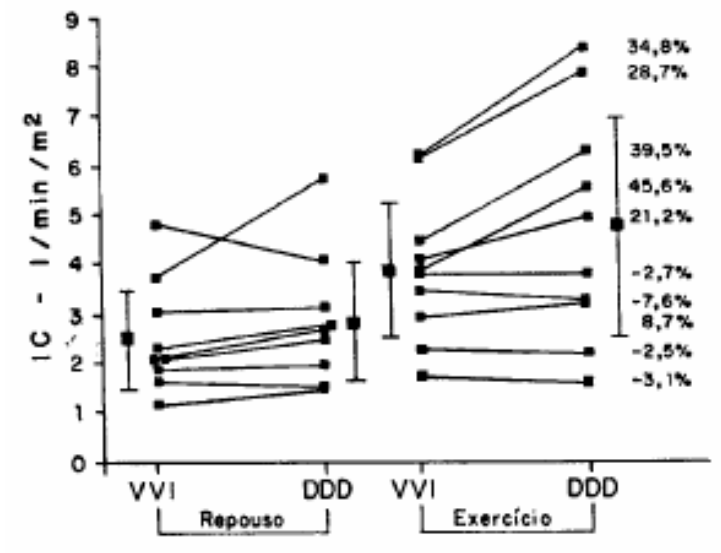

Figura 4 . Comportamento individual do indice cardiaco com mudança de modo de estimulação WI para DDD no repouso e exercicio; média e desvio padrăo nas condiçōes WVI-R, DDD-R, WI.E e DDD-E; e variaçə̄o percentual do índice cardíaco com a mudança de modo WV para DDD durante o exercício.

Dado que o índice cardíaco é função do índice sistólico, da freqüência cardíaca e da resistência vascular sistêmica, e que no modo WI, a freqüência cardíaca é fixa, com valor programado neste estudo em torno de $70 \mathrm{bpm}$, pode-se observar, na tabela II, a participação de cada um desses fatores na elevação do débito cardíaco, com a mudança do modo de estimulação. A freqüência cardíaca foi o principal fator de aumento do índice cardíaco com uma elevação média de 10,5\% $(p<0,05)$, enquanto o índice sistólico aumentou 3,8\% (NS) e a resistência vascular periférica diminuiu 8,9\% (NS). 
KARLÖF 1974. KAPPENBERGER et al., 1982; KRUSE et al., 1982; e PEHRSSON \& ASTRÖM, 1983, referem que, com a mudança do modo ventricular para atrioventricular ao repouso, ocorreram alterações do débito cardíaco de 9,6\%; 8,2\%; $25,0 \%$ e $22,2 \%$, sendo a contribuição da freqüência cardíaca de 15,3\%;2,8\%;2,9\% e 2,8\%, respectivamente. Nesta situação, KARLÖF, 1974; KAPPENBERGER et al., 1982 e PEHRSSON \& ASTRÖM, 1983, referem variação do índice sistólico de $-16,7 \% ;+9,6 \%$ e $+19,1 \%$ e PEHRSSON \& ASTRÖM, 1983, referem queda da resistência vascular sistêmica de 23,6\%.

\subsection{Comportamento durante o exercício}

Durante o exercício, a mudança do modo WI para DDD permitiu o incremento do índice cardíaco de 20,6\% $(p<0,05)$ como valor médio. (tabela II.)

A análise da variação percentual dos componentes cronotrópico e inotrópico demonstrou aumento médio da freqüência cardíaca de 40,8\% $(p<0,001)$ e diminuição do índice sistólico da ordem de $11,7 \%(N S)$. Praticamente não ocorreu modificação da resistência vascular periférica, com a mudança de modo de estimulação durante o exercício, quando foi observada diminuição média de 1,0\% (NS). (tabela II.)

KARLÖF, 1974; KAPPENBERGER et al., 1982; KRUSE et al., 1982; e PEHRSSON \& ASTRÖM, 1983, referem, que a mudança do modo de estimulação WI para DDD, durante a realização do exercício, propiciou aumento do débito cardíaco de 19,5\%;15,5\%; 31,2\%; 32,2\%; 36,1\% e 41,7\%, usando, respectivamente: exercício moderado com carga fixa; $200 \mathrm{kgm} / 5 \mathrm{~min} ; 30 \%$ da carga máxima; $60 \%$ da carga máxima; exercício moderado com carga fixa durante seis minutos; e carga máxima. Naquelas condições, a contribuição da freqüência cardíaca foi respectivamente: 51,8\%; 56,9 \%; $44,1 \% ; 76,5 \% ; 48,0 \%$ e $83,1 \%$. 
KARLÖF, 1974; KAPPENBERGER et al., 1982; e PEHRSSON \& ASTRÖM, 1983, referem que a mudança do modo de estimulação VVI para DDD, durante a realização do exercício, provocou alteração do índice sistólico de -22,1\%; -24,7\%; -9,2\% e -23,0\%, usando, respectivamente: exercício moderado com carga fixa; 200kgm/5min; exercício moderado com carga fixa durante seis minutos; e carga máxima.

Apenas PEHRSSON \& ASTRÖM, 1983, observaram o comportamento da resistência vascular sistêmica e em apenas uma das condições estudadas (carga máxima), quando foi registrada queda da resistência vascular sistêmica de 32,4\%, com a mudança do modo WI para DDD, durante o exercício.

A comparação do desempenho do índice cardíaco dos pacientes do presente estudo, ao exercício (figura 4), demonstra que o aumento pouco expressivo do índice cardíaco médio pode ser explicado pelo comportamento individual significativamente diferente de paciente para paciente.

Foi observado que cinco pacientes apresentaram queda ou elevação discreta do índice cardíaco (variação percentual de $-7,6$ a 8,7\% com média de $-1,4 \%$ ) durante o esforço, com a mudança do modo ventricular inibido (WI) para atrioventricular universal (DDD). Por outro lado, os outros cinco pacientes atingiram aumentos expressivos do índice cardíaco (variação percentual de 21,2 a 45,6\% com média de 33,8\%), com a mudança do modo de estimulação.

KARLÖF, 1974, chamou a atenção para a grande variabilidade dos resultados, citando que certos pacientes apresentavam aumento do débito cardíaco maior que $20 \%$ com a mudança do modo ventricular para atrioventricular, durante o exercício, enquanto outros pacientes ficavam muito abaixo deste valor.

PEHRSSON \& ASTRÖM, 1983, também chamaram a atenção para este tipo de comportamento. Descreveram uma correlação direta $(r=0,90)$ entre as medidas das 
pressões em aorta, com os modos ventricular e atrioventricular, durante o repouso, e a melhora do débito cardíaco. Essa correlação, no entanto, não prognosticou o incremento do débito cardíaco durante o exercício.

Em face desses achados, os resultados hemodinâmicos obtidos permitiram a separação dos pacientes em dois grupos distintos: o grupo A ficou constituído pelos pacientes que apresentaram queda ou pequena elevação do índice cardíaco com a mudança do modo ventricular (WI) para atrioventricular universal (DDD) durante o exercício (pacientes números 3, 5, 6, 7 e 8); e o grupo $B$, pelos que apresentaram elevação expressiva do índice cardíaco na mesma condição (pacientes 1, 2, 4, 9 e 10).

A análise estatística realizada demonstrou desempenho hemodinâmico significativamente diferente entre esses dois grupos, não apenas com relação ao índice cardíaco, como também com relação ao comportamento do índice sistólico, do índice do trabalho sistólico do ventrículo esquerdo, da resistência vascular sistêmica e da resistência arteriolar pulmonar, em todas as condições estudadas. Diante da homogeneidade dos achados clínicos, radiológicos e ecocardiográficos dos pacientes do presente estudo (tabela Ic), julgamos de interesse discutir separadamente os resultados obtidos, com o intuito de tentar encontrar o mecanismo que levou ao comportamento hemodinâmico distinto entre os dois grupos.

\section{Estudo comparativo entre os Grupos A e B}

\subsection{Comportamento da Freqüência Cardíaca}

\section{a) GRUPO A}

No grupo $A$, a freqüência cardíaca média com o modo ventricular na condição repouso (VVI-R) foi de 73,2 bpm e na condição exercício (VVI-E) foi de 72,6 bpm (figura 5). A falta de adaptação da freqüência cardíaca ao exercício foi conseqüência do próprio 
modo de estimulação. A pequena variação medida na freqüência cardíaca, da ordem de $0,8 \%$, pode ser explicada por de erro de leitura do computador.

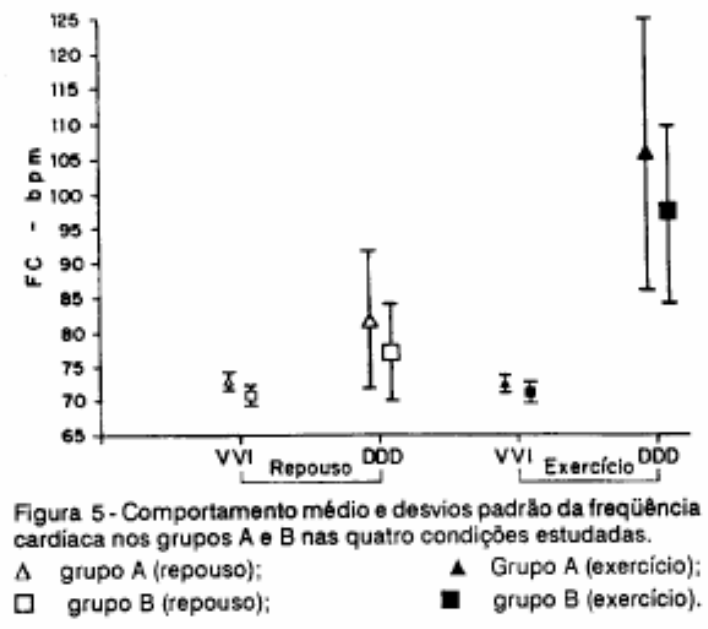

No grupo $A$, a freqüência cardíaca média com o modo atrioventricular na condição repouso (DDD-R) foi de 82,2 bpm, aumentando para 105,2 bpm durante o exercício, (DDD-E), representando este o incremento $28,0 \%$. (figura 5.)

b) GRUPO B

No grupo B, a freqüência cardíaca média na condição WI-R foi de 71,0 bpm e na condição VVI-E, de 71,2 bpm (figura 5). A mesma observação feita para o outro grupo é cabível também para este, dado que o modo WI não permite variação na freqüência cardíaca.

No grupo B a freqüência cardíaca média, na condição DDD-R, foi de 77,2 bpm, passando para 97,2 na condição DDD-E, representando incremento de 25,9\%. (figura 5.)

A análise dos resultados da freqüência cardíaca demonstra que a mudança de modo de estimulação WI para DDD representou: no grupo $A$, ao repouso, incremento de 
$12,3 \%$ (NS) e, durante o exercício, de $44,9 \%(p<0,05)$ (tabela IV); no grupo B, ao repouso, incremento de $8,7 \%$ (NS) e durante o exercício de $36,5 \%(p<0,02)$. (tabela V.)

Tendo em vista que a freqüência de estimulação no modo DDD foi expressão exata da freqüência sinusal, foi possível constatar que, durante o exercício, em ambos os grupos, a adaptação da freqüência cardíaca propiciada pelo modo DDD foi significativa.

Por outro lado, a análise do comportamento dos grupos entre si, mostrou que não existiram diferenças no comportamento da freqüência cardíaca para qualquer uma das condições estudadas (tabela VI), embora os valores obtidos no grupo A, no modo DDD, fossem mais elevados, tanto na condição repouso quanto durante o exercício, podendo sugerir uma pior condição hemodinâmica dos pacientes deste grupo.

Esses resultados nos permitiram verificar que o parâmetro freqüência cardíaca não teve influência na diferença entre as respostas hemodinâmicas dos grupos $A$ e $B$. Observou-se ainda que o modo atrioventricular universal permitiu uma melhor adaptação fisiológica da freqüência cardíaca, em ambos os grupos.

\subsection{Função ventricular esquerda}

Vários tipos de abordagem têm sido utilizados para a detecção de alterações discretas a moderadas da função ventricular esquerda. Habitualmente são empregados os índices de ejeção dessa câmara. Os mais utilizados têm sido a pressão de enchimento, índice cardíaco, o trabalho sistólico, o trabalho minuto e a fração de ejeção. Muitas vezes, mesmo que os valores basais desses índices se apresentem dentro dos limites da normalidade, a resposta cardiovascular ao esforço pode ser subnormal. (BRAUNWALD, 1988.)

Em indivíduos normais, durante o exercício dinâmico em decúbito, o DC se eleva mais de seis mililitros por minuto para cada mililitro de aumento do consumo de oxigênio por minuto; o volume sistólico e a fração de ejeção geralmente se elevam; e a pressão 
diastólica final do ventrículo esquerdo, que em repouso é menor que $12 \mathrm{mmHg}$, eleva-se discretamente, permanece inalterada, ou decresce discretamente. Em pacientes portadores de disfunção do ventrículo esquerdo, a pressão diastólica final se eleva mais do que três milímetros de mercúrio, geralmente excedendo $12 \mathrm{mmHg}$; mas o volume sistólico e a fração de ejeção permanecem constantes ou decrescem. Existem vários graus intermediários de alteração entre a resposta normal e a do ventrículo insuficiente ao esforço. (ROSS et al., 1966; GELBERG et al., 1979.)

Na figura 6 podemos notar o comportamento do índice sistólico médio nos grupos A e B.

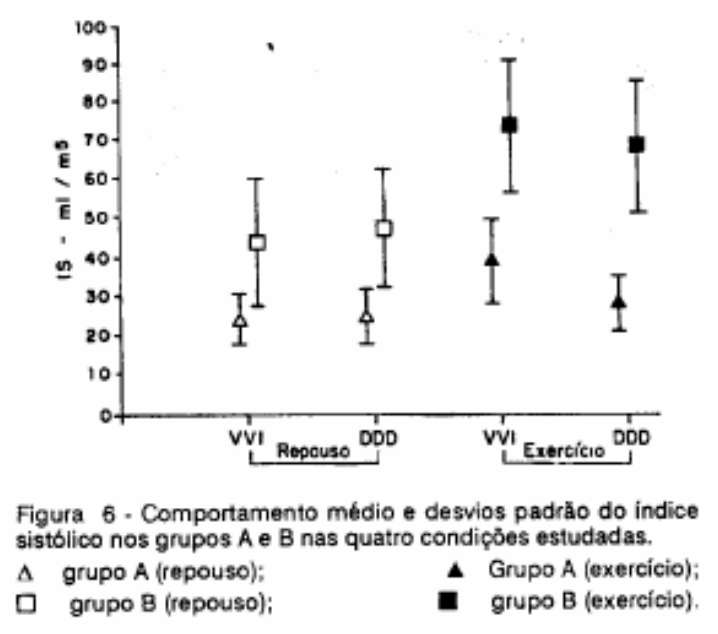

a) GRUPO A

A análise individualizada do grupo A (figura 1a), na condição WI-R, mostrou que quatro pacientes encontravam-se no subgrupo III, estando o paciente restante no subgrupo IV. Com a realização do exercício (condição WI-E) verificou-se que apenas três pacientes conseguiram melhorar o desempenho ventricular, tendo passado dois pacientes para o subgrupo I e um para o subgrupo II; enquanto um paciente permaneceu no subgrupo III, restando um paciente no subgrupo IV. 
O comportamento médio desses pacientes demonstrou índice cardíaco de 1,8 I/min. $\mathrm{m}^{2}$ e pressão média do capilar pulmonar de $8,6 \mathrm{mmHg}$ na condição WI-R; e índice cardíaco de 2,8 $\mathrm{l} / \mathrm{min} \cdot \mathrm{m}^{2}$ e pressão média do capilar pulmonar de 17,0 $\mathrm{mmHg}$, na condição VVI-E. (tabela IV.)

O cálculo do índice do trabalho sistólico demonstrou, na condição VVI-R, valor médio de $31,4 \mathrm{gm} / \mathrm{m}^{2}$ e na condição VVI-E, e de $48,8 \mathrm{gm} / \mathrm{m}^{2}$. (tabela IV.)

Durante o modo DDD na condição repouso, verificou-se que os cinco pacientes do grupo A encontravam-se no subgrupo III. Com a realização do exercício, verificou-se que um paciente passou para o subgrupo I, dois pacientes encontravam-se no subgrupo II, permanecendo dois pacientes no subgrupo III. (figura 1b.)

O comportamento médio desses pacientes demonstrou índice cardíaco de 2,0 I/min. $\mathrm{m}^{2}$ e pressão média do capilar pulmonar de $7,0 \mathrm{mmHg}$, na condição DDD-R; e índice cardíaco de 2,8 l/min. $\mathrm{m}^{2}$ e pressão média do capilar pulmonar de 16,6 mmHg, na condição DDD-E. (tabela IV.)

O índice do trabalho sistólico, na condição DDD-R, foi de $33,1 \mathrm{gm} / \mathrm{m}^{2}$ e na condição DDD-E foi de $37,1 \mathrm{gm} / \mathrm{m}^{2}$. (tabela IV.)

\section{b) GRUPO B}

No grupo B, na condição WI-R, três pacientes encontravam-se no subgrupo I e dois no subgrupo III. Com a realização do exercício (condição WI-E) verificou-se que dois pacientes permaneceram no subgrupo I e três passaram para o subgrupo II (figura 3a.)

O comportamento médio desses pacientes demonstrou um desempenho ventricular satisfatório, com índice cardíaco de 3,1 l/min. $\mathrm{m}^{2}$ e pressão média do capilar pulmonar de 9,4mmHg no repouso; e índice cardíaco de 4,9 I/min. $\mathrm{m}^{2}$ e pressão média do capilar pulmonar de $14,8 \mathrm{mmHg}$, durante o exercício. (tabela V.) 
O índice do trabalho sistólico na condição WI-R, foi de $52,4 \mathrm{gm} / \mathrm{m}^{2}$ e, na condição WI-E, de $82,7 \mathrm{gm} / \mathrm{m}^{2}$. (tabela V.)

No grupo B, na condição DDD-R, três pacientes encontravam-se no subgrupo I, e dois pacientes no subgrupo III. Com a realização do exercício (condição DDD-E), verificou-se que três pacientes encontravam-se no subgrupo I e dois no subgrupo II. (figura 1b.)

O comportamento médio desses pacientes, na condição DDD-R, confirmou o bom desempenho do ventrículo esquerdo com índice cardíaco de 3,6 l/min.m² e pressão média do capilar pulmonar de 5,8 mmHg. Com o exercício (condição DDD-E), o índice cardíaco foi de $6,6 \mathrm{l} / \mathrm{min} \cdot \mathrm{m}^{2}$ e a pressão média do capilar pulmonar, de $13,0 \mathrm{mmHg}$. (tabela V.)

O índice do trabalho sistólico, na condição DDD-R, foi de $57,2 \mathrm{gm} / \mathrm{m}^{2}$ e, durante o exercício (condição DDD-E), foi de 90,9 gm/m2. (tabela V.)

A análise da função ventricular esquerda de nossos pacientes demonstrou que a mudança de modo de estimulação WI para DDD acarretou: no grupo A, ao repouso, incremento do índice do trabalho sistólico de 5,3\% (NS) e, durante o exercício, queda de $24,1 \%(p<0,05)$ (tabela IV); no grupo B, ao repouso, incremento de 9,1\% do índice do trabalho sistólico (NS) e, durante o exercício, incremento de 9,9\% (NS) (tabela V.)

A análise da pressão média do capilar pulmonar, nas quatro condições estudadas, demonstrou que a mudança de modo de estimulação WI para DDD acarretou: no grupo A, durante o repouso, queda da pressão média do capilar pulmonar de $18,6 \%$ (NS) e, durante o exercício, queda de $2,4 \%$ (NS) (tabela IV); no grupo B, durante o repouso, queda da pressão média do capilar pulmonar de $38,3 \%(p<0,01)$ e, durante o exercício, queda de $12,2 \%$ (NS) (tabela V.) 
ROSS et al, 1966, analisando hemodinamicamente 38 pacientes sob esforço contínuo, utilizaram as variações da pressão diastólica final do ventrículo esquerdo e do índice sistólico, para avaliar o comportamento hemodinâmico de portadores de função ventricular esquerda normal, de anormalidade da dinâmica ventricular esquerda (estenose aórtica) e de depressão da função ventricular esquerda. Nas figuras $2 a$ e $2 b$ podemos notar a distribuição de nossos pacientes, segundo os critérios estabelecidos por esses autores.

Podemos verificar que, segundo aqueles critérios, com o modo ventricular (WI), três pacientes foram considerados normais (dois do grupo A e um do grupo B), cinco pacientes foram considerados portadores de alterações da dinâmica ventricular esquerda (três do grupo A e dois do grupo B), e dois pacientes do grupo B ficaram na faixa não definida entre normal e com anormalidade da dinâmica ventricular. Nenhum paciente, neste modo de estimulação, pôde ser definido como portador de depressão da função ventricular. (figura 2a.)

Com o modo DDD, três pacientes foram considerados normais (um do grupo A e dois do grupo B), seis foram considerados portadores de anormalidade da dinâmica ventricular (três do grupo A e três do grupo B), e um paciente do grupo A foi considerado portador de depressão da função ventricular (porém praticamente na faixa limítrofe). (figura 2b.)

Segundo esses critérios, foi possível observar-se que, à exceção de um paciente do grupo A (quando estimulado em modo DDD), todos os pacientes do presente estudo foram classificados como portadores de função ventricular normal ou portadores de anormalidade da dinâmica ventricular. A comparação dos resultados do presente estudo com os resultados de ROSS et al., 1966, sugere que, durante o modo DDD, seis de 
nossos pacientes apresentavam comportamento da dinâmica ventricular semelhante a um portador de estenose aórtica valvar.

A comparação do trabalho sistólico do ventrículo esquerdo entre os dois grupos demonstrou claramente a superioridade dos resultados obtidos no desempenho dos pacientes do grupo B, estatisticamente significante em todas as condições estudadas, embora os valores obtidos no grupo A não tenham sido muito rebaixados. A capacidade de aumento do trabalho com o exercício foi preservada para todas as condições estudadas, embora, com o modo DDD, no grupo A, este aumento tenha sido de apenas $12 \%$.

Por outro lado, o comportamento da pré-carga, quando foram comparados os grupos A e B entre si, não mostrou diferenças significativas para nenhuma das condições estudadas.

Os dados acima analisados demonstraram que, ao repouso, em ambos os grupos de pacientes, houve uma tendência à melhora do desempenho ventricular esquerdo com o modo DDD.

Durante o exercício, porém, o desempenho do ventrículo esquerdo, com o modo atrioventricular universal (DDD), mostrou um comportamento heterogêneo, melhorando no grupo B e piorando no grupo A. Verificou-se que os pacientes do grupo A pioravam seu desempenho ventricular, quando ocorria a elevação da freqüência cardíaca.

Corroborando com os achados clínicos, radiológicos e ecocardiográficos, a avaliação da função ventricular esquerda demonstrou que os pacientes estudados podiam ser considerados normais ou portadores de anormalidade da dinâmica ventricular, não existindo ainda diferenças com relação à distribuição dos pacientes entre os grupos. 
A heterogeneidade do comportamento hemodinâmico, em um grupo clinicamente homogêneo e pouco sintomático, mostrou que a avaliação clínica e mesmo ecocardiográfica de repouso podia ser insuficiente para a real avaliação da reserva cardiocirculatória desses pacientes. A existência de pacientes do grupo B que se apresentavam no subgrupo III durante o repouso, pôde sugerir que esses pacientes já apresentavam uma condição basal mais comprometida em relação aos demais pacientes desse mesmo grupo.

\subsection{Resistência vascular periférica}

As alterações da circulação periférica podem ser tão importantes quanto o coração, na mediação da reposta corporal ao exercício. O aumento do débito cardíaco obtido em repouso pela infusão de uma dose máxima de isoproterenol, que aumenta grandemente a contratilidade e a freqüência cardíaca, sequer se aproxima do nível comumente observado durante o exercício. As alterações da circulação periférica atuam harmonicamente para aumentar a capacidade do leito vascular e fazer retornar o sangue ao coração (GUYTON, 1981). Talvez a mais importante dessas alterações seja a vasodilatação dos músculos ao exercício. A grande redução da resistência vascular sistêmica age de modo análogo reduzindo muito a resistência de retorno do sangue ejetado pelo ventrículo esquerdo de volta ao átrio esquerdo. Entretanto, apesar da ampla vasodilatação dos músculos em exercício, a pressão arterial tende a aumentar primariamente, como conseqüência do aumento do débito cardíaco e também da vasoconstricção que ocorre em outros leitos vasculares que não os do coração e dos músculos em exercício. (VATNER \& PAGANI, 1977.)

Tem sido amplamente demonstrado o importante papel da adaptação da póscarga no desempenho hemodinâmico de indivíduos normais e cardiopatas. Quando aplicada ao ventrículo intacto, a pós-carga pode ser definida como uma tensão, força ou 
estresse que atua nas fibras da parede ventricular, após o início do encurtamento, sendo o principal determinante da quantidade de sangue ejetado pelo ventrículo esquerdo, (SONNENBLICK \& DOWNING, 1962; FORD, 1980.)

SARNOFF et al., 1960; CLANCY et al., 1968; BUGGE-ASPERHEIM \& KILL, 1969; FURNIVAL et al., 1970 e LaFARGE et al., 1970, demonstraram que o volume sistólico do ventrículo esquerdo permanece constante, mesmo quando a resistência aórtica é agudamente alterada. Este fenômeno, batizado de "autorregulação homeométrica", implica em que o ventrículo esquerdo é hábil para ajustar seu volume sistólico, sem a alteração do seu volume diastólico final, quando requisitado a gerar maior ou menor pressão. No entanto esta situação pode ser modificada pela presença de disfunção ventricular, quando alterações da resistência periférica passam a provocar comportamento inversamente proporcional no volume sistólico.

Quando a função ventricular esquerda é deprimida, a pós-carga torna-se um determinante importante da melhora do desempenho cardíaco. A pós-carga pode aumentar como conseqüência da vasoconstricção resultante da influência no leito arterial de alterações estruturais, humorais e neurais, que ocorre em resposta a uma queda do débito cardíaco. Esta pós-carga aumentada pode reduzir o débito cardíaco posteriormente. COHN, 1973, demonstrou que, em corações com disfunção ventricular primária, um aumento inapropriado da impedância aórtica podia ser um fator de progressão da disfunção de bomba, e que reduções farmacológicas da pós-carga poderiam ser benéficas para elevar o débito cardíaco. 


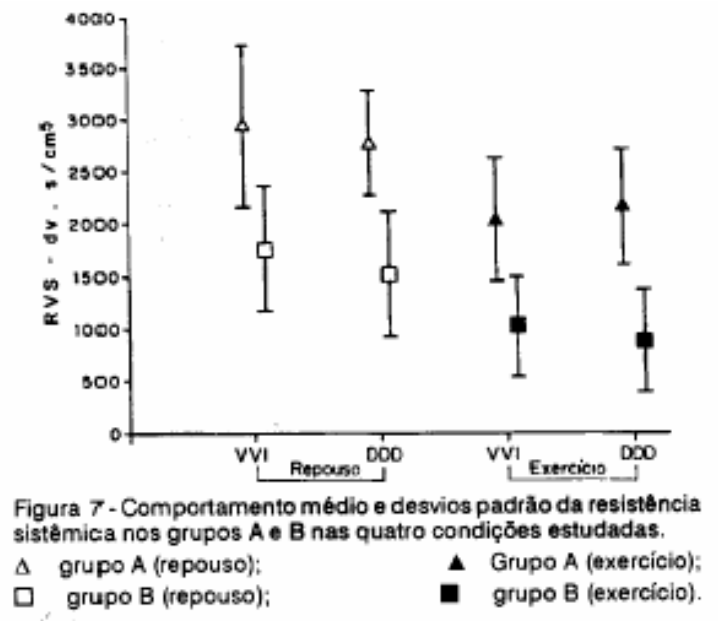

A observação da figura 7 permite comparar o comportamento da resistência vascular sistêmica nos grupos A e B:

No grupo A, na condição WI-R, a resistência vascular sistêmica de repouso foi de 2953,2 dyn.s $/ \mathrm{cm}^{5}$, passando a 2014,1 dyn.s $/ \mathrm{cm}^{5}$, na condição WI-E (tabela IV), representando queda de $31,8 \%$ (tabela III.)

Na condição DDD-R a resistência vascular sistêmica foi de 2773,6 dyn.s/cm , passando a 2163,3 dyn,s/cm ${ }^{5}$, na condição DDD-E (tabela IV), portanto com queda de $22,0 \%$ (tabela III.)

Nos pacientes do grupo B, com a condição VVI-R, a RVS foi 1741,7 dyn.s/cm passando a 1038,2 dyn,s/cm ${ }^{5}$, no exercício (tabela V), representando queda de $40,4 \%$ (tabela III.)

Na condição DDD-R, a RVS foi de 1501 dyn.s $/ \mathrm{cm}^{5}$ e, em DDD-E, foi de 860,0 dyn,s/cm ${ }^{5}$ (tabela V), representando queda de 42,7\% (tabela III.)

A análise da pós-carga demonstrou que a mudança do modo de estimulação ventricular (VVI) para atrioventricular (DDD) ocasionou: no grupo A, queda da RVS de 
$6,1 \%$ no repouso (NS), e aumento da resistência vascular sistêmica de $7,4 \%$, durante o exercício (NS) (tabela IV); no grupo B, queda da resistência vascular sistêmica de 13,8\% ao repouso (NS), e de 17,2\% durante o exercício $(p<0,02)$ (tabela V).

LAGE, 1986, estudando a reposta hemodinâmica de 39 pacientes portadores de miocardiopatia leve a severa, incluindo chagásicos e não chagásicos, ao repouso e ao exercício, em posição supina, encontrou níveis médios de resistência vascular sistêmica de 2078, com desvio padrão de 600 dyn.s $/ \mathrm{cm}^{5}$ para o repouso, e de 1314 , com desvio padrão de 455 dyn.s $/ \mathrm{cm}^{5}$, durante exercício com carga máxima, para os portadores de miocardiopatia com CF I e II. Para os portadores de CF III e IV, os níveis de resistência vascular sistêmica foram de 3468, com desvio padrão de 1441 dyn.s $/ \mathrm{cm}^{5}$, para o repouso; e 2719 com desvio padrão de 1446 dyn.s/cm ${ }^{5}$, para o exercício.

A comparação dos valores da resistência vascular sistêmica entre os dois grupos (figura 7) demonstrou níveis mais elevados de resistência vascular sistêmica nos pacientes do grupo A. Esse comportamento foi verificado, no modo ventricular (WI), durante o repouso $(p<0,01)$ e o exercício $(p<0,01)$, assim como no modo atrioventricular universal(DDD), durante o repouso $(p<0,001)$ e o exercício $(p<0,001)$.(tabela VI)

Os níveis de resistência vascular sistêmica apresentados pelos pacientes do grupo A também foram mais elevados, quando comparados com valores médios encontrados para pacientes portadores de insuficiência cardíaca congestiva de CF semelhante (I e II), de outras etiologias, enquanto os pacientes do grupo B apresentaram valores de resistência vascular sistêmica no limite superior da normalidade. Paralelamente, os pacientes do grupo B apresentaram uma melhor adaptação da póscarga ao exercício, enquanto a dos pacientes do grupo A foi menos adequada, particularmente com o modo DDD. 


\subsection{Função ventricular direita}

O desempenho do ventrículo direito tanto pode refletir a função miocárdica dessa câmara cardíaca, como também, passivamente, as condições do ventrículo esquerdo ou da circulação pulmonar. Considera-se que a disfunção passiva do ventrículo direito, devida à hipertensão arterial pulmonar, seja resultante da transmissão retrógrada da elevação da pressão média do capilar pulmonar e da pressão diastólica final do ventrículo esquerdo. (FRANCIOSA et al., 1985.)

KORR et al., 1982; MORRISON et al., 1983; BAKER et al., 1984; LAGE et al., 1984, em estudos realizados, demonstraram que o desempenho do ventrículo direito é mais dependente da pós-carga do que da própria contratilidade ou da pré-carga, fato que sugere ser a resistência vascular pulmonar o maior determinante da função do ventrículo direito.

a) GRUPO A

Todos os pacientes do grupo A, na condição WI-R, encontravam-se no subgrupo III. Durante o exercício (condição VVI-E) encontramos dois pacientes no subgrupo I, um no subgrupo II, um no subgrupo III e um paciente no subgrupo IV. (figura 3a.)

O comportamento médio dos pacientes demonstra índice cardíaco de repouso de 1,8 $\mathrm{I} / \mathrm{min} \cdot \mathrm{m}^{2}$ e pressão média do átrio direito de $4,6 \mathrm{mmHg}$. Com a realização do exercício, o índice cardíaco encontrado foi de $2,8 \mathrm{l} / \mathrm{min} \cdot \mathrm{m}^{2}$ e a pressão média do átrio direito, de 8,0 mmHg. (tabela IV.)

Na condição DDD-R, todos os pacientes do grupo A também se apresentavam no subgrupo III. Durante o exercício (DDD-E), um paciente passou para o subgrupo I, dois para o subgrupo II, permanecendo os dois restantes no subgrupo III. (figura 3b.) 
O comportamento médio do índice cardíaco foi de $2,0 \mathrm{l} / \mathrm{min} \cdot \mathrm{m}^{2}$ e a pressão média do átrio direito de 2,4 $\mathrm{mmHg}$ no repouso, sendo o índice cardíaco de 2,8 $\mathrm{l} / \mathrm{min} \cdot \mathrm{m}^{2}$ e a pressão média do átrio direito de 7,2 mmHg durante o exercício. (tabela IV.)

b) GRUPO B

No grupo B, o comportamento da função ventricular direita, à condição WI-R, mostrou três pacientes no subgrupo I e dois pacientes no subgrupo III. Com a realização do exercício (DDD-E), foram encontrados dois pacientes no subgrupo I e três no subgrupo II. (figura 3a.)

O índice cardíaco médio foi de $3,1 \mathrm{l} / \mathrm{min} \cdot \mathrm{m}^{2}$ e a pressão média do átrio direito de $5,0 \mathrm{mmHg}$, durante o repouso, e o índice cardíaco de $4,9 \mathrm{l} / \mathrm{min} \cdot \mathrm{m}^{2}$ e a pressão média do átrio direito de $8,6 \mathrm{mmHg}$, durante o exercício. (tabela V.)

Durante a condição DDD-R, três pacientes estavam no subgrupo I e dois no subgrupo III. Com a realização do exercício (DDD-E), foram observados três pacientes no subgrupo I e dois no subgrupo II. (figura 3b.)

O índice cardíaco médio foi de $3,6 \mathrm{l} / \mathrm{min} \cdot \mathrm{m}^{2}$ e a pressão média do átrio direito de 2,8 $\mathrm{mmHg}$, no repouso, passando para índice cardíaco de 6,6 l/min. $\mathrm{m}^{2}$ e pressão média do átrio direito de $5,8 \mathrm{mmHg}$, durante o exercício. (tabela V.)

A observação das figuras 3a e 3b demonstra que o modo DDD proporcionou, em média, a melhor função ventricular direita, tanto em repouso, quanto durante o exercício, para os pacientes dos grupos A e B.

A análise da pressão média do átrio direito demonstrou que a mudança do modo VVI para o modo DDD proporcionou: no grupo A, queda de $47,8 \%$ da pressão média do átrio direito durante o repouso (NS), e queda de $10,0 \%$ ao exercício (NS) 
(tabela IV); e no grupo B, queda de $44,0 \%$ da pressão média do átrio direito durante 0 repouso $(p<0,02)$ e queda de 32,6 ao exercício $(p<0,02)$ (tabela V.)

A análise do comportamento da pressão média do átrio direito entre os grupos mostrou que não existia diferença significativa em nenhuma das condições estudadas (tabela VI). Esses dados confirmaram que não existiam na volemia diferenças que justificassem o comportamento diferente entre os dois grupos.

\subsection{Resistência arteriolar pulmonar}

Tem sido demonstrada relação inversamente proporcional entre a resistência vascular pulmonar e a fração de ejeção do ventrículo direito em indivíduos normais, avaliados em posição supina, nas condições repouso e exercício (MORRISON et al., 1982). Esses e outros autores observaram redução da resistência vascular pulmonar com o exercício, fato que significa uma diminuição da pós-carga do ventrículo direito com a conseqüente adequação do desempenho do ventrículo direito em condições normais. (EKELUND, 1966; EKELUND e HOLMGREN, 1967; HARRIS e HEATH, 1977; MORRISON et al., 1982.; BUGNI, 1984.)

a) GRUPO A

No grupo A, na condição VVI-R, a resistência arteriolar pulmonar calculada foi de 315,5 dyn.s $/ \mathrm{cm}^{5}$, e na condição VVI-E foi 236,7 dyn.s $/ \mathrm{cm}^{5}$ (tabela IV), representando queda de $25,0 \%$ (tabela III.)

Na condição DDD-R, a resistência arteriolar pulmonar foi de 240,4 dyn.s $/ \mathrm{cm}^{5}$, e na condição DDD-E, foi de 222,3 dyn.s $/ \mathrm{cm}^{5}$ (tabela IV), representando queda de $7,5 \%$ (tabela III.) 
b) GRUPO B

Os pacientes do, grupo B, na condição VVI-R, apresentaram resistência arteriolar pulmonar de 131,9 dyn.s/cm ${ }^{5}$, e durante o exercício (WI-E), de 103,0 dyn.s/cm ${ }^{5}$ (tabela V), representando queda de $21,9 \%$ (tabela III.)

Na condição DDD-R, a resistência arteriolar pulmonar foi de 118,0 dyn.s $/ \mathrm{cm}^{5}$ e, ao exercício (DDD-E), de 101,9 dyn.s/cm $\mathrm{cm}^{5}$ (tabela V), representando queda de 13,6\% (tabela III.)

LAGE, 1986, encontrou para pacientes portadores de insuficiência cardíaca congestiva de classes funcionais I e II, resistência arteriolar pulmonar de 205,4 com desvio padrão de 127,8 dyn.s $/ \mathrm{cm}^{5}$, para a condição repouso, e de 148,3 com desvio padrão de 103,1 dyn.s/cm5 , na condição carga máxima.

A análise da resistência arteriolar pulmonar de nossos pacientes, com a mudança do modo de estimulação WI para DDD, demonstrou que: no grupo A, durante o repouso, ocorreu queda de $23,8 \%$ (NS) e, durante o exercício, queda de apenas 6,1\% (NS) (tabela IV); no grupo B, durante o repouso, queda de 10,5\% (NS) e, durante o exercício, queda de apenas $1,1 \%$ (NS) (tabela V).

A observação da figura 8 demonstrou o comportamento da resistência arteriolar pulmonar entre os grupos A e B. Verificou-se que, no grupo A, os níveis da resistência arteriolar pulmonar são mais elevados em todas as condições estudadas. A análise estatística demonstrou significância deste comportamento em todas as condições estudadas. (tabela VI.) 


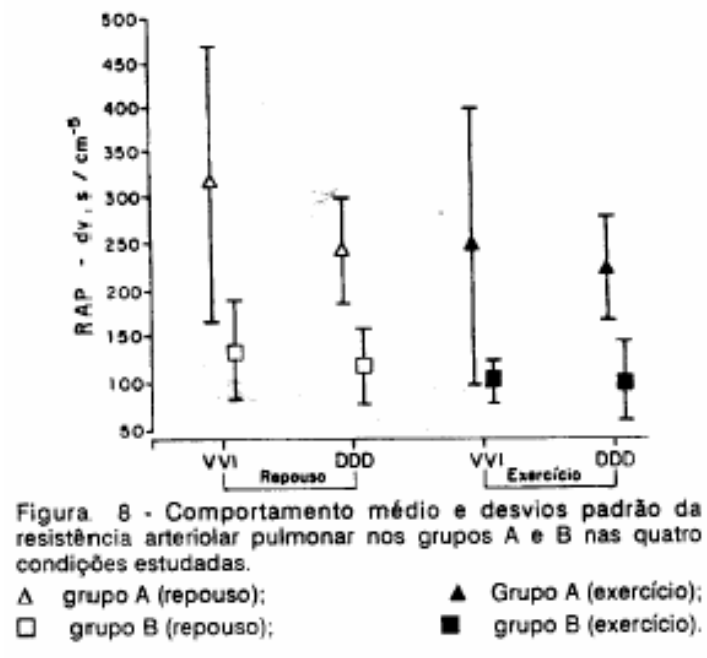

O comportamento satisfatório da função ventricular direita, tanto dos pacientes do grupo A quanto dos pacientes do grupo B; a queda da resistência arteriolar pulmonar durante o exercício em ambos os grupos de pacientes; e os níveis médios de pressão média do capilar pulmonar dentro de limites normais, sugerem que os níveis mais elevados de resistência arteriolar pulmonar, no grupo $A$, não foram devidos à falência ventricular esquerda, mas sim à existência de fatores autonômicos e humorais envolvidos na elevação dos níveis de resistência arteriolar pulmonar desses pacientes.

\section{Estudo do consumo periférico de oxigênio}

O metabolismo do oxigênio tem papel fundamental como mecanismo compensatório ao baixo desempenho hemodinâmico em portadores de insuficiência cardíaca congestiva. (BUGNI, 1984; FRANCIOSA, 1984; WEBER et al, 1984; LAGE et al., 1985; WEBER \& JANICKI, 1985a)

BUGNI, 1984; KANAREK \& HAND, 1984; WEBER \& JANICKI,1985b, demonstraram a importância da extração de oxigênio nos portadores de insuficiência cardíaca. Como o conteúdo arterial de oxigênio é semelhante nos portadores de função 
pulmonar normal, e o menor índice cardíaco é compensado por uma maior extração periférica de oxigênio $\left(\mathrm{EO}_{2}\right)$, como mecanismo compensatório na manutenção de taxas adequadas do índice de consumo de oxigênio $\left(\mathrm{IVO}_{2}\right)$, ocorre uma maior diferença arteriovenosa de oxigênio $\left(\mathrm{DavO}_{2}\right)$. KANAREK \& HAND, 1984, demonstraram que existe um limite a partir do qual inicia-se o metabolismo anaeróbico. SNELL \& MITCHELL, 1984; WEBER et al., 1984a; WEBER \& JANICKI, 1985b demonstraram que este limite pode ocorrer antes do início do esforço máximo.

NORDLANDER et al., 1987, estudaram o consumo de oxigênio periférico e miocárdico em oito portadores de bloqueio atrioventricular avançado e marcapasso atrioventricular universal, nas condições repouso, pernas elevadas, esforço padronizado de $30 \mathrm{~W}$ e esforço padronizado de $60 \mathrm{~W}$. Verificaram variação percentual da $\mathrm{DavO}_{2}$, durante o modo $\mathrm{WI}$, de $98,3 \%$, com a mudança da condição repouso para exercício padronizado com $30 \mathrm{~W}$; e de $128,8 \%$, com a mudança da condição repouso para esforço padronizado com 60 W. Com o modo DDD, a variação percentual, a partir do repouso, foi de $90,6 \%$ e $118,9 \%$, respectivamente, para esforço padronizado de $30 \mathrm{~W}$ e esforço padronizado de $60 \mathrm{~W}$.

Durante o repouso, a mudança do modo WI para DDD foi acompanhada de uma diminuição da diferença arteriovenosa de oxigênio de 10,2\%, enquanto que, durante o exercício, a mudança de modo de estimulação WI para DDD propiciou diminuição da $\mathrm{DavO}_{2}$ de $13,7 \%$ e $14,1 \%$, respectivamente, para esforço de 30 e $60 \mathrm{~W}$.

Neste mesmo trabalho, NORDLANDER et al., 1987, demonstraram que o consumo miocárdico de oxigênio durante exercício moderado foi semelhante para os modos WI e DDD, para uma dada condição, independentemente da freqüência cardíaca e do índice cardíaco atingidos. Concluem que o modo atrioventricular oferece maior 
débito cardíaco que o modo ventricular, com consumo miocárdico de oxigênio semelhante.

Grupo A

No grupo A, com o modo WI, verifica-se, durante o repouso (WI-R), $\mathrm{DavO}_{2}$ de 5,4 vol.\%, $\mathrm{EO}_{2}$ de 0,27 e $\mathrm{IVO}_{2}$ de $93,4 \mathrm{ml} / \mathrm{min} \cdot \mathrm{m}^{2}$. Com a realização do exercício (VVI-E), verifica-se $\mathrm{DavO}_{2}$ de 10,9 vol.\%, $\mathrm{EO}_{2}$ de 0,54 e $\mathrm{IVO}_{2}$ de $298,6 \mathrm{ml} / \mathrm{min} . \mathrm{m}^{2}$ (tabela IX), representando aumentos da $\mathrm{DavO}_{2}$ de 102,7\% $(p<0,001)$, da $\mathrm{EO}_{2}$ de $101,2 \%(p<0,001)$ e do $\mathrm{IVO}_{2}$ de $219,7 \%(p<0,01)$ (tabela VIII.)

No grupo $A$, com o modo DDD, verifica-se durante o repouso (DDD-R), $\mathrm{DavO}_{2}$ de 4,6 vol. \%, $\mathrm{EO}_{2}$ de 0,23 e $\mathrm{IVO}_{2}$ de $88,9 \mathrm{ml} / \mathrm{min} \cdot \mathrm{m}^{2}$. Com a realização do exercício (DDDE), verifica-se $\mathrm{DavO}_{2}$ de 10,7 vol. \%, $\mathrm{EO}_{2}$ de 0,53 e $\mathrm{IVO}_{2}$ de 292,8 $\mathrm{ml} / \mathrm{min} \cdot \mathrm{m}^{2}$ (tabela IX), representando aumentos da $\mathrm{DavO}_{2}$ de 133,1\% (p<0,001), da $\mathrm{EO}_{2}$ de 129,9\% $(p<0,001)$ e do $\mathrm{IVO}_{2}$ de $229,3 \%(p<0,01)$ (tabela VIII.)

Grupo B

No grupo B, com o modo VVI, verifica-se, durante o repouso (WI-R), $\mathrm{DavO}_{2}$ de 4,5 vol.\%, $\mathrm{EO}_{2}$ de 0,23 e $\mathrm{IVO}_{2}$ de $115,5 \mathrm{ml} / \mathrm{min} \cdot \mathrm{m}^{2}$. Com a realização do exercício (WI-E), verifica-se $\mathrm{DavO}_{2}$ de 7,1 vol. $\%, \mathrm{EO}_{2}$ de 0,33 e $\mathrm{IVO}_{2}$ de $307,5 \mathrm{ml} / \mathrm{min} \cdot \mathrm{m}^{2}$ (tabela $\mathrm{X}$ ), representando aumentos da $\mathrm{DavO}_{2}$ de $56,7 \%$ (NS), da $\mathrm{EO}_{2}$ de $43,7 \%$ (NS) e do $\mathrm{IVO}_{2}$ de $166,3 \%$ (NS) (tabela VIII.)

No grupo $B$, com o modo DDD, verifica-se, durante o repouso (DDD-R), $\mathrm{DavO}_{2}$ de 4,8 vol. \%, $\mathrm{EO}_{2}$ de 0,23 e $\mathrm{IVO}_{2}$ de $136,3 \mathrm{ml} / \mathrm{min} \cdot \mathrm{m}^{2}$. Com a realização do exercício (DDDE), verifica-se $\mathrm{DavO}_{2}$ de 5,8 vol.\%, $\mathrm{EO}_{2}$ de 0,31 e $\mathrm{IVO}_{2}$ de $367,5 \mathrm{ml} / \mathrm{min} \cdot \mathrm{m}^{2}$ (tabela X), representando aumentos da $\mathrm{DavO}_{2}$ de $21,4 \%$ (NS), da $\mathrm{EO}_{2}$ de $34,4 \%$ (NS) e do $\mathrm{IVO}_{2}$ de 169,7\% (NS) (tabela VIII.) 
A mudança de modo de estimulação WI para DDD acarretou no grupo $A$, ao repouso, queda da $\mathrm{DavO}_{2}$ de $14,3 \%$, da $\mathrm{EO}_{2}$ de $14,3 \%$ e do $\mathrm{IVO}_{2}$ de 4,8\% e, ao exercício, queda da $\mathrm{DavO}_{2}$ de $1,4 \%$, da $\mathrm{EO}_{2}$ de $2,0 \%$ e do $\mathrm{IVO}_{2}$ de $1,9 \%$ (tabela IX). No grupo $\mathrm{B}$, ao repouso, acarretou aumento da $\mathrm{DavO}_{2}$ de $7,0 \%$, da $\mathrm{EO}_{2}$ de $1,1 \%$ e do $\mathrm{IVO}_{2}$ de $18,0 \%$, e, ao exercício, diminuição da $\mathrm{DavO}_{2}$ de $17,1 \%$, da $\mathrm{EO}_{2}$ de $5,4 \%$ e aumento do $\mathrm{IVO}_{2}$ de 19,5\% (tabela X). Não houve diferença estatística entre esses valores.

A comparação entre os grupos A e B demonstrou diferença significativa entre o comportamento da $\mathrm{DavO}_{2}$ na condição DDD-E; e da $\mathrm{EO}_{2}$ nas condições WI-E e DDD-E (tabela XI.)

A análise dos parâmetros do metabolismo do oxigênio demonstrou que, durante o repouso, o desempenho cardiocirculatório dos pacientes de ambos os grupos foi semelhante. Foi notada, no entanto, uma diferença muito importante de comportamento durante o exercício. Os pacientes do grupo A apresentaram elevada diferença arteriovenosa de oxigênio, decorrente da alta taxa de extração deste, como mecanismo de compensação do baixo índice cardíaco, tanto com o modo WI quanto com o modo DDD. Não atingiram, contudo, a despeito da maior extração de oxigênio, os mesmos valores de $\mathrm{IVO}_{2}$ obtidos no grupo $\mathrm{B}$. Os pacientes do grupo $\mathrm{B}$ apresentaram, com o modo $\mathrm{VVI}, \mathrm{IVO}_{2}$ semelhante ao dos pacientes do grupo $\mathrm{A}$, embora esses valores tenham sido obtidos com menores taxas de extração de oxigênio. Com o modo DDD, ocorreu uma grande elevação do $\mathrm{IVO}_{2}$ com baixos índices de extração de oxigênio.

Tais dados demonstraram a importância do exercício na avaliação desses pacientes portadores de insuficiência cardíaca subclínica. Sugerem que a utilização de teste de esforço isolado, sem a monitorização hemodinâmica e metabólica, poderia levar a resultados falsos, dado que pacientes com índices cardíacos reduzidos podem apresentar o mesmo nível de $\mathrm{IVO}_{2}$ que os pacientes com índices cardíacos mais 
elevados, desde que ocorra um aumento compensatório da $\mathrm{EO}_{2}$, ou mesmo o metabolismo anaeróbico (HOUTCHENS \& WESTERSKOW, 1984; KANAREK \& HAND, 1984)

\section{Análise da evolução clínica dos pacientes}

A sobrevida de portadores de miocardiopatia chagásica e marcapasso cardíaco artificial tem sido relatada apenas para os portadores de marcapasso ventricular, não existindo referências, na literatura, de seguimento tardio de portadores de marcapassos atrioventriculares.

GAUCH et al., 1982, estudando a evolução de 884 pacientes portadores de cardiopatia chagásica com marcapasso ventricular, demonstraram o comportamento da sobrevida daqueles pacientes, quando considerada a existência de insuficiência cardíaca congestiva, ou o tamanho da silhueta cardíaca ao estudo radiológico do tórax. Verificaram que a sobrevida geral destes pacientes é de $87 \%$, ao final do primeiro ano, de $71 \%$, após cinco anos de seguimento e de 66\%, após dez anos. Quando foi considerada a existência ou não de insuficiência cardíaca congestiva prévia, relataram os seguintes resultados: sobrevida de $66 \%, 46 \%$ e $40 \%$ após, respectivamente, um, cinco e dez anos de seguimento, quando essa deficiência estava presente; e de $95 \%, 84 \%$ e $81 \%$, para os mesmos tempos de seguimento, quando ausente.

Mediante observação do critério radiológico, verificaram que a sobrevida dos pacientes era, respectivamente, para um e cinco anos de seguimento: $100 \%$ e $83 \%$ quando a silhueta cardíaca era normal; $93 \%$ e $87 \%$ quando levemente aumentada; $94 \%$ e $83 \%$ quando moderadamente aumentada; $79 \%$ e $53 \%$ quando importantemente aumentada; e $48 \%$ e $19 \%$ quando severamente aumentada.

KRISTENSSON et al., 1985b, observaram o comportamento de 44 pacientes não chagásicos, portadores de bloqueios avançados da condução atrioventricular, com tempo 
de seguimento médio de 35 meses, em estudo duplo cego. Relataram ocorrência significativamente menor de sintomas subjetivos com o modo atrioventricular, assim como maior preferência dos pacientes por esse modo de estimulação. Verificaram que: com o modo $\mathrm{WI}, 10$ pacientes consideravam-se sem restrições; 22, com algumas restrições; 10, restritos; e dois, muito restritos. Com o modo DDD, 19 pacientes consideravam-se sem restrições; 23, com algumas restrições; dois, restritos; e nenhum muito restrito.

Todos os pacientes do presente estudo foram mantidos em modo DDD, após o estudo hemodinâmico, num período de seguimento maior que cinco anos para todos os pacientes, com exceção de três, que evoluíram para óbito (após 31,8; 53,3 e 62,4 meses do implante do marcapasso). O percentual de sobrevida de $70 \%$, ao final de cinco anos, situa a evolução dos pacientes do presente estudo na mesma faixa da casuística geral relatada por $\mathrm{GAUCH}$ et al., 1982. Pelo critério radiológico, seria de se esperar para nossos pacientes sobrevida maior que $80 \%$ ao final dos cinco anos.

A ocorrência de três óbitos entre pacientes do grupo A e em nenhum paciente do grupo B, a maior necessidade de medicamentos nos pacientes do grupo A, e o maior número de pacientes em classe funcional $\mathrm{I}$, no grupo $\mathrm{B}$, ressaltaram a confiabilidade dos resultados do estudo hemodinâmico e seu valor na predição da evolução clínica e adaptação ao modo atrioventricular. 


\section{V - CONCLUSÕES}

Tendo em vista os resultados obtidos, conclui-se que:

1. Foram identificados dois grupos de pacientes ( $A$ e $B$ ), que se diferenciaram pelo comportamento do débito cardíaco e da resistência vascular sistêmica, nas condições do presente trabalho.

No grupo A, a mudança do modo de estimulação ventricular para atrioventricular, durante o exercício, não propiciou aumento do índice cardíaco, a despeito da elevação da freqüência cardíaca, observando-se elevação da resistência vascular sistêmica e diminuição do índice sistólico.

No grupo B, a melhora do desempenho hemodinâmico, com a mudança do modo de estimulação ventricular para atrioventricular, durante o exercício, caracterizada pelo aumento do índice cardíaco, deveu-se ao aumento da freqüência cardíaca, manutenção do índice sistólico e diminuição da resistência vascular periférica.

2. Níveis anormalmente elevados de resistência vascular sistêmica, em pacientes chagásicos com bloqueios avançados da condução atrioventricular, têm valor na predição de que a estimulação atrioventricular universal não trará melhora do desempenho hemodinâmico durante o esforço quando comparada à estimulação ventricular. 


\section{VI - REFERÊNCIAS BIBLIOGRÁFICAS}

ALDINI, G. General views on the application of galvanism to medical purposes: principally in cases of suspended animation. London, J. Callow, 96,1819 apud KARLÖF, 1974.

ALICANDRI, C.; FOUAD, F.M.; TARAZI, R.C.; CASTLE, L.; MORANT, V. Three cases of hypotension and syncope with ventricular pacing. Possible role of atrial reflexes. Am. J.Cardiol., 42:137-142, 1978.

ALT, E.; VOLKER, R.; HOGL., B.; MacCARTER, D First clinical results with a new temperature-controlled rate-reponsive pacemaker. Comparison of Activitrax and Nova MR pacemakers with WI/AAI pacing. Circulation, 78(5-pt 2):III 116-124, 1988.

ARDITO, R.V.; GRECO, O.T.; BRAMBATTI, J.C.; FEDOZZI, N.M.; LORGA, A.M.;

BRAILE, D.M. Comparation of the DDD stimulation related to the VVI in Chagas' disease patients and in non Chagas' disease patients (multicentric studies). PACE, 10(3-II):636, 1987.

BAKER, B.J.; WILEN, M.M.; BOYD, C.M.; DINH, H.; FRANCIOSA, J.A. Relation of right ventricular ejection fraction to exercise capacity in chronic left ventricular failure. Am. J. Cardiol, 54:596-599, 1984.

BARRATT-BOYES, B.G. \& WOOD, E.H. Cardiac output and related measurements and pressure values in the right heart associated vessels, together with analysis of the hemodynamic response to the inhalation of high oxigen mixtures in healthy subjects. $J$. Lab. Clin. Med., 51:72-90, 1958.

BATSON, H.C. An introduction to statistics in the medical sciences. 1.ed. Chicago, University of Illinois College of Medicine, 1956. 
BENCHIMOL, A.; ELLIS, J.G.; DIMOND, E.G. Hemodynamic consequences of atrial and ventricular pacing in patients with normal and abnormal hearts. Am. J. Med., 39:911-922, 1965.

BERNSTEIN, A.D. Modifications of the NASPE Mode Code Committee. PACE, 10:340, 1987.

BERNSTEIN, A.D.; BROWNLEE, R.R.; FLETCHER, R.; GOLD, R.D.; SMITH, N.P.D.; SPIELMAN, S.R. Report of the NASPE - Mode Committee. PACE, 7:395-402, 1984.

BEVEGARD, S.; HOLMGREN, A.; JONSSON, B. Circulatory studies in well trained athletes at rest and during heavy exercise, with special reference to stroke volume and the influence of body position. Acta Physiol. Scand., 57:26-50, 1963.

BLACKMON, J.R.; ROWELL, L.B.; KENNEDY,J.W.; TWISS, R.D.; CONN, R.D. Physiological significance of maximal oxygen intake in "pure" mitral stenosis. Circulation, 36:497-510, 1967.

BRAUNWALD, E. Assessment of cardiac function.In: Heart disease. A textbook of cardiovascular medicine. 3.ed. Philadelphia, W.B. Saunders, 1988. p.449-470.

BUGGE-ASPERHEIM, B. \& KILL, F. Cardiac response to increased aortic pressure: changes in output and left ventricular pressure pattern at various levels of inotropy. Scand. J. Clin. Lab. Invest., 24:345-360, 1969.

BUGNI, W.J. Invasive exercise testing. In: GLASSER, S.P., ed. Clinical testing cardiology., Philadelphia, W. B. Saunders, 1984. p.467-478.

CALLAGHAN, J.C. \& BIGELOW, W.G. An electrical artificial pacemaker for standstill of the heart. Ann. Surg., 134:8-17, 1951. 
CHAMBERLAIN, D.A.; LEINBACH, R.C.; VASSAUX, C.E.; KASTOR, J.A.; DeSANCTIS, R.W.; SANDERS, C.A. Sequential atrioventricular pacing in heart block complicating acute myocardial infarction. N. Engl. J. Med., 282:577-587, 1970.

CHAPMAN, C.B.; FISHER, J.N.; SPROULE, B. Behavior of stroke volume at rest and during exercise in human beings. J. Clin. Invest., 39:1208-1213, 1960.

CHARDACK, W.M.; GAGE, A.A.; GREATBATCH, W. A transistorized, self-contained, implantable pacemaker for the long-term correction of complete heart block. Surgery, 48:643-654, 1960 .

CLANCY, R.L.; GRAHAM., T.P.Jr.; ROSS, J.Jr.; SONNENBLICK, E.H.; BRAUNWALD, E. Influence of aortic pressure-induced homeometric autoregulation on myocardial performance Am. J. Physiol., 214:1186-1192, 1968.

CLEMENT,D.L.\&SHEPHERD,J.T. Regulation of peripheral circulation during muscular exercise. In: SONNENBLICK, E.H. \& LESCH, M., ed. Exercise and heart disease. New York, Grune \& Stratton, 1977. p.77-85.

COHN, J.N. Vasodilator therapy for the heart failure: the influence of impedance on left ventricular performance. Circulation, 48:5-8, 1973.

COSTA, R.; MOREIRA, L.F.P.; PÊGO-FERNANDES, P.M.; LIMA, E.C.; STOLF, N.A.G. PILEGGI, F.; JATENE, A.D.; ARMELIN, E. Efeitos hemodinâmicos da estimulação ventricular e atrioventricular seqüencial. Arq. Bras. Cardiol., 43:41-45, 1984a.

COSTA, R.; MOREIRA, L.F.P.; PÊGO-FERNANDES, P.M.; SCALABRINI NETO, A.; SOSA, E.; PILEGGI, F.; STOLF, N.A.G.; JATENE, A.D. Importância da estimulação atrioventricular na hipersensibilidade do seio carotídeo. Arq. Bras.Cardiol., 43(suppl.1):12, 1984b. 
COSTA, R.; MOREIRA, L.F.P.; RATI, M.; SCALABRINI NETO, A.; STOLF, N.A.G.; JATENE, A.D. Hemodynamic effects of atrial synchronous ventricular inhibited pacing in patients with Chagas' cardiomyopathy. In: PEREZ-GOMES, F., ed. Cardiac pacing; electrophysiogy; tachyarrhythmias. Madrid, Editorial Grouz, 1985a. p. 513-518.

COSTA, R.; MOREIRA, L.F.P.; PÊGO-FERNANDES, P.M.; MARTINELLI FILHO, M.; STOLF, N.A.G.; PILEGGI, F.; JATENE, A.D. Importância da manutenção do sincronismo atrioventricular no tratamento da doença do nó sinusal. Arq. Bras. Cardiol.,45:91-95, 1985b.

COSTA, R.; MOREIRA, L.F.P.; MARTINELLI FILHO, M.; PÊGO-FERNANDES, P.M.; STOLF, N.A.G.; VERGINELLI, G.; JATENE, A.D. Marcapasso atrioventricular universal. Critérios de indicação e benefícios. Arq. Bras.Cardiol.,46:225-230, 1986.

CRITERIA COMMITTEE OF THE NEW YORK HEART ASSOCIATION. Nomenclatures and criteria for diagnosis of diseases of the heart and great vessels. 6.ed. Boston, Little Brown, 1964, p. 1-23.

CURTIS, J.J.; MADIGAN, N.P.; WHITING, R.B.; MUELLER, K.J.; PEZZELLA, A.T.; WALLS, J. T.; HEINEMANN, F.M. Clinical experience with permanent atrioventricular sequential pacing. Ann. Thorac. Surg., 32:179-187, 1981.

DODINOT, B. \& KUBLER, L. Dual chamber pacemaker induced arrhythmias: pathology of the"physiologic". Stimucoeur Medical, 10:220-235, 1982.

DREIFUS, L.S.; MITAMURA, H.; RHAUDA, A.;VAIL, S.; MICHELSON, E.L.; BERKOVITS, B.V.;PETERSON,D.D.;FIGUEROA,W.F. Effects of AV sequential versus asynchronous AV pacing on pulmonary hemodynamics. PACE, 9:171-177, 1986. 
EKELUND, L.G. Circulatoryand respiratory adaptation during prolonged exercise in the supine position. Acta Physiol. Scand., 68:382-396, 1966.

EKELUND, L.G. \& HOLMGREN, A. Central hemodynamics during exercise. Circo Res.,20/21 (suppl.1):133-143, 1967.

EL GAMAL, M.I.H. \&VAN GELDER, L.M. Chronic ventricular pacing with ventriculo-atrial conduction versus atrial pacing in three patients with symptomatic sinus bradycardia. PACE,4:100-105, 1981.

ELMQUIST, R. \& SENNING, A. An implantable pacemaker for the heart. Medical Electronics Indo Int. Conf. Paris, 1959 apud KARLÖF,1974.

ESPINOSA, R.; CARRASCO, A.; BELANDRIA, F.; FUENMAYOR, A.M.; MOLINA, C.; GONZALES, R.; MARTINEZ, O. Life expectancy anlysis in patients with Chagas' disease: prognosis after one decade (1973-1983). Int. J. Cardiol., 8:45-56, 1985.

FANANAPAZIR, L.; SRINIVAS,V.; BENNETT, D.H.Comparison of resting hemodynamic indices and exercise performance during atrial synchronized and asynchronous ventricular pacing. PACE, 6:202-209, 1983.

FETTER, J.; BENDITT, D.G.; MIANULLI, M. Usefulness of transcutaneous triggering of conventional implanted pulse generators by an activity-sensing pacemaker for predicting effectiveness of rate response pacing. Am. J. Cardiol.,62:901-905, 1988.

FORD, L.E. Effect of afterload reduction on myocardial energetics. Circ. Res., 46:161166, 1980.

FORICHON, E. Contribution aux estimations de morbidite dans la maladie de Chagas. Rev Pathol. Trop., 4:57-78, 1975. 
FRANCIOSA, J.A. Exercise testing in chronic congestive heart failure. Am. J.Cardiol., 53:1447-1450, 1984.

FRANCIOSA, J.A.; PARK, M.; LEVINE, T .B. Lack of correlation between exercise capacity and indexes of resting left ventricular performance in heart failure. Am. J. Cardiol., 47:33-39, 1981.

FRANCIOSA, J.A.; BAKER, B.J.; SETH, L. Pulmonary versus systemic hemodynamics in determining exercise capacity of patients with chronic left ventricular failure. Am. Heart J., 110:807-813, 1985.

FURMAN, S. Dual chamber pacemakers: Upper rate behavior. PACE, 8:197-214, 1985.

FURMAN, S. \& ROBINSON, G. The use of an intracardiac pacemaker in the correction of total heart block. Surg. Forum, 9:245, 1958 apud KARLÖF,1974.

FURMAN, S. \& FISHER, J.D. Endless loop tachycardia in an A-V universal (DDD) pacemaker. PACE, 5:486-489, 1982.

FURNIVAL, C.M.; LINDEN, R.J.; SNOW, H.M. Inotropic changes in the left ventricle: The effect of changes in heart rate, aortic pressure and end-diastolic pressure. $J$. Physiol.(Lond.), 211 :359-387, 1970.

GAUCH, P.R.A.; KORMANN, D.S.; PACHÓN, J.C.; KORMANN, S.J.; NEVES, R.C.; ALBORNOZ, R.N.; GALVÃO FILHO, S.S.; MELO, C.S.; MAGALHÃES, H.M.; JATENE, A.D. Curva de sobrevida atuarial de pacientes portadores de miocardiopatia chagásica crônica tratados com marcapasso cardíaco. Arq. Bras. Cardiol., 39(suppl.1):186, 1982.

GELBERG, H.J.; RUBIN, S.A.; PORTS, T.A.; BRUNDAGE, B.H.; PARMLEY, W.W.; CHATTERJEE, K. Detection of left ventricular functional reserve by supine exercise 
hemodynamics in patients with severe, chronic heart failure. Am. J. Cardiol., 44:10621067, 1979.

GILLETTE, P.C.; ZINNER, A.; KRATZ, J.; SHANNON,C.;WAMPLER,D.;OTT,D. Atrialtracking (synchronous) pacing in a pediatric and young adult population. J. Am. Colto Cardiol., 9:811-815, 1987.

GRECO, O.T.; LORGA, A.M.; ARDITO, R.V.; GARZON, S.A.C.; JACOB, J.L.B.; AYOUB, J.C.A.; NICOLAU, J.C.; ANSELMO, E.F.; BRAILE, D.M. Marcapasso cardíaco multiprogramável em pacientes chagásicos. Arq. Bras. Cardiol., 43(suppl.1):19, 1984.

GROSSMAN, W. Blood flow measurement: the cardiac output.In: GROSSMAN, W., ed. Cardiac catheterization and angiography. 2.ed. Philadelphia, Lea \& Lebiger, 1980a. p. 89102.

GROSSMAN, W. Hemodynamic principies: pressure measurements. In: GROSSMAN, W., ed. Cardiac catheterization and angiography. 2.ed. Philadelphia, Lea \& Lebiger, 1980b. p. 103-115.

GUYTON, A.C. The relationship of cardiac output and arterial pressure control. Circulation, 64:1079-1088, 1981.

HARRIS, P. \& HEA TH, D. Unexplained pulmonary hypertension. In: HARRIS, P. \& HEATH, D., ed. The human pulmonary circulation. 2ed. New York, Livingstone Churchill, 1977. p. $418-440$.

HAUSER, R.G.; WIMER, E.A.; TIMMIS, G.C.; GOR DON, S.; STALLER, B.; KLODNYCKY, M.; EISENHAUER, A.; GOREN, C.; MORAN, J.F.; DAVIS, A.A.; WALSH, R.; McDONOUGH, T.; LAWLESS, C.; WYNDHAM, C. Twelve years of clinical experience with lithium pulse generators. PACE, 9:1277-1281, 1986. 
HEDMAN, A. \& NORDLANDER, R. QT sensing rate responsive pacing compared to fixed rate ventricular inhibited pacing: a controlled clinical study. PACE, 12:374-385, 1989.

HETZEL, M.R.; GINKS, W.R.; PICKERSGILL, A.J.; LEATHAM, A. Value of pacing in cardiac failure associated with chronic atrioventricular block. Br. Heart J., 40:864-869, 1978.

HORWITZ, L.D.; ATKINS, J.M.; LESHIN, S.J. Role of Frank-Starling mechanism in exercise. Cir. Res., 31:868-873, 1972.

HOUTCHENS, B.A. \& WESTENSKOW, D.R. Oxygen consumption in septic shock: collective review. Circ. Shock, 13:361-384, 1984.

HUMEN, D.P.; KOSTUK, W.J.; KLEIN, G.J. Activity-sensing, rate responsive pacing: Improvement in myocardial performance with exercise. PACE, 8:52-59, 1985.

HYMAN, A. S. Resuscitation of the stopped heart by intracardlal therapy. Arch.Intern. Med., 50: 283-305, 1962.

JOHNSON, A.D.; LAIKEN, S.L.; ENGLER, R.L. Hemodynamic compromise associated with ventriculoatrial conduction following transvenous pacemaker placement. Am. J. Med., 65:75-79, 1978.

KANAREK, D. \& HAND, R.W. The response of cardiac and pulmonary disease to exercise testing. Clin. ChestMed., 5:181-187, 1984.

KAPPENBERGER, L.; GLOOR, H.O.; BABOTAI, I.; STEINBRUNN, W.; TURINA, M. Hemodynamic effects of atrial synchronization in acute and long-term ventricular pacing. PACE, 5:639-645, 1982. 
KARLÖF, I. Haemodynamic studies at rest and during exercise in patients treated with artificial pacemaker. Acta Med. Scand., 565(suppl.):1-24, 1974.

KENNY, R.A.; INGRAM, A.; MITSUOKA, T.; WALSH, K.; SUTTON, R. Optimum pacing mode for patients with angina pectoris. Br. Heart J., 56:463-468, 1986.

KORMANN, D.S.; ARAÚJO, H.C.; BEMBON, J.C.; FONTES, V.F.; MAGALHÃES, H.M.; JATENE, A.D. Marcapasso cardíaco de freqüência baixa em chagásicos com grande cardiomegalia. Arq. Bras. Cardiol., 28(suppl.2):302-303, 1975.

KORR, K.S.; GANDSMAN, E.J.; WINKLER, M.L.; SHULMAN, R.S.; BOUGH, E.W. Hemodynamic correlates of right ventricular ejection fraction measured with gated radionuclide angiography. Am. J. Cardiol., 49:71-77, 1982.

KRAMER, B.; MASSIE, B.; TOPIC, N. Hemodynamic differences between supine and upright exercise in patients with congestive heart failure. Circulation, 66:820-825, 1982.

KRISTENSSON, B.E.; KRUSE, I.; RYDÉN, L. Clinical problems in atrial synchronous ventricular inhibited pacing: A long-term follow- up of 54 patients. PACE, 7:693-701, 1984.

KRISTENSSON, B.E.; ARNMAN, K.; RYDÉN, L. The haemodynamic importance of atrioventricular synchrony and rate increase at rest and during exercise. Eur. Heart J., 6:773-778, 1985a.

KRISTENSSON, B.E.; ARNMAN, K.; SMEDGARD, P.; RYDÉN, L. Physiological versus single rate ventricular pacing: A double-blind cross-over study. PACE, 8:73-84, 1985b.

KRUSE, I. \& RYDÉN,L. Comparison of physical work capacity and systolic time intervals with ventricular inhibited and atrial synchronous ventricular inhibited pacing. Br. Heart J., 46:129-136, 1981. 
KRUSE, I.; ARNMAN, K.; CONRADSON, T.B.; RYDÉN, L. A comparison of acute and long-term hemodynamic effects of ventricular inhibited and atrial synchronous ventricular inhibited pacing. Circulation, 65:846-855, 1982.

LaFARGE, C.G.; MONROE, R.G.; GAMBLE, W.J.; ROSENTHAL, A.; HAMMOND, R.P. Left ventricular pressure and norepinephrine efflux from the innervated heart. Am. J. Physiol., 219:519-524, 1970.

LAGE, S.H.G. Avaliação da reserva cardiocirculatória na insuficiência cardíaca congestiva: estudo hemodinâmico e metabólico em repouso e em exercício. São Paulo, 1986. [Tese Doutoramento -Faculdade de Medicina da Universidade de São Paulo].

LAGE, S.H.G.; RAMIRES, J.A.F.; RATI, M.; BELLOTTI, G.; PILEGGI, F. Avaliação do comportamento hemodinâmico em repouso e exercício na insuficiência cardíaca. Arq. Bras. Cardiol., 43(suppl.1):41, 1984.

LAU, C.P. \& CAMM, A.J. Role of left ventricular function and doppler-derived variables in predicting hemodynamic benefits of rate responsive pacing. Am. J. Cardiol., 62:906-911, 1988.

LAU, C.P.; TSE, W.S.; CAMM, A.J. Clinical experience with Sensolog 703: a new activity sensing rate responsive pacemaker. PACE, 11:1444-1455, 1988.

LAU, C.P.; BUTROUS, G.S.; WARD, D.E.; CAMM, A.J. Comparison of exercise performance of six rate-adaptive right ventricular cardiac pacemakers. Am. J. Cardiol., 63:833-838, 1989.

LEINBACH, R.C.; CHAMBERLAIN, D.A.; KASTOR, J.A.; HARTHORNE, J.W.; SANDERS, C.A. A comparison of the hemodynamic effects of ventricular and sequential A-V pacing in patients with heart block. Am. Heart J., 78:502-508, 1969. 
LEWIS, M.E.; SUNG, R.J.; ALTER, B.R.; MYERBURG, R.J. Pacemaker-induced hypotension. Chest,79:354-355,1981.

LITTLE, R. Physiology of the heart and circulation. 2.ed. Chicago, Year Book Medical Publishers, 1981. p. 149-176.

MADIGAN, N.P.; FLAKER, G.C.; CURTIS, J.J.; REID, J.; MUELLER, K.J.; MURPHY, T.J. Carotid sinus hypersensitivity: beneficial effects of dual-chamber pacing. Am. J. Cardiol., 53:1034-1040, 1984.

MAHLER, F.; COVELL, J.W.; ROSS Jr., J. Systolic pressure-diameter relations in the normal conscious dog. Cardiovasc. Res., 9:447-455, 1975.

MAHMUD, R.; LEHMANN, M.; DENKER, S.; GILBERT, C.J.; AKHTAR, M. Atrioventricular sequential pacing: differential effect on retrograde conduction related to level of impulse collision. Circulation, 68:23-32, 1983.

MANGER, W.M. Neural regulation of the heart Adv. Cardiol., 30:30-73, 1982

MARIN-NETO, J.A.; MACIEL, B.C.; GALLO Jr., L.; JUNQUEIRA Jr., L.F.; AMORIM, D.S. Effect of parasympathetic impairment on the haemodynamic reponse to handgrip in Chagas' Heart disease. Br. Heart. J., 55:204-210, 1986.

MARTINELLI FILHO, M.; COSTA, R.; PEREIRA-BARRETTO, A.C.; RAMIRES, J.A.F.; RATI, M.; ESTEVES NETO, A.; ARTEAGA-FERNANDEZ, E.; MADY, C.; VERGINELLI, G.; PILEGGI, F. Comportamento hemodinâmico de portadores de miocardiopatia chagásica submetidos à estimulação elétrica artificial. Valor do emprego de digitálicos. Rev. Hosp. Clin. Fac. Med. São Paulo, 38:46-49, 1983. 
MARTINELLI FILHO, M.; COSTA, R.; MOREIRA, L.F.P.; SOSA, E.; PILEGGI, F.; BELLOTTI, G. Correlation between symptomatology and retrogradory conduction in sick sinus syndrome(SSS) and cardiac pacing. PACE, 8(3-II):A 61, 1985.

MARTINELLI FILHO, M.; COSTA, R.; YASBEK, P.;SOSA, E.A.; BELLOTTI, G.; PILEGGI, F. DDD $\times$ VVI stimulation in patients with chronic Chagas' disease. A comparative study through ergoespirometry and echocardiography. Clin. Prog.Electrophysiol. Pacing, 4 (suppl.):54, 1986.

MARTINELLI FILHO, M.; COSTA, R.; MOREIRA, L.F.P.; MAGLIO NETO, C.; LEE, J.H.; SCANNAVACA, M.; SOSA, E.A.; BELLOTTI, G.; PILEGGI, F. Arrhythmias associated with atrioventricular stimulation in chronic Chagas' disease. PACE, 10(3-11):'712, 1987.

MITSUOKA, T.; KENNY, R.A.; YEUNG, T.A.; CHAN, S.L.; PERRINS, J.E.; SUTTON, R. Benefits of dual chamber pacing in sick sinus syndrome. Br. Heart J., 60:338-347,1988.

MOREIRA, L.F.P.; COSTA, R.; PÊGO-FERNANDES, P.M.; MARTINELLI FILHO, M.; StOlF, N.A.G.; VERGINELlI, G.; PILEGGI, F.; JATENE, A.D. Determinação da condução retrógrada em pacientes chagásicos. Importante fator prognóstico nos implantes de marcapasso. Arq. Bras. Cardiol., 43(supl.1):17, 1984.

MOREIRA, L.F.P; COSTA, R.; PÊGO-FERNANDES, P.M., STOLF, N.A.G.; JATENE, A.D.; ARMELIN, E. Reevaluation of the role of atrial systole in the closure of atrioventricular valves. In: PEREZ-GOMES, F., ed. Cardiac pacing; electrophysiology; tachyarrhythmias. Madrid, Editorial Grouz, 1985. p. 554-560.

MOREIRA, L.F.P.; COSTA, R.; STOLF, N.A.G.; JATENE, A.D. Pacing rate increase as cause of syncope in a patient with severe cardiomyopathy. PACE, 12:1027-1029, 1989. 
MORRISON, D.; SORENSEN, S.; CALDWELL, J.; WRIGHT, L.; RITCHIE, J.; KENNEDY, J.W.; HAMILTON, G. The normal right ventricular response to supine exercise. Chest, 82:686-691, 1982.

MORRISON, D.; GOLDMAN, S.; WRIGHT, A.L.; HENRY, R.; SORENSON, S.; CALDWELL, J.; RITCHIE, J. The effect of pulmonary hypertension on systolic function of the right ventricle. Chest, 84:250-257, 1983.

NAITO, M.; DREIFUS, L.S.; DAVID, D.; MICHELSON, E.L.; MARDELLI, T.J.; KMETZO, J.J. Reevaluation of the role of atrial systole to cardiac hemodynamics: evidence for pulmonary venous regurgitation during abnormal atrioventricular sequencing. Am. Heart J., 105:295-302, 1983

NATHAN, D.A.; CENTER, s.; WU, C.Y.; KELLER, W. An implantable, synchronous pacemaker for the long-term correction of complete heart block. Circulation, 27:682-685, 1963.

NISHIMURA, R.A.; GERSH, B.J.; HOLMES, D.R.Jr.; VLIETSTRA, R.E.; BROADBENT, J.C. Outcome of dual-chamber pacing for the pacemaker syndrome. Mayo Clin. Proc., 58:452-456, 1983.

NORDLANDER, R.; PEHRSSON, S.K.; ASTRÖM, H.; KARLSSON, J. Myocardial demands of atrial-triggered versus fixed-rate ventricular pacing in patients with complete heart block. PACE 10:1154-1159, 1987.

OGAWA, S.; DREIFUS, L.S.; SHENOY, P.N.; BROCKMAN, S.K.; BERKOVITS, B.V. Hemodynamic consequences of atrioventricular and ventriculoatrial pacing. PACE,1:8-15, 1978.

ORRINGER, C.E. Acute left ventricular failure. Compr. Ther., 9:61-65, 1983. 
PARMLEY, W.W. Pathophysiology of congestive heart failure. Am. J. Cardiol., 55:9A-14A, 1985.

PARSONNET, V.; FURMAN, S.; SMYTH, N.P.D.; BILITCH, M. Optimal resources for implantable cardiac pacemakers. Circulation, 68:227A-244A, 1983.

PARSONNET, V.; ESCHER, D.J.W.; FURMAN, S.; GILLETTE, P.C.; GOLDMAN, B.S.; HARTHORNE, J.W.; HAUSER, R.G.; LEVINE, P.A.; MALONEY, J. Indications for dualchamber pacing. PACE, 7:318-319, 1984.

PATEL, A.K.; YAP, V.U.; THOMSEN, J.H. Adverse effects of right ventricular pacing in a patient with aortic stenosis. Chest, 72:103-107, 1977.

PEHRSSON, S.K. Influence of heart rate and atrioventricular synchonization on maximal work tolerance in patients treated with artificial pacemakers. Acta Med. Scand., 214:311315, 1983.

PEHRSSON, S.K. \& ASTRÖM, H. Left ventricular function after long-term treatment with ventricular inhibited compared to atrial triggered ventricular pacing. Acta Med. Scand., 214:295-304, 1983.

PERRINS, E.J.; MORLEY, C.A.; CHAN, S.L.; SUTTON, R. Randomised controlled trial of physiological and ventricular pacing. Br. Heart J., 50:112-117,1983.

RAMIRES, J.A.F. Hipertensão arterial sistêmica: estudo, em repouso e exercício, das alterações hemodinâmicas, da função ventricular e dos fatores que influenciam o débito cardíaco. São Paulo, 1984. [Tese Livre-Docência -Faculdade de Medicina da Universidade de São Paulo]. 
RAZA, S.T.; LAJOS, T.Z.; BHAYANA, J.N.; LEE, A.B.Jr.; LEWIN, A.N.; GEHRING, B.; SCHIMERT, G. Improved cardiovascular hemodynamics with atrioventricular sequential pacing compared with ventricular demand pacing. Ann. Thorac. Surg., 38:260-264, 1984.

REDIKER, D.E; EAGLE, K.A.; HOMMA, S.; GILLAM, L.D.; HARTHORNE, J.W. Clinical and hemodynamic comparison of $\mathrm{VVI}$ versus DDD pacing in patients with DDD pacemakers. Am. J. Cardiol., 61:323-329, 1988.

REITER, M.J. \& HINDMAN, M.C. Hemodynamic effects of acute atrioventricular sequential pacing in patients with left ventricular dysfunction. Am. J. Cardiol., 49:687-692, 1982.

ROSS JR., J.; GAULT, J.H.; MASON, D.T.; LINHART, J.W.; BRAUNWALD, E. Left ventricular performance during muscular exercise in patients with and without cardiac dysfunction. Circulation, 34:597-608, 1966.

RUSHMER, R.F. Constancy of stroke volume in ventricular responses to exertion. Am. J. Physiol., 196:745-750, 1959.

SAGAWA, K. The end-systolic pressure-volume relation of the ventricle: definition, modifications and clinical use. Circulation, 63:1223-1227, 1981.

SAMET, P.; CASTILlO, C.; BERNSTEIN, W.H. Hemodynamic sequelae of atrial, ventricular, and sequential atrioventricular pacing in cardiac patients. Am. Heart J., 72:725-729, 1966.

SAMET, P.; CASTIllO, C.; BERNSTEIN, W.H. Hemodynamic consequences of sequential atrioventricular pacing. Subjects with normal hearts. Am. J. Cardiol., 21:207212,1968 . 
SANT'ANNA, J.R.; LUCCHESE, F.A.; KALIL, R.K.; PRATES, P.R.; PEREIRA, E.; NORONHA, J.F.; NESRALLA, I.A. Sobrevida tardia de pacientes com marcapasso cardíaco artificial permanente. Arq. Bras. Cardiol., 39(suppl.1):185, 1982.

SARNOFF, S.J.; MITCHELL, J.H.; GILMORE, J.P.; REMENSNVDER, J.P. Homeometric autoregulation in the heart. Circ. Res., 8:1077-1091, 1960.

SCULLY, H.E.; BELLO, A.G.; BEIERHOLM, E.; FREDERIKSEN, J.; WEISFELDT, M.L.; DAGGETT, W.M. The relationship between the atrial systole-ventricular systole interval and left ventricular function. J. Thorac. Cardiovasc. Surg., 65:684-694, 1973.

SHEFER, A.; ROZENMAN, Y.; DAVID, Y.B.; FLUGELMAN, M.Y.; GOTSMAN, M.S.; LEWIS, B.S. Left ventricular function during physiological cardiac pacing: relation to rate, pacing mode, and underlying myocardial disease. PACE, 10:315-325, 1987.

SHEMIN, R.J.; SCOTT, W.C.; KASTL, D.G.; MORROW, A.G. Hemodynamic effects of various modes of cardiac pacing after operation for idiopathic hypertrophic subaortic stenosis. Ann. Thorac. Surg., 27:137-140, 1979.

SKINNER, N.S.; MITCHELL, J.H.; WALLACE, A.G.; SARNOFF, S.J. Hemodynamic effects of altering the timing of atrial systole. Am. J. Physiol., 205:499-505, 1963.

SMEDGARD, P.; KRISTENSSON, B.E.; KRUSE, I.; RYDÉN, L. Rate-responsive pacing by means of activity sensing versus single rate ventricular pacing: a double-blind crossover study. PACE, 10:902-915, 1987.

SNELL, P.G. \& MITCHELL, J. The role of maximal uptake in exercise performance. Clin. Chest Med., 5:51-62, 1984. 
SONNENBLICK, E.H. \& DOWNING, S.E. Afterload as a primary determinant of ventricular performance. Am. J. Physiol., 204:604-610, 1962.

STONE, J.M.; BHAKTA, R.D.; LUTGEN, J. Dual chamber sequential pacing management of sinus node dysfunction: advantages over single-chamber pacing. Am. Heart J., 104:1319-1327, 1982.

SWAN, H.J.C. \& GANZ, W. Hemodynamic measurements in clinical practice: a decade in review. J. Am. Coll. Cardiol. 1:103-113, 1983.

THADANI, U. \& PARKER, J.O. Hemodynamics at rest and during supine and sitting bicycle exercise in normal subjects. Am. J. Cardiol., 41:52-59, 1978.

THEVENET, A.; HODGES, P.C.; LILLEHEI, C.W. The use of a myocardial electrode inserted percutaneously for control of complete atrioventricular block by an artificial pacemaker. Dis. Chest, 34: 621-631, 1958.

VATNER, S.F. \& PAGANI, M. Cardiovascular adjustments to exercise: hemodynamics and mechanisms. In: SONNENBLICK, E.H. \& LESCH, M., ed. Exercise and heart disease. New Vork, Grune \& Stratton, 1977. p.127-144.

VATNER, S.F.; HIGGINS, C.B.; WHITE, S.; PATRICK, T.; FRANKLIN, D. The peripheral vascular response to severe exercise in untethered dogs before and after complete heart block. J. Clin.Invest., 50:1950-1960, 1971.

WANG, V.; MARSHALL, R.J.; SHEPHERD, J.T. The effect of changes in posture and of graded exercise on stroke volume in man. J. Clin. Invest., 39:1051-1061, 1960.

WEBER, K. T. \& JANICKI, J.S. Cardiopulmonary exercise testing for evaluation of chronic cardiac failure. Am. J. Cardiol., 55:22A-31A, 1985a. 
WEBER, K. T. \& JANICKI, J.S. Lactate production during maximal and submaximal exercise in patients with chronic heart failure. J. Am. Coll. Cardiol., 6:717-724, 1985b.

WEBER, K. T.; JANICKI, J.S.; LIKOFF, M.J. Exercise testing in the evaluation of cardiopulmonary disease. In: LOKE, J., ed. Exercise: physiology and clinical applications. Philadelphia, W.B.Saunders, 1984a. p.173-180.

WEBER, K. T.; LIKOFF, M.J.; JANICKI, J.S.; ANDREWS, V. Advances in the evaluation and management of chronic cardiac failure. Chest, 85:253-259, 1984b.

WEINER, D.A. Evaluating the conditions of patients with congestive heart failure by exercise testing. Arch. Intern. Med., 143:1978-1980, 1983.

WESTVEER, D.C.; STEWART, J.R.; GOODFLEISH, R.; GORDON, S.; TIMMIS, G.C. Prevalence and significance of ventriculo-atrial conduction. PACE, 7:784-789, 1984.

WILCKEN, D.E.L.; CHARLIER, A.A.; HOFFMAN, J.I.E.; GUZ, A. Effects of alterations in aortic impedance on the performance of the ventricles. Circ. Res., 14:283-293, 1964.

YANG, S.S.; BENTIVOGLIO, L.G.; MARANHO, V.; GOLDBERG, H. From cardiac catheterization data to hemodynamic parameters. 2.ed. Philadelphia, F. A. Davis, 1978.

YEE, R., BENDITT, D.G.; KOSTUK, W.J.; KO, P. T.; PURVES, P.; KLEIN, G.J. Comparative functional effects of chronic ventricular demand and atrial synchronous ventricular inhibited pacing. PACE, 7:23-28, 1984.

ZANINI, R.; FACCHINETTI, A.; GALLO, G.; BENEDINI, G.; METRA, M.; ASSANELLI, D.; CICOGNA, R. Survival rates after pacemaker implantation: a study of patients paced for sick sinus syndrome and atrioventricular block. PACE, 12:1065-1069, 1989. 
ZEGELMAN, M.; CIESLINSKI, G.; KREUZER, J. Rate response during submaximal exercise: comparison of three different sensors. PACE, 11:1888-1895, 1988.

ZIMMERN, S.H.; CLARK, M.F.; AUSTIN, W.K.; FEDOR, J.M.; GALLAGHER, J.J.; SVENSON, R.H.; DUNCAN, J.L. Characteristics and clinical effects of myopotencial signals in a unipolar DDD pacemaker population. PACE, 9:1019-1025, 1986.

ZOLL, P.M. Resuscitation of the heart in ventricular standstill by external electric stimulation. N. Engl. J. Med., 247:768-771, 1952. 
VII - APÊNDICE 
TABELA 1 - DADOS HEMODINÂMICOS INDIVIDUAIS OBTIDOS EM REPOUSO E EM EXERCÍCIO

\begin{tabular}{|c|c|c|c|c|c|c|c|c|c|c|c|c|c|c|}
\hline Caso & Condição & Modo & $\begin{array}{c}\text { FC } \\
(\mathrm{bpm})\end{array}$ & $\begin{array}{c}\text { PAD } \\
(\mathrm{mmHg})\end{array}$ & $\begin{array}{c}\text { PAP } \\
(\mathrm{mmHg})\end{array}$ & $\begin{array}{c}\mathrm{PCP} \\
(\mathrm{mmHg})\end{array}$ & $\begin{array}{c}\text { PDfVE } \\
(\mathrm{mmHg})\end{array}$ & $\begin{array}{c}\mathrm{PA} \\
(\mathrm{mmHg})\end{array}$ & $\begin{array}{c}\mathrm{DC} \\
(\mathrm{l} / \mathrm{min})\end{array}$ & $\begin{array}{c}\mathrm{IC} \\
\left(\mathrm{I} / \mathrm{min} \cdot \mathrm{m}^{2}\right)\end{array}$ & $\begin{array}{c}\text { IS } \\
\left(\mathrm{ml} / \mathrm{m}^{2}\right)\end{array}$ & $\begin{array}{c}\text { ITS } \\
\left(\mathrm{gm} / \mathrm{m}^{2}\right)\end{array}$ & $\begin{array}{c}\text { RVS } \\
\left(\text { dyn.s } / \mathrm{cm}^{5}\right)\end{array}$ & $\begin{array}{c}\text { RAP } \\
\left(\text { dyn.s } / \mathrm{cm}^{5}\right)\end{array}$ \\
\hline \multirow[t]{4}{*}{1} & $\bar{R}$ & "VVI & 70,0 & 8,0 & 22,0 & 15,0 & 16,0 & 98,0 & 7,8 & 4,9 & 69,6 & 78,6 & 923,1 & 71,8 \\
\hline & & DDD & 88,0 & 5,0 & 18,0 & 10,0 & 9,0 & 106,0 & 6,5 & 4,1 & 46,2 & 60,3 & 1243,1 & 98,5 \\
\hline & E & VVI & 70,0 & 10,0 & 27,0 & 17,0 & 16,0 & 114,0 & 10,0 & 6,3 & 89,3 & 117,8 & 832,0 & 80,0 \\
\hline & & DDD & 107,0 & 6,0 & 26,0 & 9,0 & 9,0 & 118,0 & 13,4 & 8,4 & 78,3 & 116,0 & 668,7 & 101,5 \\
\hline \multirow[t]{4}{*}{2} & $\mathrm{R}$ & VVI & 72,0 & 4,0 & 12,0 & 7,0 & 8,0 & 98,0 & 4,5 & 3,0 & 41,9 & 51,9 & 1671,1 & 88,9 \\
\hline & & DDD & 72,0 & 1,0 & 10,0 & 3,0 & 6,0 & 96,0 & 4,6 & 3,1 & 42,9 & 54,2 & 1652,2 & 121,7 \\
\hline & E & VVI & 72,0 & 5,0 & 17,0 & 10,0 & 10,0 & 98,0 & 6,0 & 4,1 & 56,3 & 67,4 & 1231,8 & 92,7 \\
\hline & & DDD & 72,0 & 3,0 & 17,0 & 5,0 & 6,0 & 98,0 & 7,3 & 4,9 & 68,2 & 86,3 & 1038,3 & 131,1 \\
\hline \multirow[t]{4}{*}{3} & $R$ & VVI & 73,0 & 6,0 & 14,0 & 8,0 & 20,0 & 95,0 & 2,9 & 1,6 & 22,2 & 26,3 & 2438,4 & 164,4 \\
\hline & & DDD & 70,0 & 5,0 & 16,0 & 10,0 & 14,0 & 97,0 & 2,7 & 1,5 & 21,2 & 25,1 & 2751,4 & 179,4 \\
\hline & $E$ & VVI & 73,0 & 9,0 & 25,0 & 23,0 & 15,0 & 99,0 & 4,0 & 2,2 & 30,7 & 31,8 & 1782,2 & 39,6 \\
\hline & & DDD & 70,0 & 6,0 & 20,0 & 13,0 & 18,0 & 96,0 & 3,9 & 2,2 & 31,3 & 35,3 & 1827,4 & 142,1 \\
\hline \multirow[t]{4}{*}{4} & $\mathrm{R}$ & VVI & 72,0 & 6,0 & 20,0 & 11,0 & 9,0 & 94,0 & 3,4 & 2,0 & 27,2 & 30,7 & 2076,7 & 212,4 \\
\hline & & DDD & 69,0 & 3,0 & 15,0 & 7,0 & 9,0 & 92,0 & 4,6 & 2,6 & 38,3 & 44,3 & 1558,0 & 140,0 \\
\hline & $E$ & VVI & 72,0 & 11,0 & 30,0 & 17,0 & 14,0 & 99,0 & 7,8 & 4,5 & 62,3 & 69,4 & 907,8 & 134,1 \\
\hline & & DDD & 105,0 & 9,0 & 32,0 & 17,0 & 22,0 & 110,0 & 10,8 & 6,3 & 59,6 & 75,3 & 746,8 & 110,9 \\
\hline \multirow[t]{4}{*}{5} & $R$ & VVI & 74,0 & 5,0 & 15,0 & 8,0 & 10,0 & 90,0 & 2,9 & 1,9 & 25,3 & 28,2 & 2312,9 & 190,5 \\
\hline & & DDD & 72,0 & 2,0 & 11,0 & 4,0 & 9,0 & 100,0 & 3,0 & 1,9 & 26,6 & 34,8 & 2604,7 & 186,0 \\
\hline & E & VVI & 71,0 & 13,0 & 33,0 & 25,0 & 26,0 & 126,0 & 4,6 & 2,9 & 41,2 & 56,6 & 1967,4 & 139,3 \\
\hline & & DDD & 101,0 & 11,0 & 32,0 & 20,0 & 20,0 & 135,0 & 5,0 & 3,2 & 31,5 & 49,3 & 1986,0 & 192,2 \\
\hline \multirow[t]{4}{*}{6} & $R$ & VVI & 74,0 & 1,0 & 15,0 & 5,0 & 5,0 & 97,0 & 1,8 & 1,2 & 16,2 & 20,2 & 4278,6 & 445,7 \\
\hline & & DDD & 92,0 & 2,0 & 14,0 & 6,0 & 8,0 & 98,0 & 2,1 & 1,4 & 15,1 & 18,9 & 3692,3 & 307,7 \\
\hline & $E$ & VVI & 74,0 & 6,0 & 27,0 & 12,0 & 21,0 & 109,0 & 2,5 & 1,7 & 22,9 & 30,2 & 3237,7 & 471,5 \\
\hline & & DDD & 133,0 & 6,0 & 23,0 & 13,0 & 12,0 & 107,0 & 2,5 & 1,6 & 12,4 & 15,8 & 3277,9 & 324,5 \\
\hline \multirow[t]{4}{*}{7} & $\mathrm{R}$ & VVI & 73,0 & 8,0 & 34,0 & 16,0 & 21,0 & 119,0 & 2,7 & 2,1 & 26,9 & 40,5 & 3313,4 & 537,3 \\
\hline & & DDD & 84,0 & 1,0 & 24,0 & 10,0 & 23,0 & 114,0 & 3,4 & 2,7 & 32,1 & 45,4 & 2640,7 & 327,2 \\
\hline & $E$ & VVI & 73,0 & 6,0 & 32,0 & 15,0 & 14,0 & 93,0 & 4,4 & 3,5 & 47,8 & 50,7 & 1571,1 & 307,0 \\
\hline & & DDD & 115,0 & 9,0 & 38,0 & 26,0 & 3,0 & 114,0 & 4,1 & 3,2 & 28,0 & 33,5 & 2053,8 & 234,7 \\
\hline \multirow[t]{4}{*}{8} & $\mathrm{R}$ & VVI & 72,0 & 3,0 & 16,0 & 6,0 & 7,0 & 104,0 & 3,3 & 2,3 & 31,5 & 42,0 & 2422,8 & 239,9 \\
\hline & & DDD & 93,0 & 2,0 & 15,0 & 5,0 & 6,0 & 110,0 & 4,0 & 2,7 & 29,0 & 41,4 & 2179,1 & 201,8 \\
\hline & $E$ & VVI & 72,0 & 6,0 & 26,0 & 10,0 & 12,0 & 113,0 & 5,7 & 3,9 & 53,5 & 74,9 & 1512,4 & 226,1 \\
\hline & & DDD & 107,0 & 4,0 & 26,0 & 11,0 & 11,0 & 119,0 & 5,5 & 3,7 & 35,0 & 51,4 & 1671,2 & 218,0 \\
\hline \multirow[t]{4}{*}{9} & $R$ & $\mathrm{VVI}$ & 70,0 & 2,0 & 13,0 & 6,0 & 8,0 & 105,0 & 2,9 & 2,0 & 29,3 & 39,4 & 2812,3 & 191,1 \\
\hline & & DDD & 82,0 & 0,0 & 9,0 & 2,0 & 4,0 & 101,0 & 3,5 & 2,5 & 30,0 & 40,4 & 2295,5 & 159,1 \\
\hline & $E$ & VVI & 70,0 & 6,0 & 22,0 & 14,0 & 18,0 & 112,0 & 5,4 & 3,8 & 54,3 & 72,3 & 1560,7 & 117,8 \\
\hline & & DDD & 109,0 & 1,0 & 27,0 & 15,0 & 18,0 & 121,0 & 7,9 & 5,5 & 50,8 & 73,2 & 1213,1 & 121,3 \\
\hline \multirow[t]{4}{*}{10} & $\mathrm{R}$ & $\mathrm{VVI}$ & 71,0 & 5,0 & 15,0 & 8,0 & 12,0 & 95,0 & 5,9 & 3,7 & 52,0 & 61,6 & 1225,5 & 95,3 \\
\hline & & DDD & 75,0 & 5,0 & 15,0 & 7,0 & 9,0 & 91,0 & 9,1 & 5,7 & 76,0 & 86,8 & 759,0 & 70,6 \\
\hline & E & VVI & 72,0 & 11,0 & 27,0 & 16,0 & 19,0 & 91,0 & 9,7 & 6,1 & 84,8 & 86,5 & 658,9 & 90,6 \\
\hline & & DDD & 93,0 & 10,0 & 26,0 & 19,0 & 20,0 & 109,0 & 12,5 & 7,9 & 84,6 & 103,5 & 633,3 & 44,8 \\
\hline
\end{tabular}

FC: freqüência cardíaca; PAD: pressão média do átrio direito; PAP: pressão média da artéria pulmonar; PCP: pressão média do capilar pulmonar; PDfVE: pressão de enchimento do

ventrículo esquerdo; PA: pressão média da aorta; DC: débito cardíaco; IC: índice cardíaco; IS: índice sistólico; ITS: índice do trabalho sistólico; RVS: resistência vascular sistêmica; RAP: resistência arteriolar pulmonar; R: repouso; E: exercício; VVI: modo ventricular inibido; DDD: modo atrioventricular universal. 
TABELA 2 - DADOS INDIVIDUAIS DO METABOLISMO DE OXIGÊNIO

\begin{tabular}{|c|c|c|c|c|c|c|c|c|c|}
\hline CASO & CONDIÇÃO & MODO & $\mathrm{SvO}_{2}$ & $\mathrm{SaO}_{2}$ & $\begin{array}{c}\mathrm{CvO}_{2} \\
\text { (vol.\%) }\end{array}$ & $\begin{array}{c}\mathrm{CaO}_{2} \\
\text { (vol.\%) }\end{array}$ & $\begin{array}{l}\mathrm{DavO}_{2} \\
\text { (vol.\%) }\end{array}$ & $\mathrm{EO}_{2}$ & $\begin{array}{c}\mathrm{IVO}_{2} \\
\left(\mathrm{ml} / \mathrm{min} \cdot \mathrm{m}^{2}\right)\end{array}$ \\
\hline \multirow[t]{4}{*}{2} & $\mathrm{R}$ & VVI & 78,0 & 94,5 & 16,4 & 20,0 & 3,5 & 0,18 & 106,9 \\
\hline & & DDD & 76,5 & 92,5 & 16,1 & 19,5 & 3,4 & 0,18 & 105,6 \\
\hline & $E$ & VVI & 74,5 & 93,0 & 15,7 & 19,6 & 3,9 & 0,20 & 158,5 \\
\hline & & DDD & 65,0 & 92,0 & 13,7 & 19,4 & 5,7 & 0,30 & 281,5 \\
\hline \multirow[t]{4}{*}{3} & $\mathrm{R}$ & $\mathrm{VVI}$ & 77,0 & 100,0 & 15,6 & 20,6 & 5,0 & 0,24 & 80,3 \\
\hline & & DDD & 78,0 & 99,0 & 15,8 & 20,3 & 4,5 & 0,22 & 67,2 \\
\hline & $\mathrm{E}$ & VVI & 46,0 & 100,0 & 9,3 & 20,6 & 11,2 & 0,55 & 251,8 \\
\hline & & DDD & 49,5 & 98,0 & 10,0 & 20,0 & 10,0 & 0,50 & 218,9 \\
\hline \multirow[t]{4}{*}{4} & $\mathrm{R}$ & VVI & 78,0 & 100,0 & 20,0 & 25,9 & 5,9 & 0,23 & 115,8 \\
\hline & & DDD & 84,0 & 100,0 & 21,5 & 25,9 & 4,4 & 0,17 & 115,7 \\
\hline & $\mathrm{E}$ & VVI & 51,0 & 100,0 & 13,1 & 25,9 & 12,8 & 0,50 & 575,6 \\
\hline & & DDD & 74,0 & 100,0 & 19,0 & 25,9 & 6,9 & 0,27 & 434,1 \\
\hline \multirow[t]{4}{*}{5} & $\mathrm{R}$ & VVI & 77,0 & 97,0 & 14,6 & 18,5 & 3,9 & 0,21 & 72,8 \\
\hline & & DDD & 69,0 & 93,5 & 13,1 & 17,7 & 4,7 & 0,26 & 89,7 \\
\hline & $E$ & VVI & 42,0 & 97,5 & 8,0 & 18,6 & 10,7 & 0,57 & 312,3 \\
\hline & & DDD & 42,0 & 95,5 & 8,0 & 18,1 & 10,2 & 0,56 & 324,2 \\
\hline \multirow[t]{4}{*}{6} & $\mathrm{R}$ & $\mathrm{VVI}$ & 60,0 & 96,5 & 13,2 & 21,3 & 8,1 & 0,38 & 97,3 \\
\hline & & DDD & 70,0 & 98,5 & 15,4 & 21,9 & 6,5 & 0,30 & 90,0 \\
\hline & E & VVI & 35,0 & 97,0 & 7,7 & 21,4 & 13,7 & 0,64 & 233,1 \\
\hline & & DDD & 37,0 & 99,5 & 8,2 & 22,2 & 14,0 & 0,63 & 230,6 \\
\hline \multirow[t]{4}{*}{7} & $R$ & VVI & 65,5 & 92,5 & 11,2 & 15,8 & 4,6 & 0,29 & 97,7 \\
\hline & & DDD & 75,5 & 92,5 & 12,9 & 15,8 & 2,9 & 0,18 & 78,7 \\
\hline & $\mathrm{E}$ & VVI & 50,0 & 94,0 & 8,6 & 16,1 & 7,5 & 0,47 & 263,0 \\
\hline & & DDD & 45,0 & 94,0 & 8,8 & 16,1 & 7,3 & 0,45 & 233,8 \\
\hline \multirow[t]{4}{*}{8} & $R$ & VVI & 75,5 & 98,0 & 18,1 & 23,3 & 5,2 & 0,22 & 118,9 \\
\hline & & DDD & 78,5 & 97,5 & 18,8 & 23,2 & 4,4 & 0,19 & 119,0 \\
\hline & $\mathrm{E}$ & VVI & 49,5 & 97,0 & 11,8 & 23,1 & 11,2 & 0,49 & 432,8 \\
\hline & & DDD & 48,0 & 99,5 & 11,5 & 23,7 & 12,2 & 0,51 & 456,5 \\
\hline \multirow[t]{4}{*}{9} & $\mathrm{R}$ & VVI & 75,0 & 96,0 & 16,5 & 21,2 & 4,7 & 0,22 & 96,1 \\
\hline & & DDD & 50,0 & 96,0 & 11,0 & 21,2 & 10,2 & 0,48 & 250,8 \\
\hline & $E$ & VVI & 54,5 & 94,5 & 12,0 & 20,9 & 8,9 & 0,42 & 337,0 \\
\hline & & DDD & 78,0 & 95,0 & 17,2 & 21,0 & 3,8 & 0,18 & 210,3 \\
\hline \multirow[t]{4}{*}{10} & $\mathrm{R}$ & VVI & 69,0 & 95,5 & 9,9 & 13,8 & 3,9 & 0,28 & 143,0 \\
\hline & & DDD & 87,5 & 96,0 & 12,6 & 13,9 & 1,3 & 0,09 & 73,0 \\
\hline & $E$ & VVI & 80,5 & 97,5 & 11,6 & 14,2 & 2,6 & 0,18 & 158,8 \\
\hline & & DDD & 50,5 & 97,5 & 7,3 & 14,2 & 6,9 & 0,49 & 544,2 \\
\hline
\end{tabular}

$\mathrm{SvO}_{2}$ : saturação venosa de oxigênio; $\mathrm{SaO}_{2}$ : saturação arterial de oxigênio; $\mathrm{CvO}_{2}$ : conteúdo venoso de oxigênio; $\mathrm{CaO}_{2}$ : conteúdo arterial de oxigênio; $\mathrm{DavO}_{2}$ : diferença arteriovenosa de oxigênio; $\mathrm{EO}_{2}$ : extração de oxigênio; $\mathrm{IVO}_{2}$ : índice de consumo de oxigênio; R: repouso; $\mathrm{E}$ : exercício. 